\title{
DebriSat Laboratory Analyses
}

January 5, 2015

Paul M. Adams ${ }^{1}$, Zachary Lingley ${ }^{2}$, Nathan Presser ${ }^{2}$, and Gouri Radhakrishnan ${ }^{1}$ ${ }^{1}$ Space Materials Laboratory, Physical Sciences Laboratories

${ }^{2}$ Electronics and Photonics Laboratory, Physical Sciences Laboratories

Prepared for:

Space and Missile Systems Center

Air Force Space Command

483 N. Aviation Blvd.

El Segundo, CA 90245-2808

Contract No. FA8802-14-C-0001

Authorized by: Space Systems Group

Distribution Statement A: Approved for public release; distribution unlimited. 


\section{Report Documentation Page}

Public reporting burden for the collection of information is estimated to average 1 hour per response, including the time for reviewing instructions, searching existing data sources, gathering and maintaining the data needed, and completing and reviewing the collection of information. Send comments regarding this burden estimate or any other aspect of this collection of information, including suggestions for reducing this burden, to Washington Headquarters Services, Directorate for Information Operations and Reports, 1215 Jefferson Davis Highway, Suite 1204, Arlington VA 22202-4302. Respondents should be aware that notwithstanding any other provision of law, no person shall be subject to a penalty for failing to comply with a collection of information if it does not display a currently valid OMB control number.

\begin{tabular}{|c|c|c|}
\hline $\begin{array}{l}\text { 1. REPORT DATE } \\
\mathbf{0 5} \text { JAN } 2015\end{array}$ & $\begin{array}{l}\text { 2. REPORT TYPE } \\
\text { Final }\end{array}$ & $\begin{array}{l}\text { 3. DATES COVERED } \\
\text { - }\end{array}$ \\
\hline \multirow{3}{*}{\multicolumn{2}{|c|}{$\begin{array}{l}\text { 4. TITLE AND SUBTITLE } \\
\text { DebriSat Laboratory Analyses }\end{array}$}} & $\begin{array}{l}\text { 5a. CONTRACT NUMBER } \\
\text { FA8802-14-C-0001 }\end{array}$ \\
\hline & & 5b. GRANT NUMBER \\
\hline & & 5c. PROGRAM ELEMENT NUMBER \\
\hline \multirow{3}{*}{\multicolumn{2}{|c|}{$\begin{array}{l}\text { 6. AUTHOR(S) } \\
\text { Paul M. Adams, Zachary Lingley, Nathan Presser, and Gouri } \\
\text { Radhakrishnan }\end{array}$}} & 5d. PROJECT NUMBER \\
\hline & & 5e. TASK NUMBER \\
\hline & & 5f. WORK UNIT NUMBER \\
\hline \multicolumn{2}{|c|}{$\begin{array}{l}\text { 7. PERFORMING ORGANIZATION NAME(S) AND ADDRESS(ES) } \\
\text { The Aerospace Corporation } 2310 \text { E. El Segundo, CA } 90245-4609\end{array}$} & $\begin{array}{l}\text { 8. PERFORMING ORGANIZATION REPORT } \\
\text { NUMBER } \\
\text { TOR-2015-00876 }\end{array}$ \\
\hline \multirow{2}{*}{\multicolumn{2}{|c|}{$\begin{array}{l}\text { 9. SPONSORING/MONITORING AGENCY NAME(S) AND ADDRESS(ES) } \\
\text { Space and Missile Systems Center Air Force Space Command } 483 \text { N. } \\
\text { Aviation Blvd. El Segundo, CA } 90245-2808\end{array}$}} & $\begin{array}{l}\text { 10. SPONSOR/MONITOR'S ACRONYM(S) } \\
\text { SMC }\end{array}$ \\
\hline & & $\begin{array}{l}\text { 11. SPONSOR/MONITOR'S REPORT } \\
\text { NUMBER(S) }\end{array}$ \\
\hline
\end{tabular}

12. DISTRIBUTION/AVAILABILITY STATEMENT

Approved for public release, distribution unlimited

13. SUPPLEMENTARY NOTES

The original document contains color images.

14. ABSTRACT

The DebriSat test was conducted to better understand the distribution of fragments generated from a hypervelocity impact with a modern satellite. The last such test (SOCIT) was conducted 20 years ago and satellite construction has changed considerably since then. DebriSat was a NASA program with support/collaboration from the Air Force Space and Missile Center, University of Florida and Aerospace. Tests were conducted at the Arnold Engineering Development Complex Range G Two-Stage Light Gas Gun Facility. The $50 \mathrm{~kg}$ target was a constructed by the University of Florida from materials representative of a modern LEO satellite. The Aerospace Concept Design Center advised on the selection of materials for various subsystems.

15. SUBJECT TERMS

16. SECURITY CLASSIFICATION OF:

a. REPORT

unclassified b. ABSTRACT unclassified c. THIS PAGE unclassified
17. LIMITATION OF ABSTRACT

UU

\begin{tabular}{l|l}
$\begin{array}{c}\text { 18. NUMBER } \\
\text { OF PAGES } \\
\mathbf{1 0 6}\end{array}$ & 19a. NAME OF \\
&
\end{tabular}




\section{Abstract}

The DebriSat test was conducted to better understand the distribution of fragments generated from a hypervelocity impact with a modern satellite. The last such test (SOCIT) was conducted 20 years ago and satellite construction has changed considerably since then. DebriSat was a NASA program with support/collaboration from the Air Force Space and Missile Center, University of Florida and Aerospace. Tests were conducted at the Arnold Engineering Development Complex Range G Two-Stage Light Gas Gun Facility. The $50 \mathrm{~kg}$ target was a constructed by the University of Florida from materials representative of a modern LEO satellite. The Aerospace Concept Design Center advised on the selection of materials for various subsystems. The test chamber was lined with "soft catch" foam panels to trap fragments for size distribution analysis. A witness plate assembly was constructed by Aerospace in order to catch and sample debris and returned to Aerospace after the test for analysis. Aerospace also placed SEM stub witness plates into the soft catch panels for post test retrieval and analysis. The test was conducted with a pressure of 1-2 Torr of air and used a $\sim 600$ gram projectile with a nominal velocity of $7 \mathrm{~km} / \mathrm{s}$.

The SEM stubs, witness plate assembly and DebriSat fragments were covered with black soot and were contaminated with soft catch foam fragments. The SEM stubs were also covered with a thin film of condensed soft catch vapor, similar to that seen with the Debris-LV test which also used soft catch foam panels. Deposits on the SEM stubs and witness plate assembly are predominantly carbon and consist of agglomerates of nano carbonaceous material. These deposits are primarily from the soft catch (similar to Debris-LV) though the C-C composite honeycomb face sheets and MLI are also possible sources. Disordered graphitic carbon is present based on Raman spectra and TEM lattice fringe images. Graphitic carbon was also seen in Debris-LV deposits even though there were no carbon containing materials in the target. The witness plate assembly was covered in a black layer of loose "soot", even under the protective Whipple plates. Removal of the loose material by rinsing with isopropyl alcohol revealed a thin adherent coating on one side_of the support posts indicating early directional deposition from DebriSat. The coating was carbonaceous (disordered graphite) with nano metal droplets. Fluorine from Teflon wire insulation was also common in the SEM stub and witness plates deposits. Nano droplets of metallic materials (Al, Fe, $\mathrm{Cu}, \mathrm{Zn}$, $\mathrm{Ge})$ were also present indicating melting as a result of the impact. Solidified molten metal droplets were also seen in Pre Preshot and Debris-LV debris. Aluminum was from the Al honeycomb, nadir and zenith panels, structural core and COPV liner. Aluminum oxide particles were also present. Iron was from stainless steel tubing and solenoids. Germanium was from the solar cells and copper was from wiring and solenoids. The source of the zinc has not been identified. The solidified molten nano metal droplets are crystalline based on TEM lattice fringes and consist of only a few crystallites.

The witness plates show a significant decrease in reflectance (95\% to $6 \%)$. Soft catch contamination was seen in the LWIR reflectance spectra of DebriSat fragments, SEM stubs and witness plate. As a result, it was not possible to get a clean spectrum of the debris generated by the hypervelocity impact. An additional "oxide" band, which may be from a form of aluminum oxide, was seen on some samples. 


\section{Acknowledgements}

DebriSat Team Members:

J.-C. Liou: NASA Space Debris Program Office, NASA JSC

AEDC Range G Light Gas Gun Staff

Charles Griffice: Aerospace

Marlon Sorge: Aerospace

Patti Sheaffer: Aerospace

Financial Support:

Charles Griffice and Tom Huynh

Discussions with:

Patti Sheaffer

Charles Griffice

UV-VIS-NIR Spectroscopy

Dianna Alaan 
Aerospace Technical Operating Report No. TOR-2015-00876

\section{DebriSat Laboratory Analyses}

\section{January, 2015}

Paul M. Adams ${ }^{1}$, Zachary Lingley ${ }^{2}$, Nathan Presser ${ }^{2}$ and Gouri Radhakrishnan ${ }^{1}$

${ }^{1}$ Materials Processing Department

Space Materials Laboratory

2Microelectronics Technology Department

Electronics and Photonics Laboratory

Physical Sciences Laboratories 


\section{Introduction}

- The DebriSat test was conducted to better understand the distribution of fragments generated from a hypervelocity impact with a modern satellite.

- The last such test (SOCIT) was conducted 20 years ago and satellite construction has changed considerably since then.

- In 2009 a Cosmos 2251 upper stage collided with an Iridium 33 satellite.

- Produced $2000+$ trackable fragments $(>10 \mathrm{~cm})$.

- 8 other known collisions, some only known long after occurrence.

- DebriSat was a NASA program with support/collaboration from the Air Force Space and Missile Center, University of Florida and Aerospace.

- Tests were conducted at the Arnold Engineering Development Complex, Tullahoma, Tennessee.

- Two-Stage Light Gas Gun Facility - Range G.

- Largest such facility in the United States.

- All tests used a $\sim 600$ gram projectile with a nominal velocity of $7 \mathrm{~km} / \mathrm{s}$. 


\section{Introduction (cont.)}

- Two trial tests were conducted prior to DebriSat.

- Pre Preshot. February 2014

- Debris-LV (Pre Shot). 1 April 2014

- Debris-Sat was conducted 15 April 2014

- The $50 \mathrm{~kg}$ target was constructed by the University of Florida from materials representative of a modern LEO satellite.

- Aerospace Concept Design Center advised on selection of materials for various subsystems.

- Test chamber was lined with "soft catch" foam panels to trap fragments for size distribution analysis.

- A witness plate assembly was constructed by Aerospace in order to catch and sample debris and returned to Aerospace after the test for analysis.

- Aerospace also placed SEM stub witness plates into soft catch for post test retrieval and analysis.

- Test conducted with a pressure of 1-2 Torr of air. 


\section{Introduction (cont.)}

- Documentation to date.

- Aerospace TOR-2014-03201, Time-resolved Spectroscopy of Hypervelocity Impact Flash on DebriSat, Gouri Radhakrishnan.

- Aerospace ATM-2014-03659, DebriSat Hypervelocity Impact Fragmentation Modeling, Naoki Hemmi. 
- Background

- "Darkening" of satellites has been observed as a result of suspected hypervelocity impacts.

- The material and processes responsible for the darkening is unknown.

- Objectives

- Materials collected on witness plates in the DebriSat test were analyzed in order to identify the source and conditions responsible for the darkening.

- UV-VIS-NIR-LWIR reflectance spectra were measured of post test debris for comparison with pre test sources to determine the spectral signature of material generated by a hypervelocity impact.

- Possibly determine if a hypervelocity impact occurred based on remotely sensed spectra?

- Can the source be identified - does it have a unique signature? 


\section{Projectile}

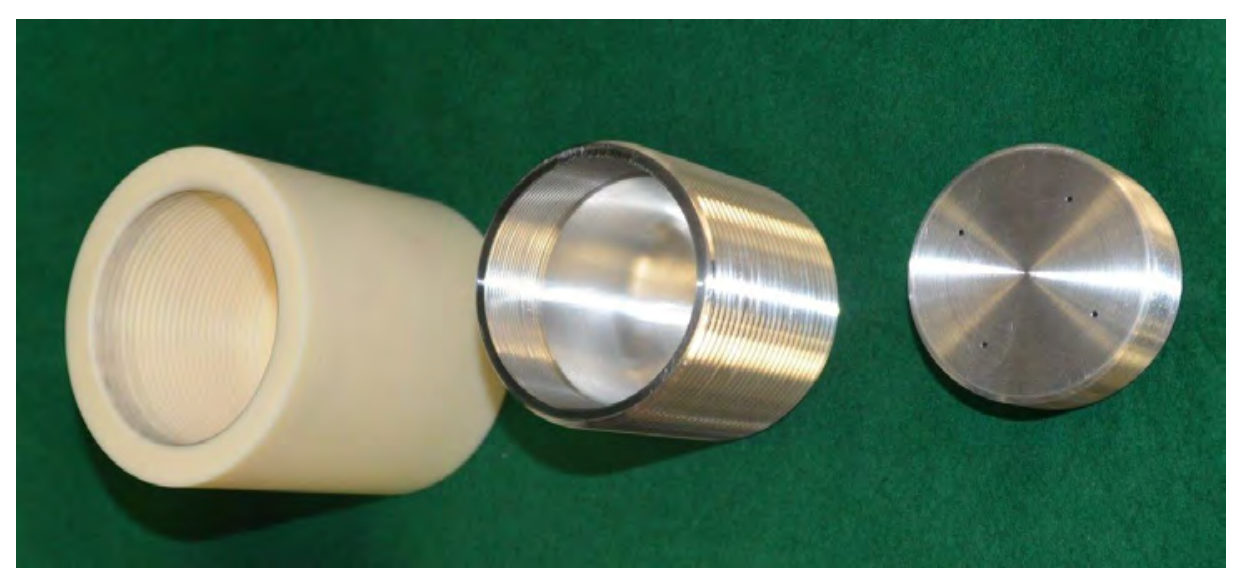

\section{Images by AEDC}

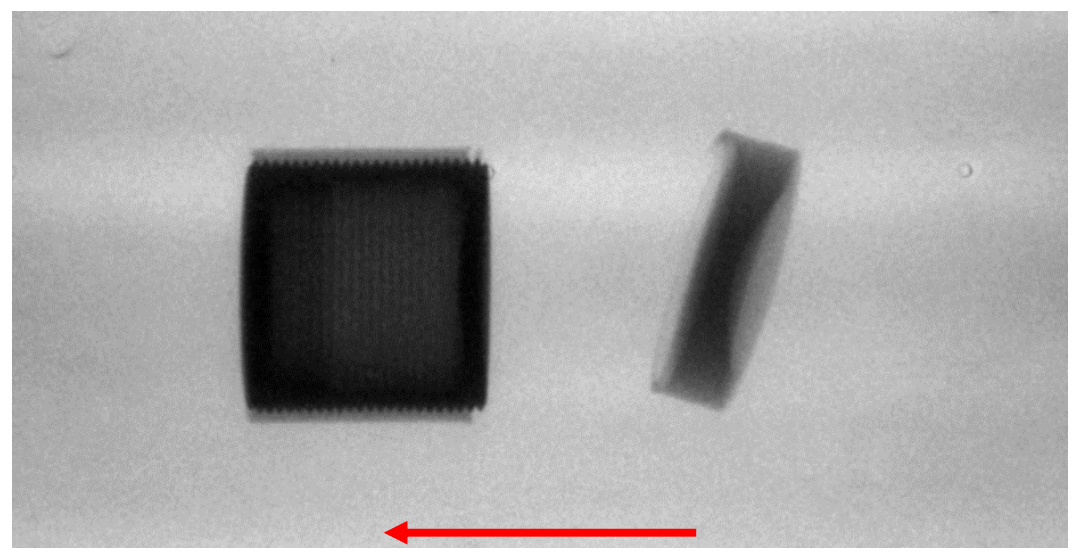

Flash X-ray of projectile in flight

- Constructed from three pieces: Outer Nylon shell (sabot) with 2 part hollow aluminum insert.

- $\sim 600$ grams, $8.6 \mathrm{~cm}$ diameter $X 10.3 \mathrm{~cm}$ long - size of a soup can.

- Velocity $\sim 6.8-6.9 \mathrm{~km} / \mathrm{s}$.

- The Nylon base separated from the Nylon-aluminum body during flight. 


\section{DebriSat Construction}
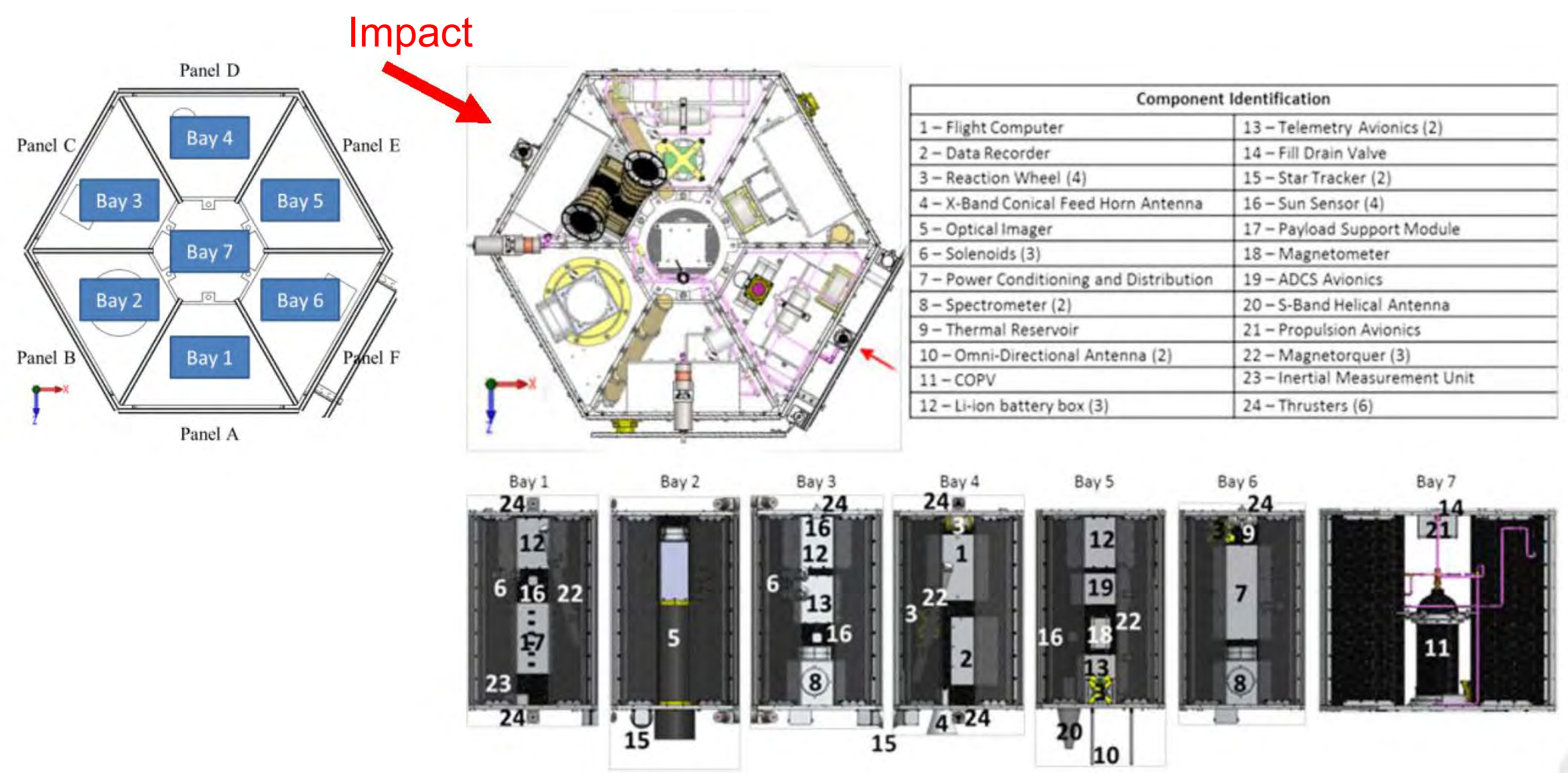

Projectile impacted normal to Bay 3

Figures from $U$. of Florida 


\section{Materials Present on DebriSat}

- Nadir and zenith panels: Aluminum 6061

- Face panels and structural ribs: Aluminum 5052 honeycomb with carbon fiber/epoxy face sheets

- COPV tank pressurized to 2 torr with air

- Optics : $\mathrm{SiO}_{2}$, sapphire

- Solenoids : Cu

- Stainless Steel $(316,304)$ : Fe, Cr, Ni

- Printed circuit boards (electronics hardware)

- Li-ion batteries: Cu-polyimide (no Li or electrolyte)

- Solar cells: Ge substrate with GaAs/InP/GalnP

- Kevlar, polyurethane, Mylar, Kapton 


\section{Installed in Chamber: Pre test}

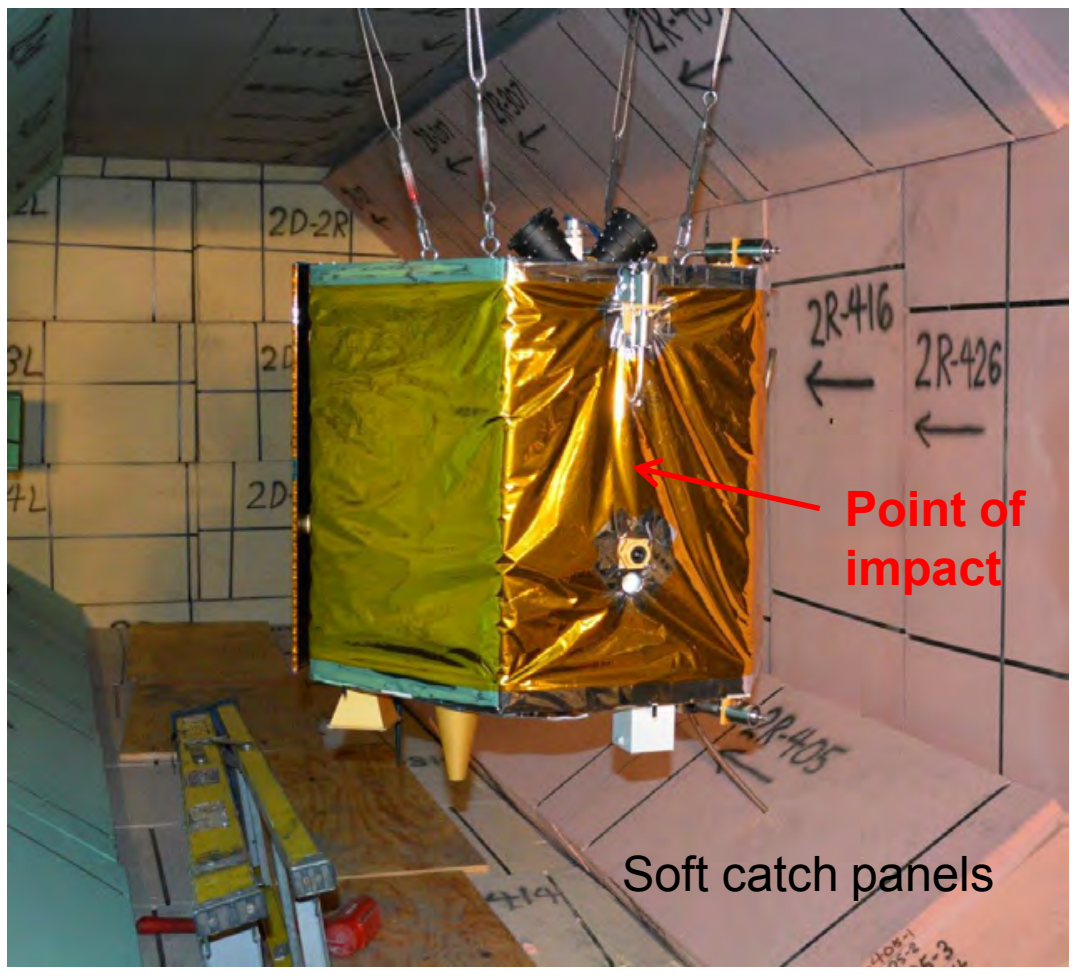

Looking down range. DebriSat is covered with multi layer insulation (MLI).

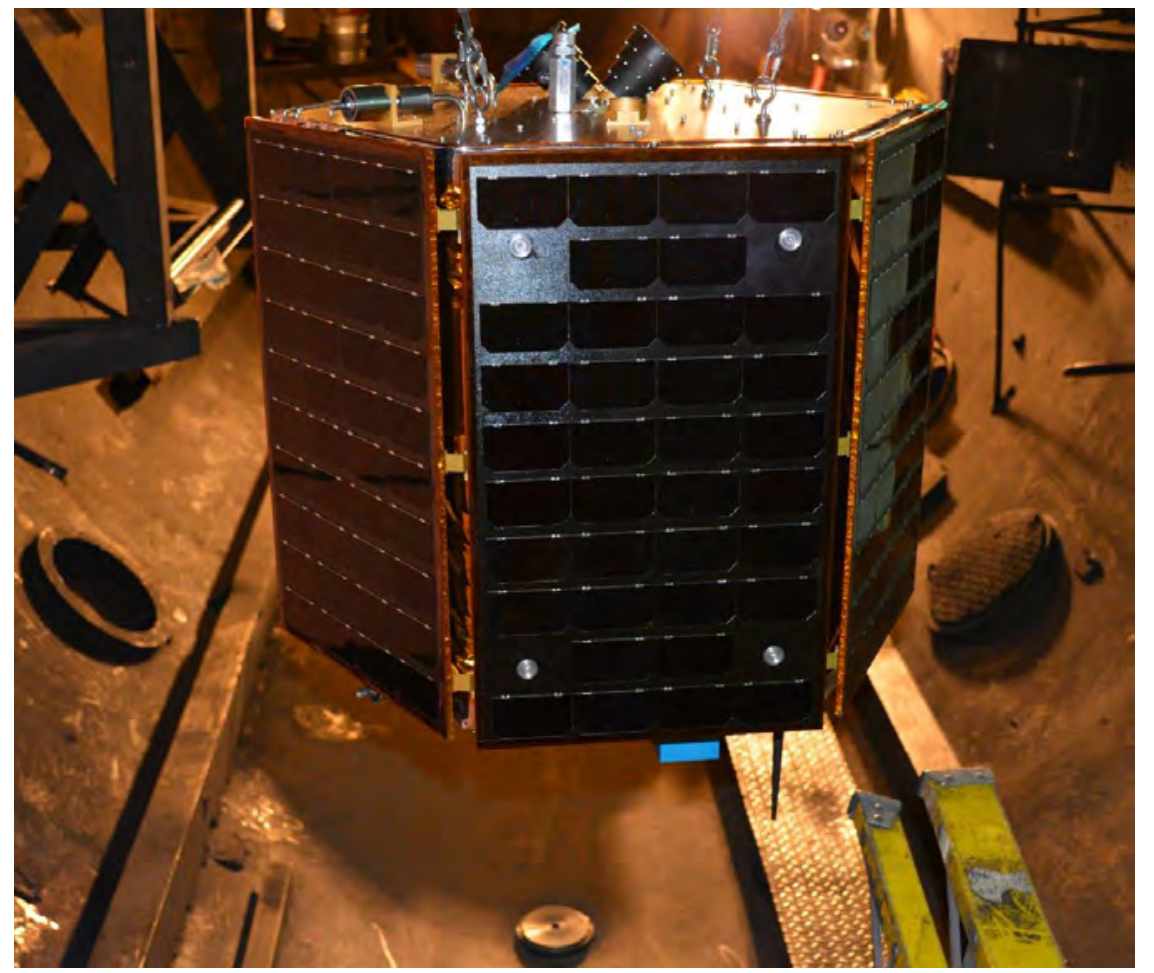

Looking up range. Solar panels - undeployed 


\section{Nadir / Under Side}

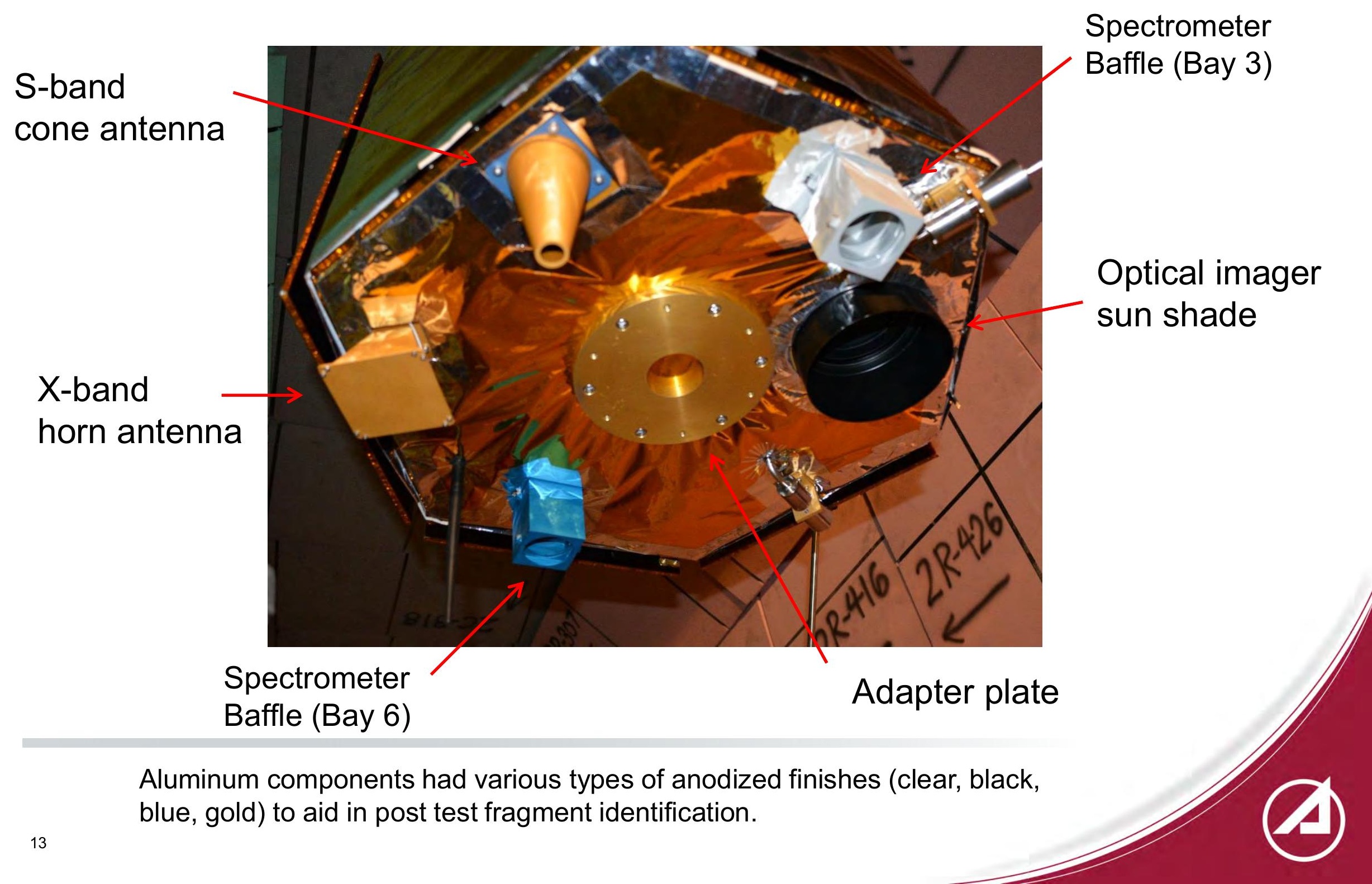




\section{Zenith / Top Side}

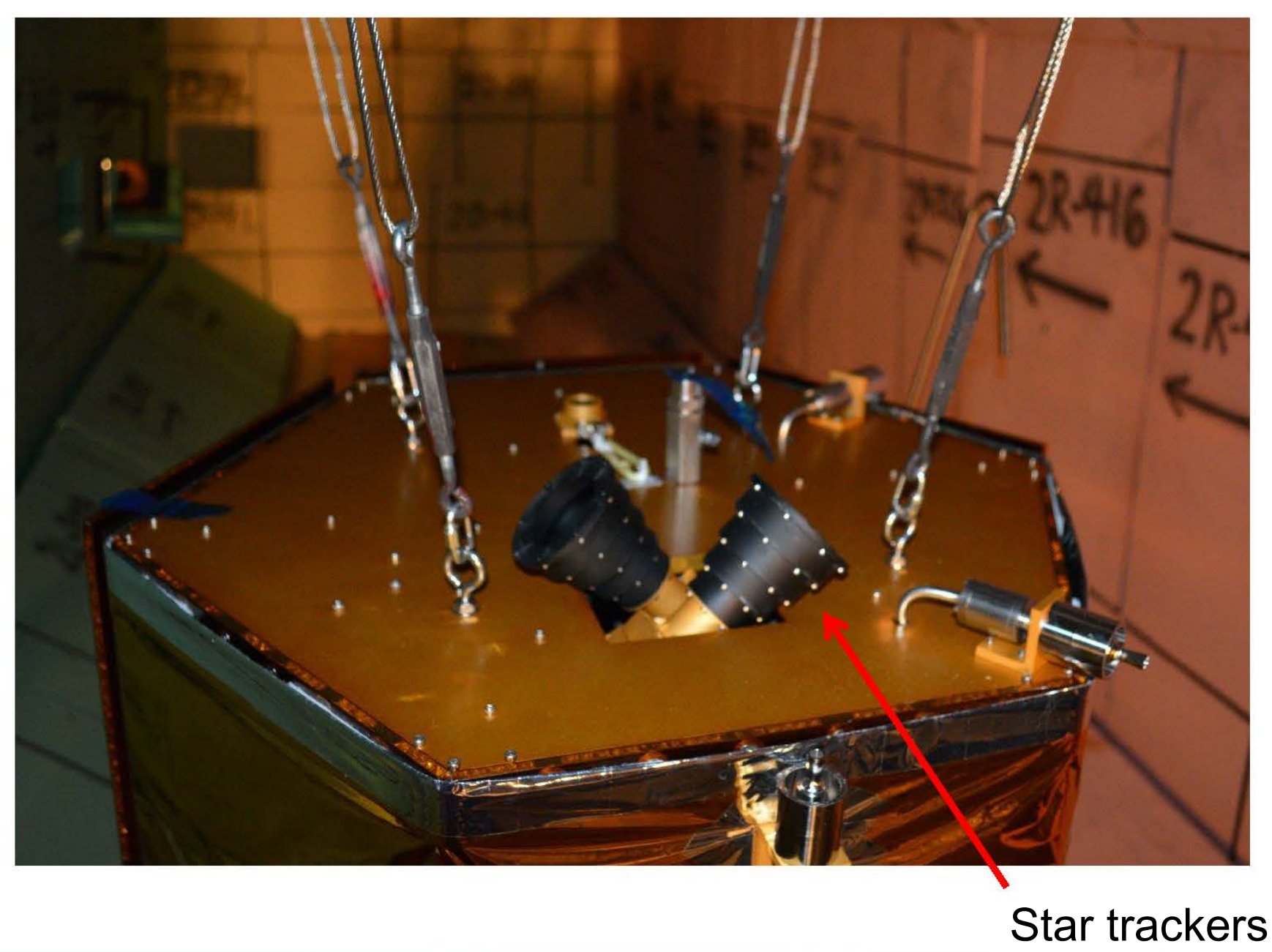


Whipple Plates

\section{Witness Plate: Pre Test}

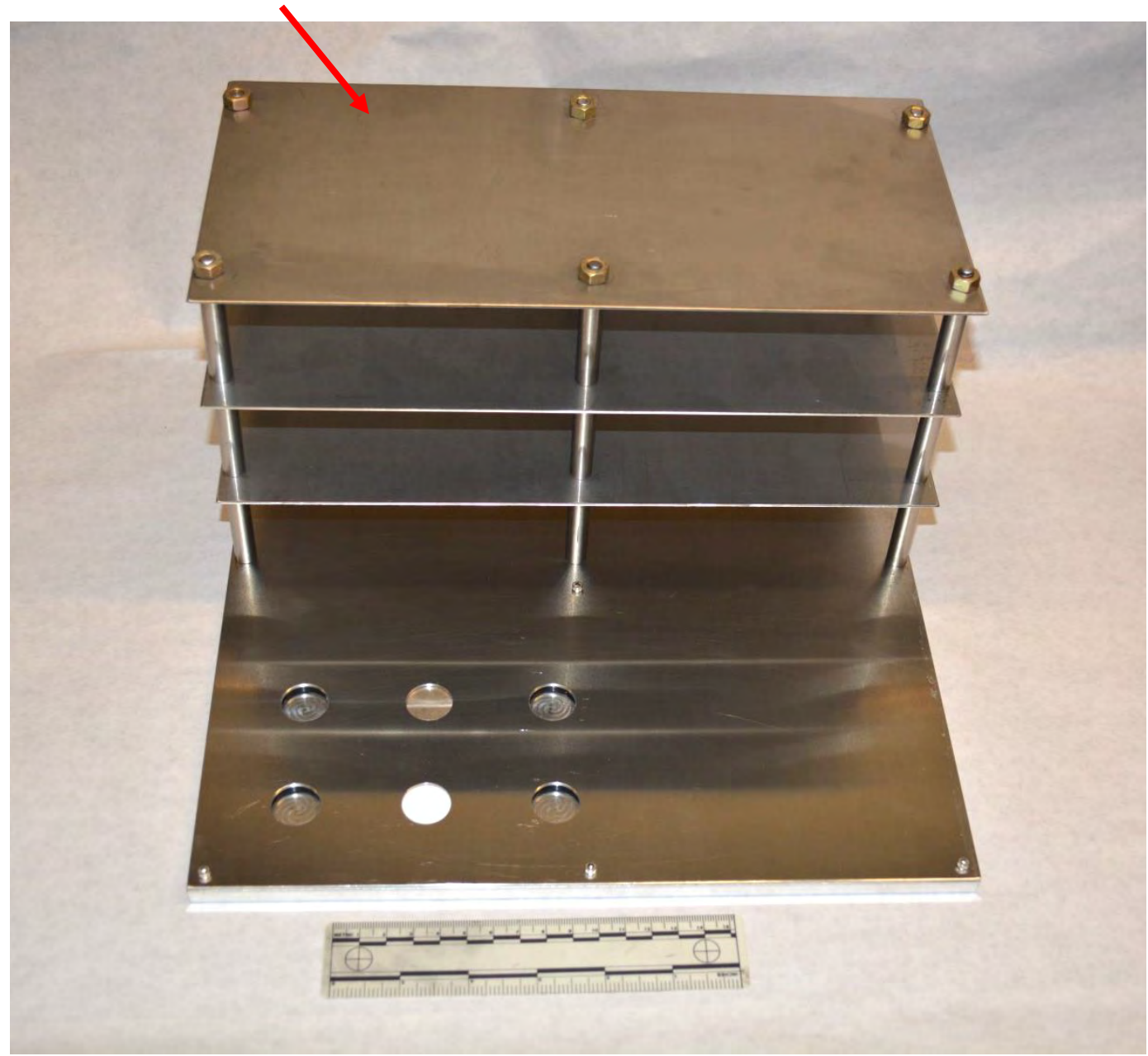

Witness plates located in same position in chamber as Debris-LV.

$\sim 3$ meters up range of DebriSat.

Direct Exposure

(4) 1" fused silica

(1) 1" Aluminum
(2) 1 " fused silica

(1) 1" Z-93 painted Al

(1) 1" Aluminum

(1) 1 " $\mathrm{NaCl}$

(1) Cu sheet

Ge ATR crystal (for FTIR)

Solar cell

Witness Plate Samples:

(1) 1" Z-93 painted Al

Multi layer insulation (not shown)

Protected Under Whipple Plates 


\section{Witness Plates Mounted in Chamber}

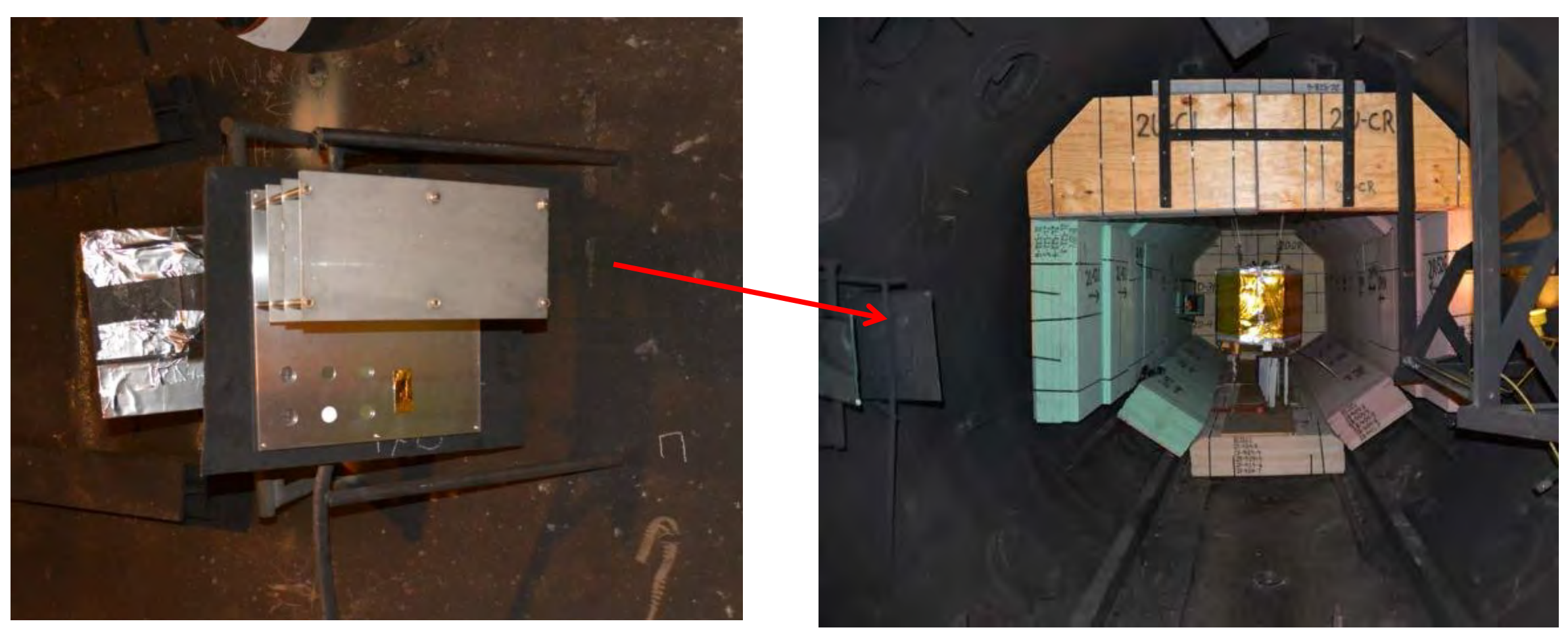

Plates mounted about 3 meters up range of DebriSat 


\section{SEM Stub Witness Plates Placed into Soft Catch Panels}

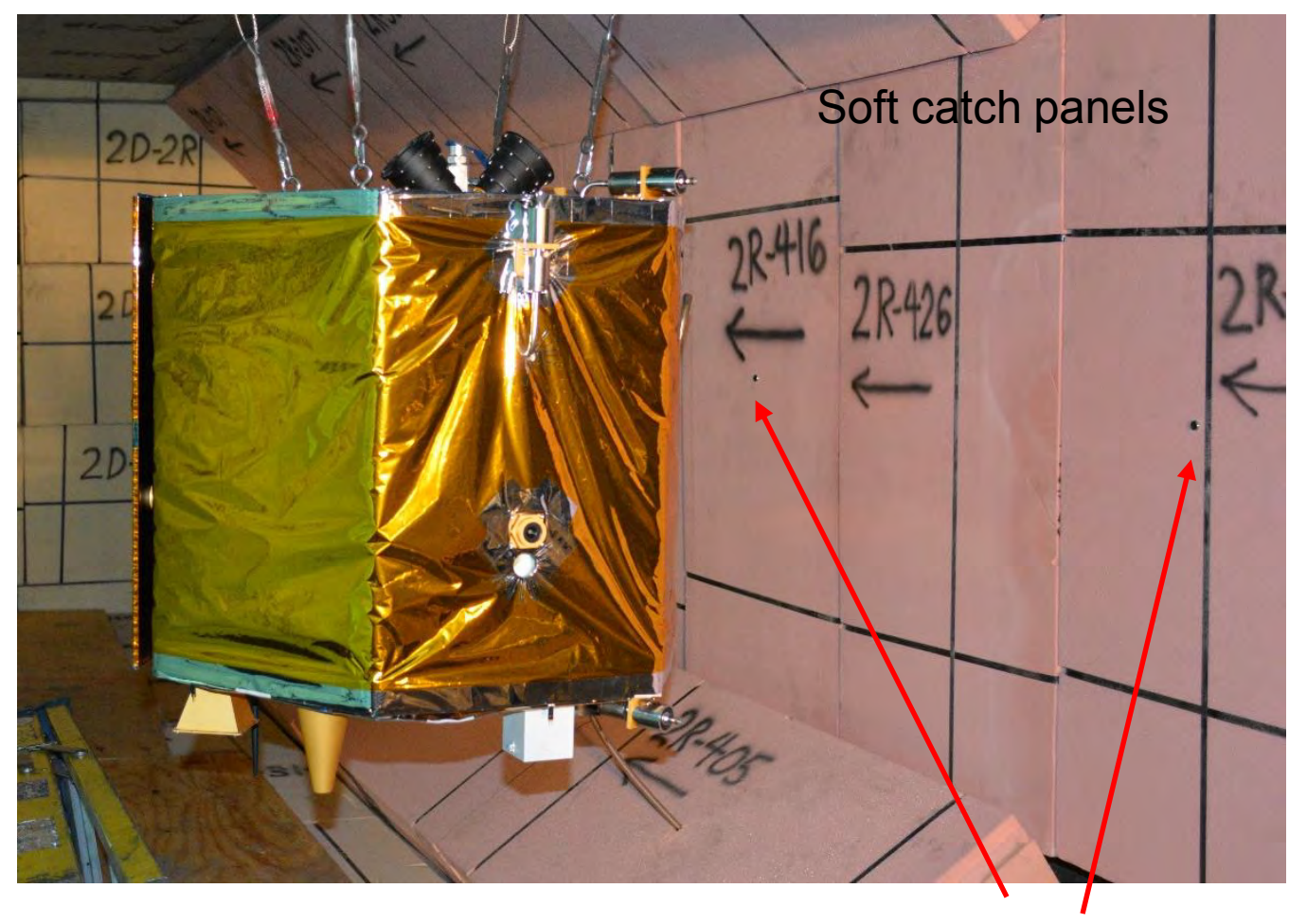

$12.5 \mathrm{~mm}$ Al SEM stubs

\section{SEM stubs}

-24 Aluminum SEM stub witness plates (12.5 mm dia) placed in soft catch with RTV adhesive.

-Tantalum sheet $(9 \mathrm{~mm} \times 9 \mathrm{~mm}$ ) epoxied to front surface in order to distinguish Al debris from stub.

-Identified on back with engraved numeral.

- 11 stubs recovered $(+)$; 5 with Ta sheet present $(++), 6$ in place $\left(^{*}\right)$

-Remaining stubs embedded in soft catch. - to be recovered at $\mathrm{U}$. of $\mathrm{F}$. 
Location of SEM Stubs (red) on Soft Catch Panels

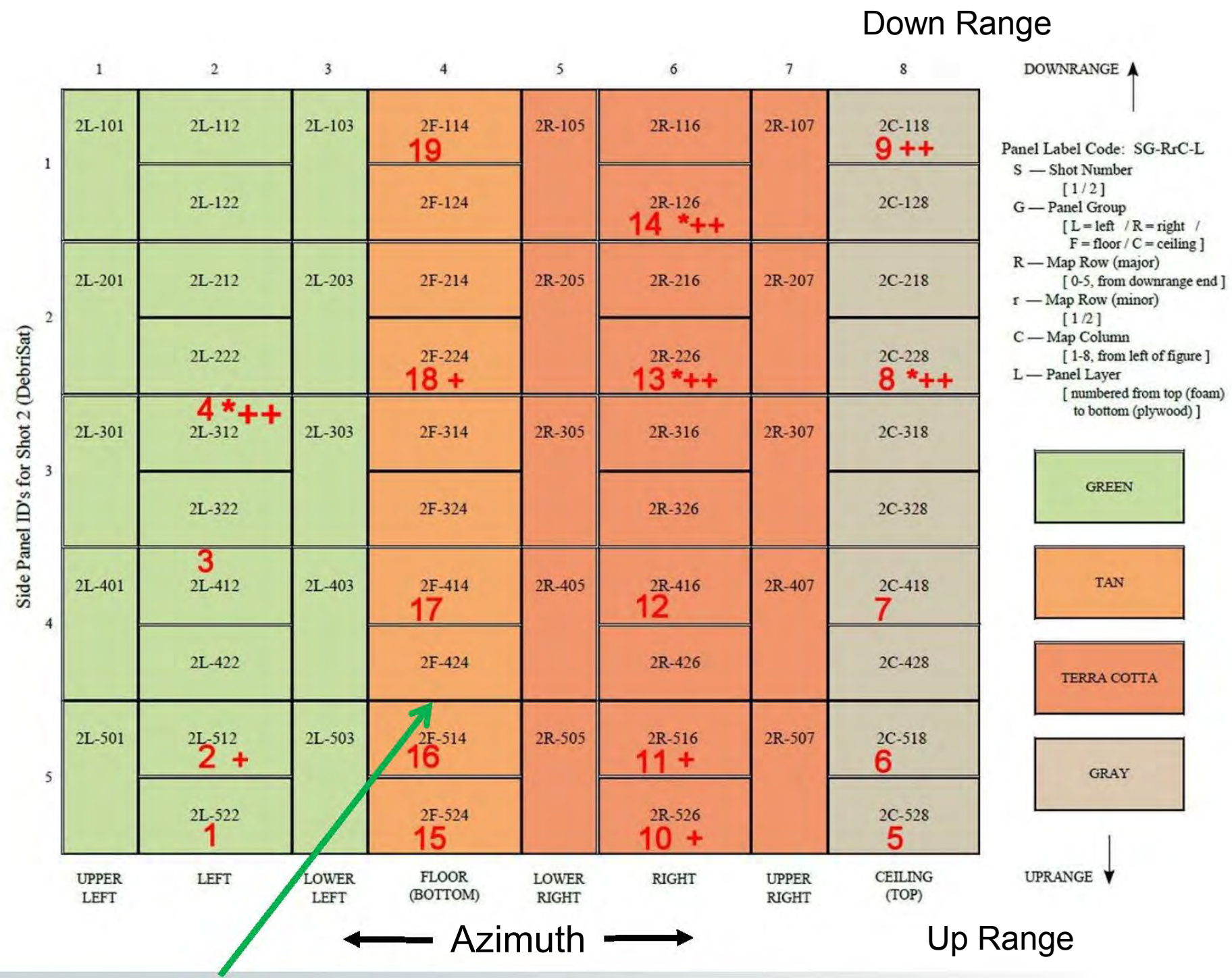

Nominal location of DebriSat is above $2 \mathrm{~F}-424$ and $2 \mathrm{~F}-514$

stubs recovered $(+)$, with Ta sheet present $(++)$, in place $\left(^{*}\right)$

18 Intact recovered stubs with $\mathrm{Ta}\left({ }^{*}++\right)$ tended to be furthest from impact site 


\section{Location of SEM Stubs (red) on Soft Catch Panels}

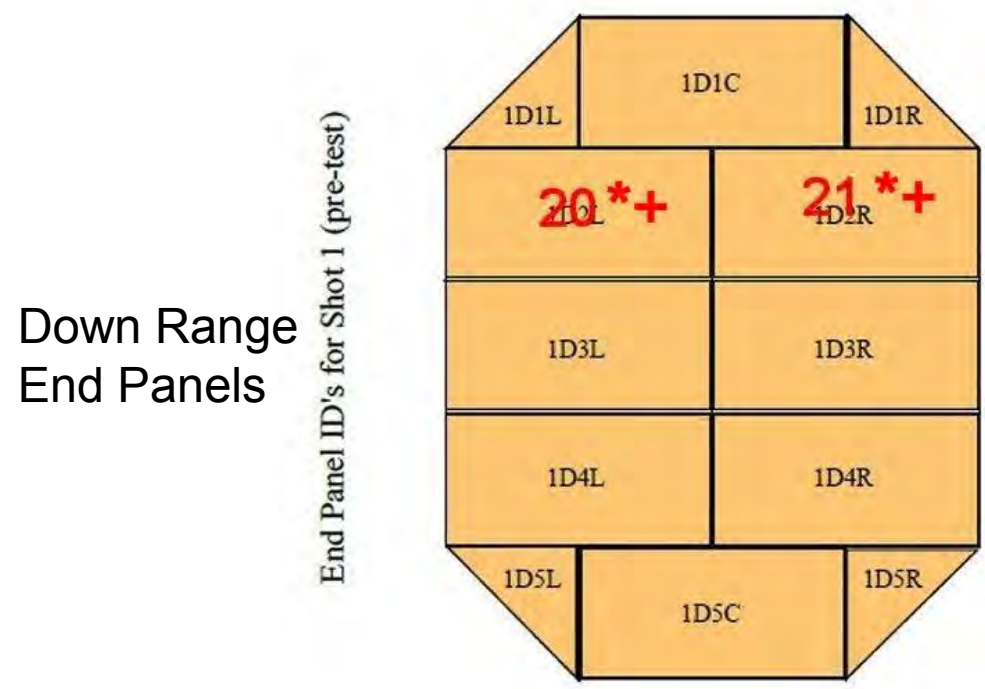

DOWNRANGE

(looking downrange)

Panel Label Code: SERC-L

$S$ - ShotNumber [1/2]

$\mathrm{E}$-PanelGroup [D=downrange]

R-Manow [1-4, from to

$C-M a p$ Column $[\mathrm{L}=$ left $/ \mathrm{R}=\mathrm{ight} / \mathrm{C}=\mathrm{Center]}$

L - Panell ayer [mumbered from top (form) to

bottom (plywood)]

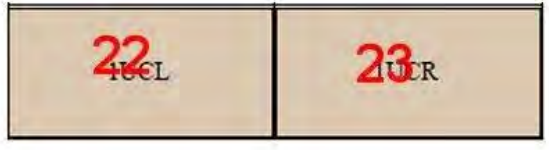

Upper Up Range End Panels

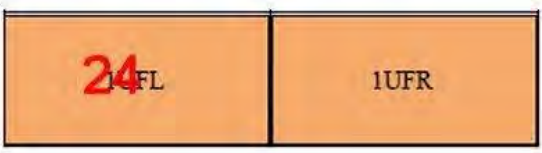

Lower Up Range End Panels

-stubs recovered $(+)$, with Ta sheet present $(++)$, in place $\left(^{*}\right)$

Panel Label Code: SEGC-L

$S$ - ShotNumber $[1 / 2]$

E-PanelGroup1 [U=uprange]

$\mathrm{C}-\mathrm{MapC}$ lume $\mathrm{I}=\mathrm{lef} / \mathrm{R}=\mathrm{ight}$

L - Panellayer [numbered from top (foam) to

bottom (plywood)] 
DebriSat Impact: Frames from High Speed Video

$$
\mathrm{T}=-180 \mu \mathrm{S}
$$

$$
\mathrm{T} \sim 0 \mu \mathrm{S}
$$

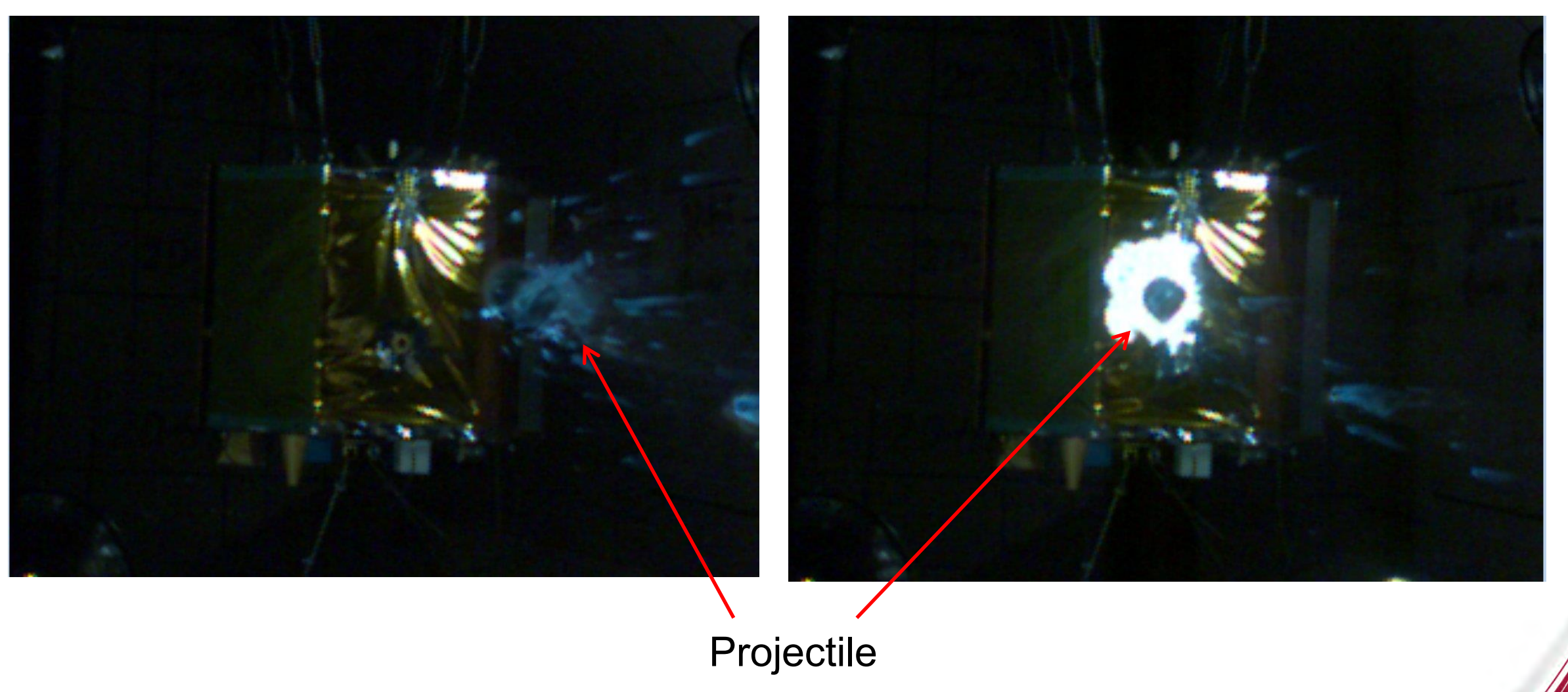

High speed camera $(65,000 \mathrm{fps})$ images from NASA 
DebriSat Impact: Frames from High Speed Video

$$
\mathrm{T}=+45 \mu \mathrm{S}
$$
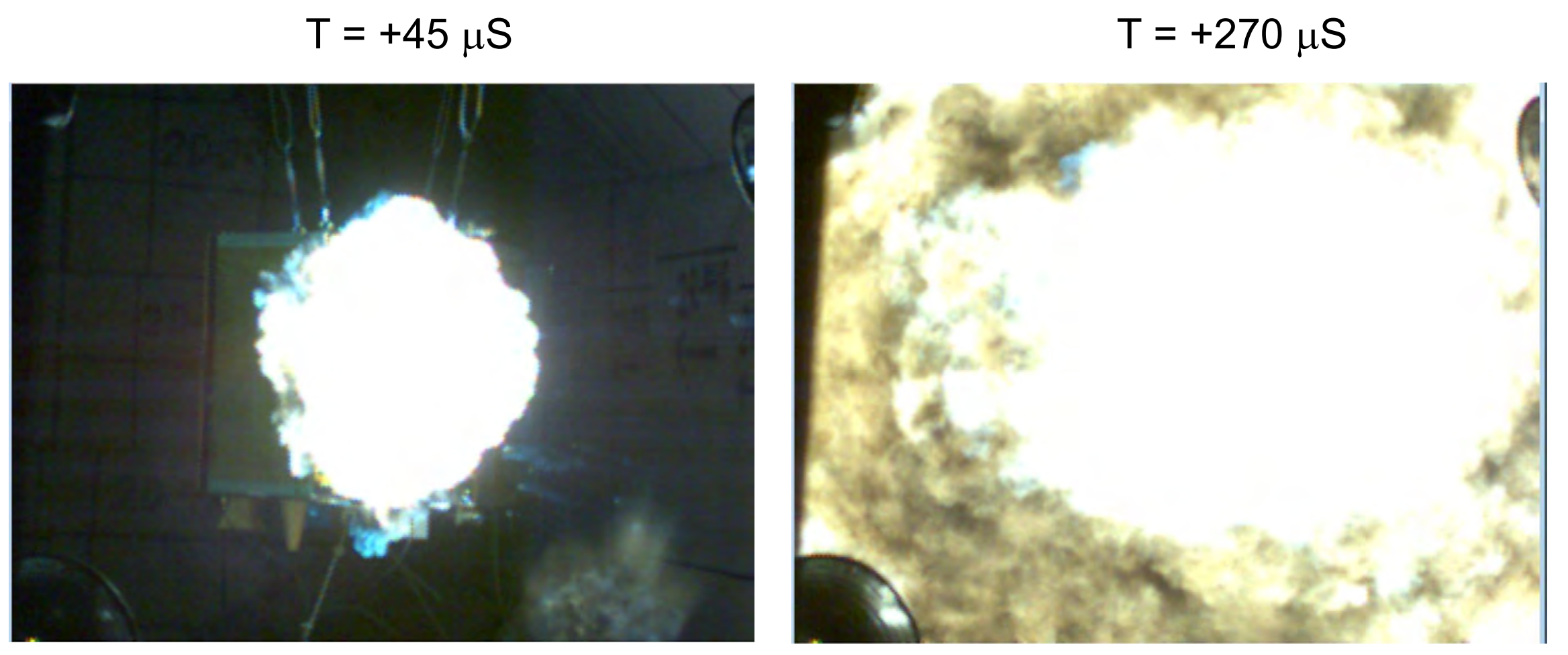

High speed camera $(65,000 \mathrm{fps})$ images from NASA 


\section{Laboratory Results (Supplemental Information and Additional Analyses in Appendix)}




\section{Laboratory Methods}

- Scanning Electron Microscopy (SEM)

- High resolution imaging.

- Atomic number contrast.

- Transmission electron microscopy (TEM)

- Ultra high resolution - lattice imaging (crystallinity)

- Electron diffraction - crystallinity - phase identification

- Energy Dispersive (X-ray) Spectroscopy (EDS) in the SEM/TEM

- Semiquantitative elemental composition.

- Elemental mapping and line scans.

- Fourier Transform Infrared (FTIR) spectroscopy

- Identification of chemical functional groups.

- Correlation with LWIR hyperspectral remote sensing signatures.

- Raman Spectroscopy

- Identification of forms of carbon

- UV-VIS-NIR Spectroscopy

- Measurement of darkening at UV-VIS-NIR wavelengths. 


\section{SEM Stubs (post test)}

8
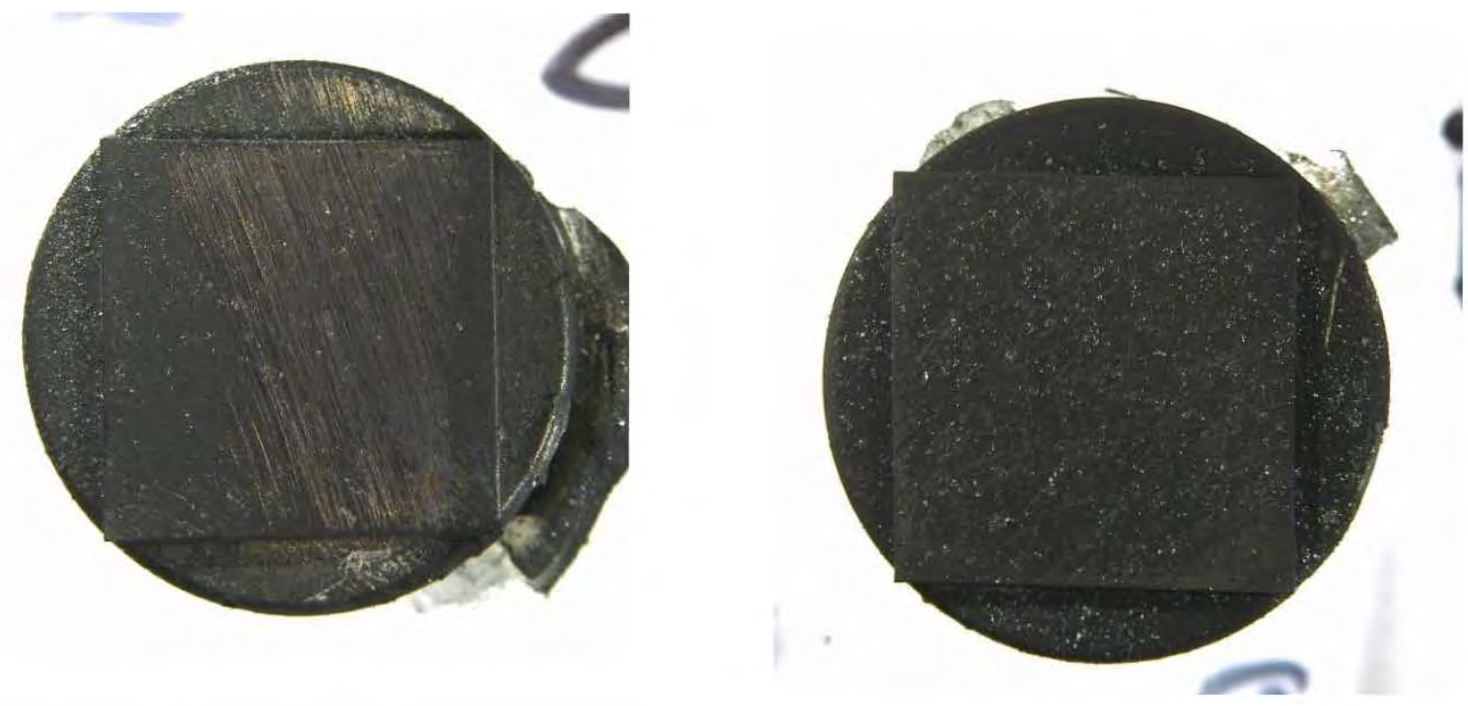

9

13
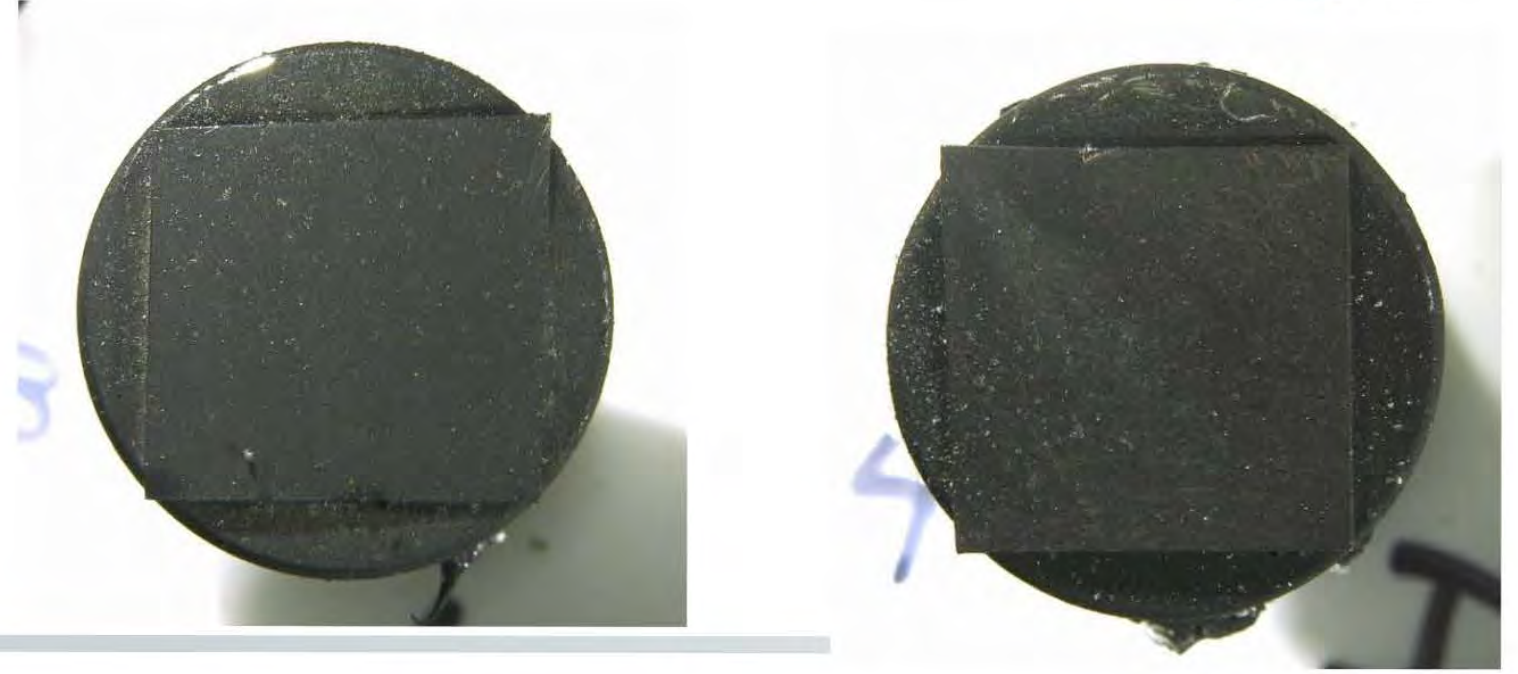

14

Stubs are covered with a black soot-like substance 


\section{SEM Stub 4:}

\section{Backscatter Electron SEM (10KX, 20KX)}
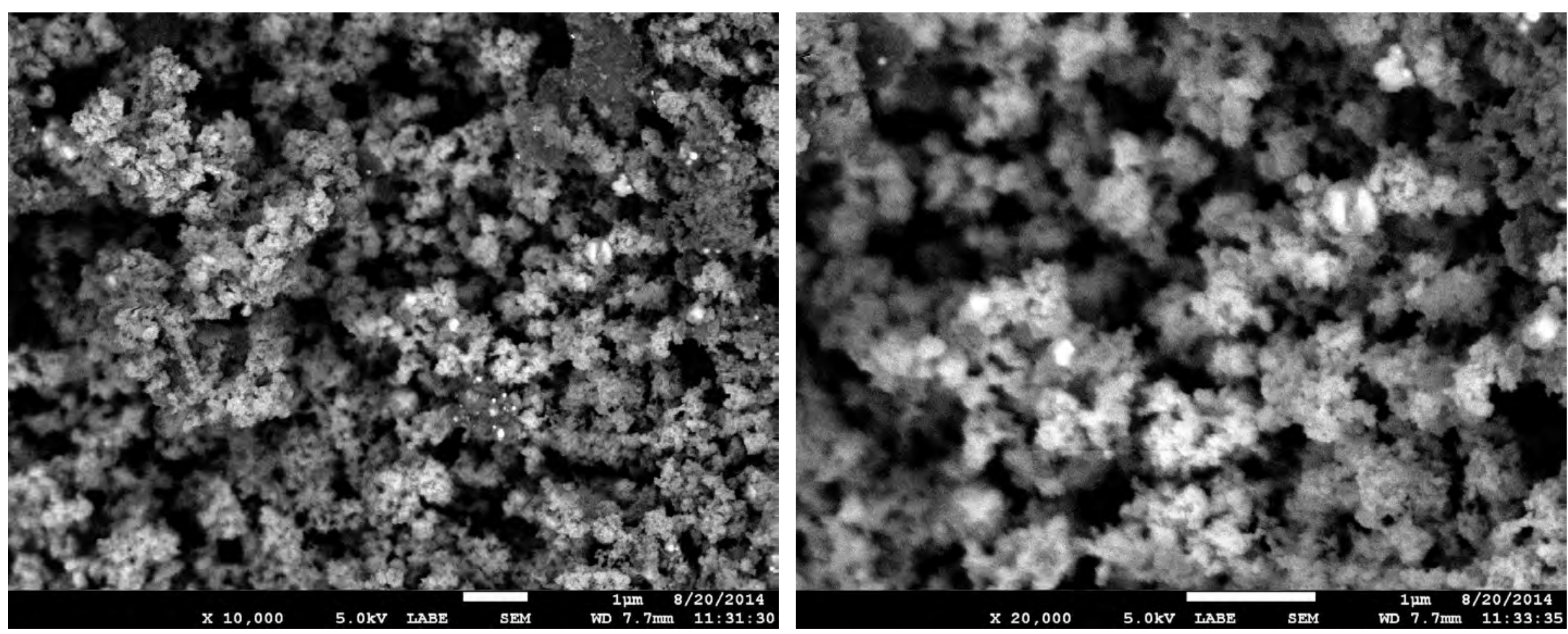

Material on surface consists of nano-sized agglomerates

Located 9 feet down range -9 O'clock 


\section{SEM Stub 9}

\section{Backscatter SEM 5KX, 10KX}
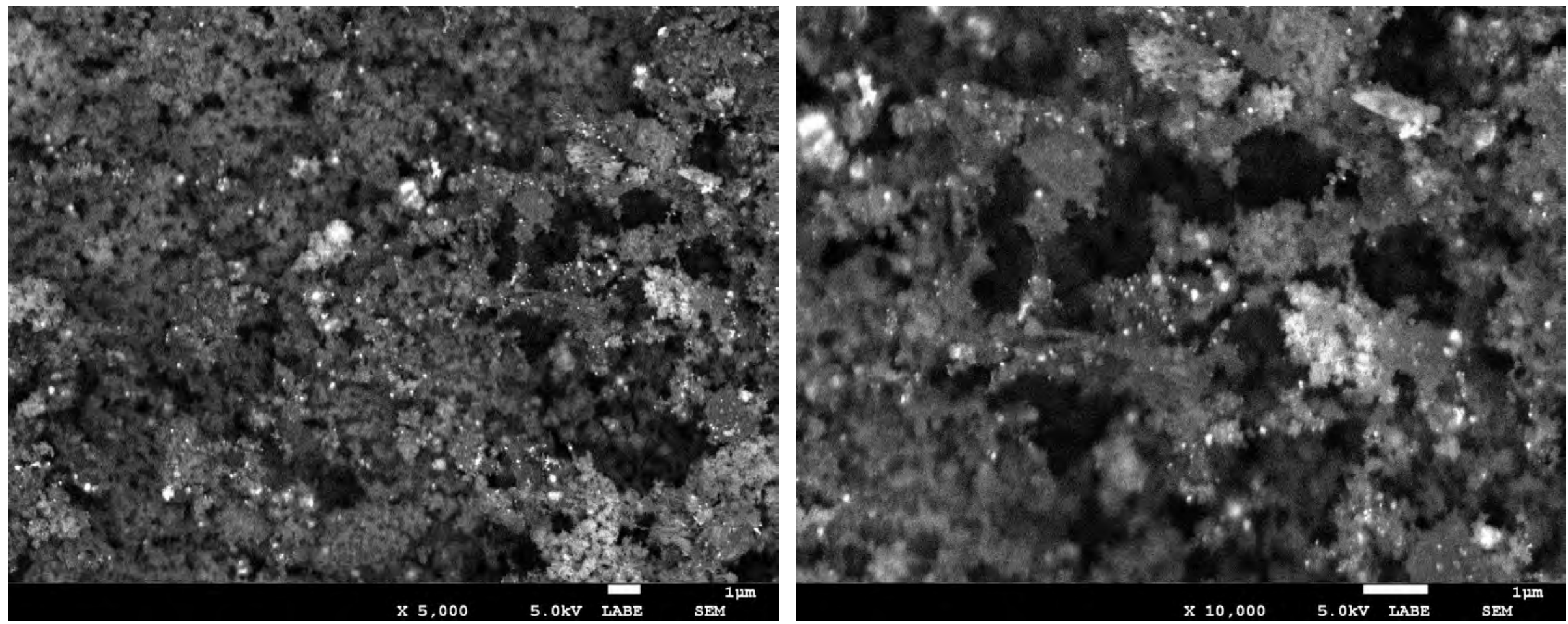

Nano-sized bright areas are high Z (Fe, Cu, Zn Ge, Al) mixed with darker carbonaceous debris.

Located 17 feet down range -12 O'clock 


\section{SEM Stub 9}

\section{Backscatter SEM 20KX, 50KX}
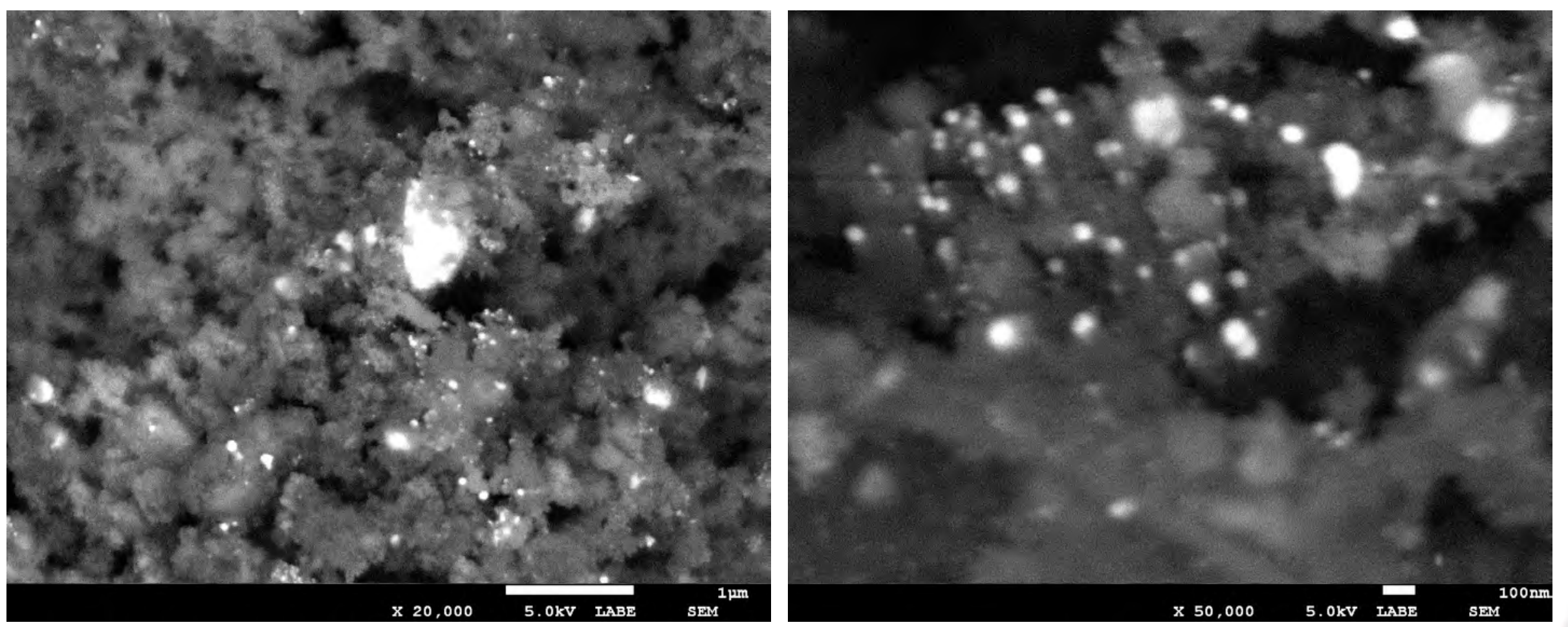

Nano bright areas appear to be solidified molten droplets of high $Z$ material ( $\mathrm{Fe}, \mathrm{Cu}, \mathrm{Zn} \mathrm{Ge}, \mathrm{Al}$ ) mixed and covered with carbonaceous debris.

Located 17 feet down range - 12 O'clock 


\section{SEM Stub 13}

\section{Secondary Electron SEM (50KX, 100KX)}
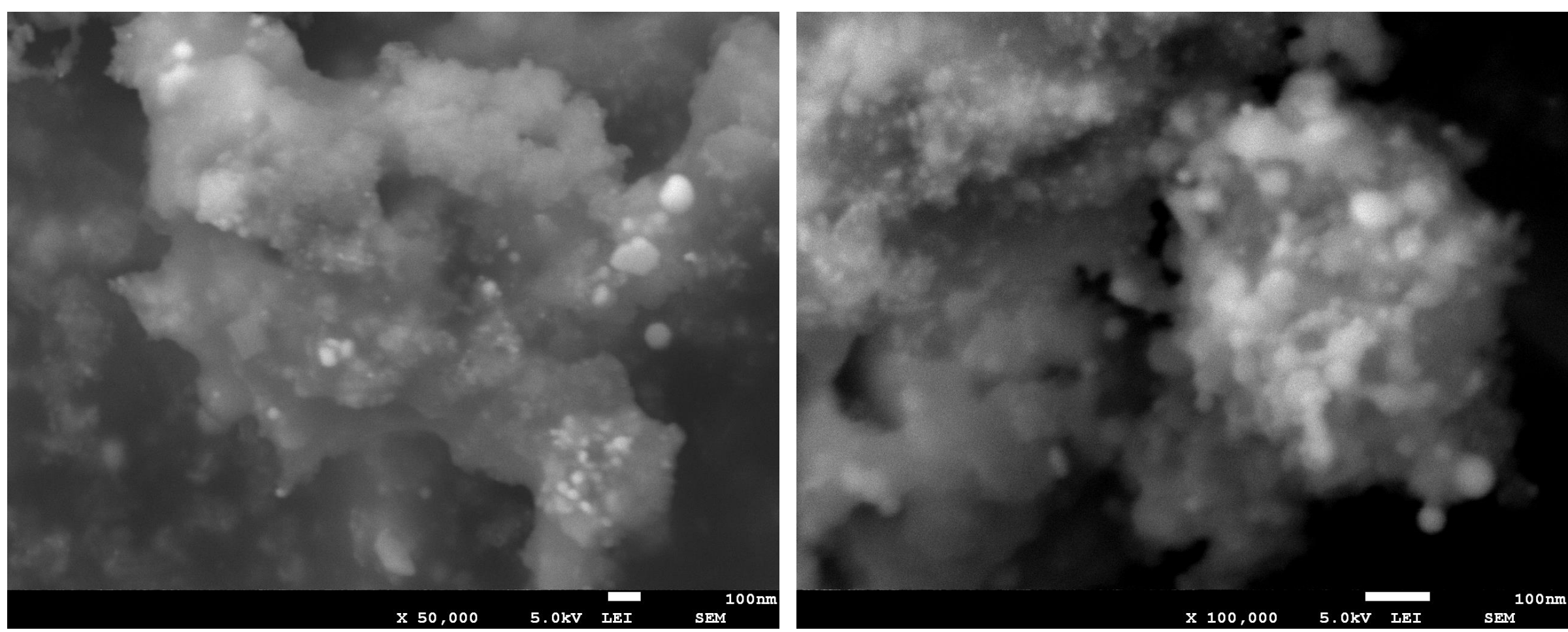

Note nano-scale particulates

Located 11 feet down range - 3 O'clock 


\section{SEM EDS}
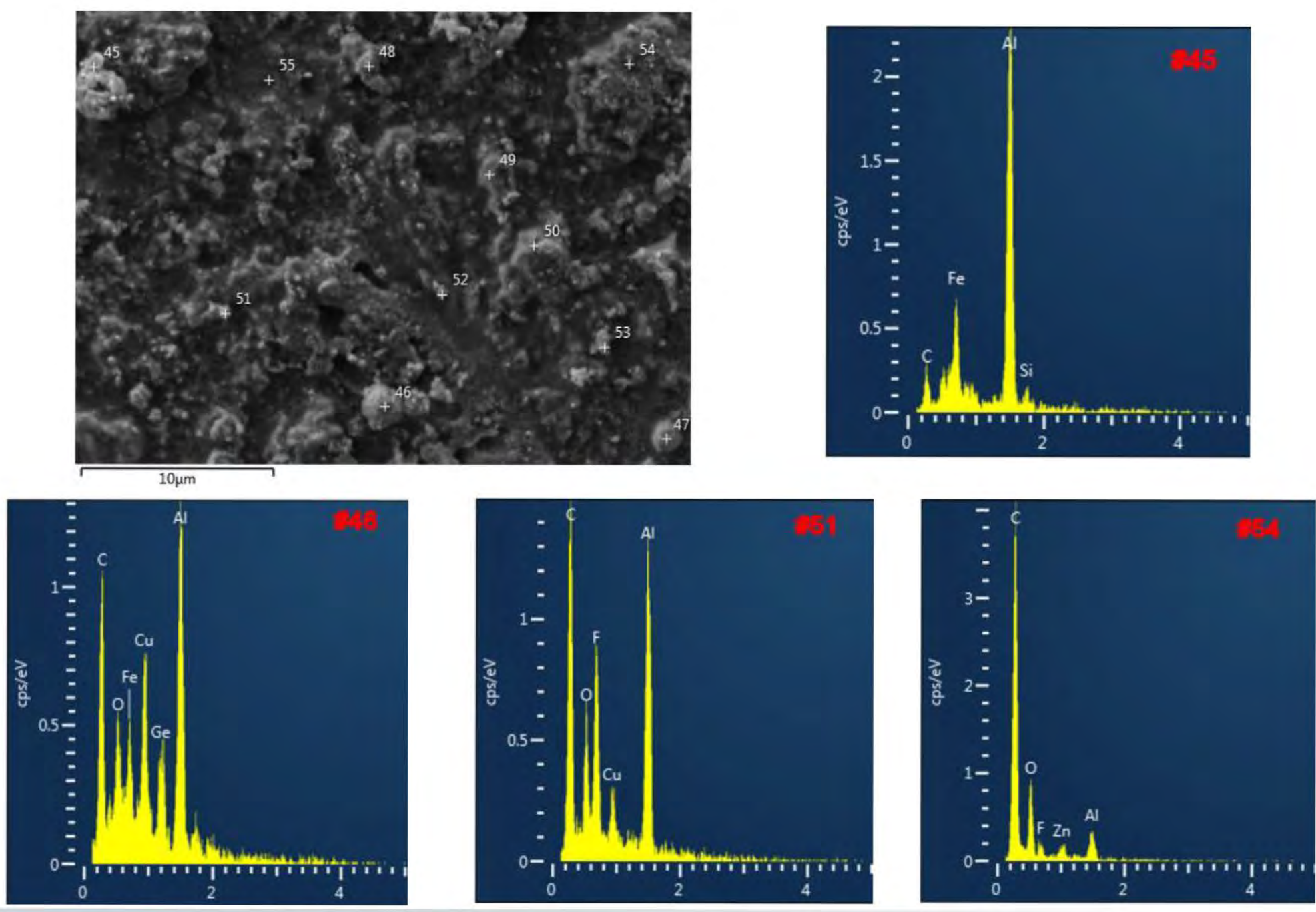

$\mathrm{Al}, \mathrm{C}, \mathrm{F}, \mathrm{Cu}, \mathrm{O}, \mathrm{Fe}$, and $\mathrm{Ge}$ are common. Bright nano droplets contain $\mathrm{Fe}, \mathrm{Cu}, \mathrm{Ge}$. 


\section{SEM Stub 14}

\section{Backscatter SEM 20KX, 50KX}

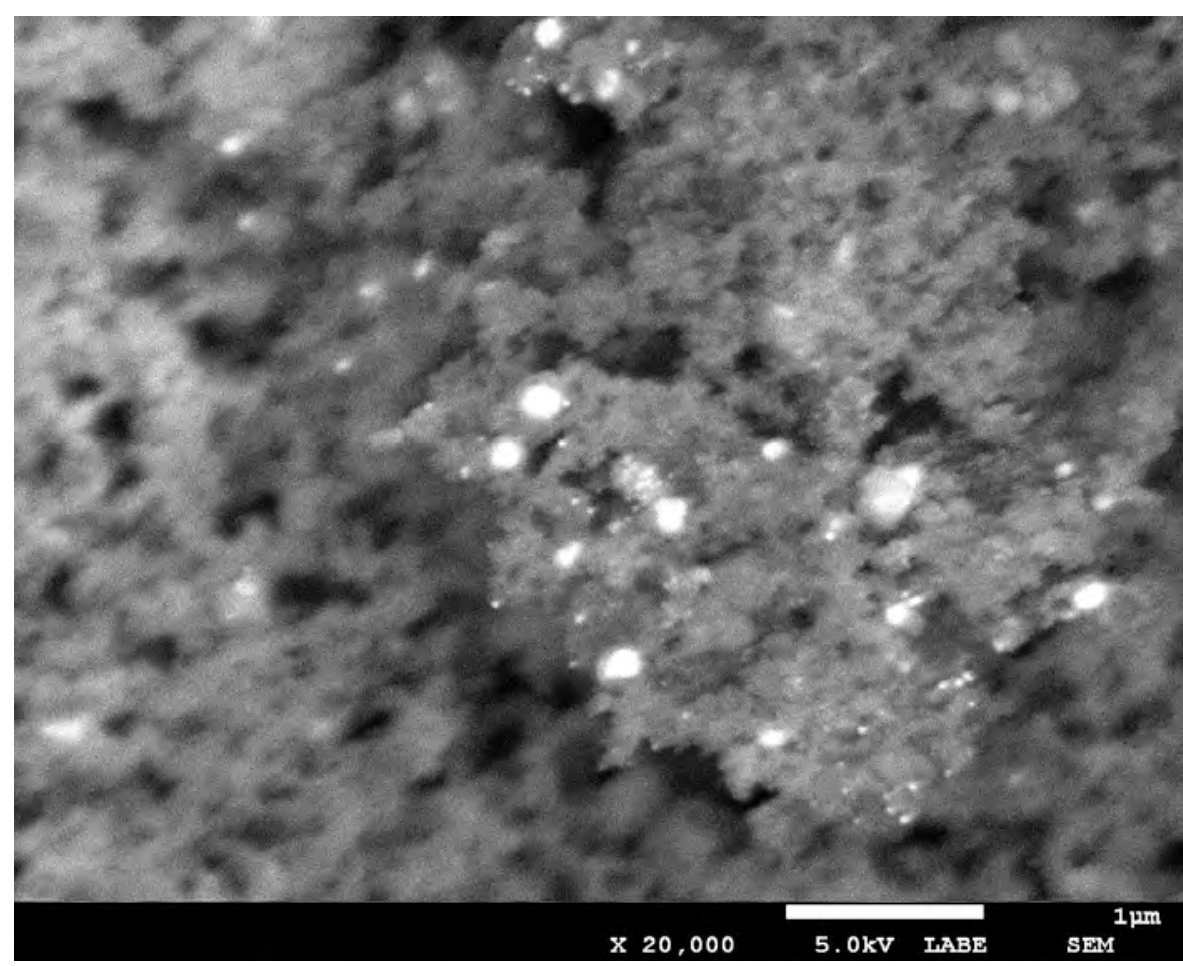

Majority of the deposit is an agglomeration of nano carbonaceous material

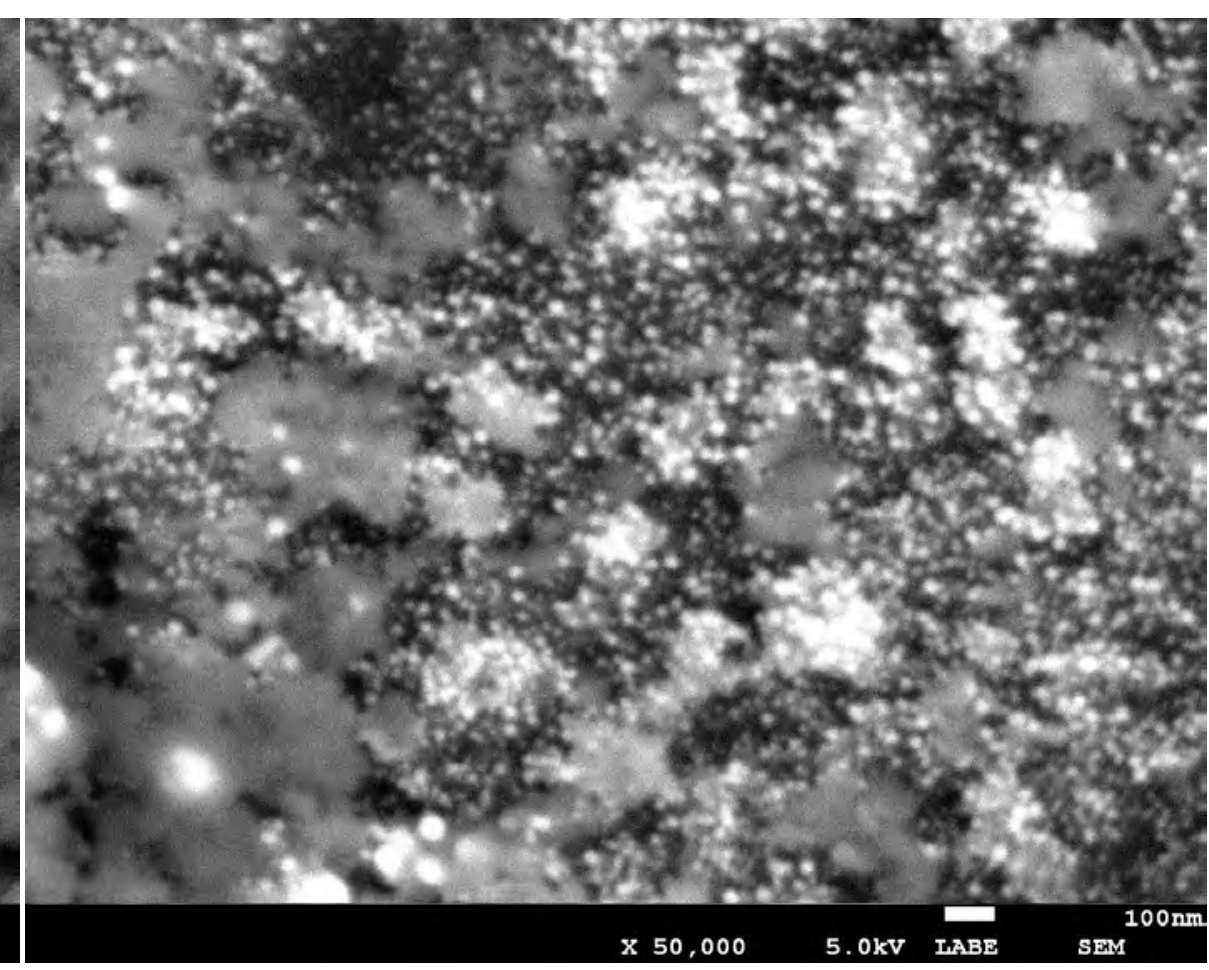

Note higher $Z$ nano particles

Located 15 feet down range - 3 O'clock 
SEM Stub 14

SEM EDS (5 KV)
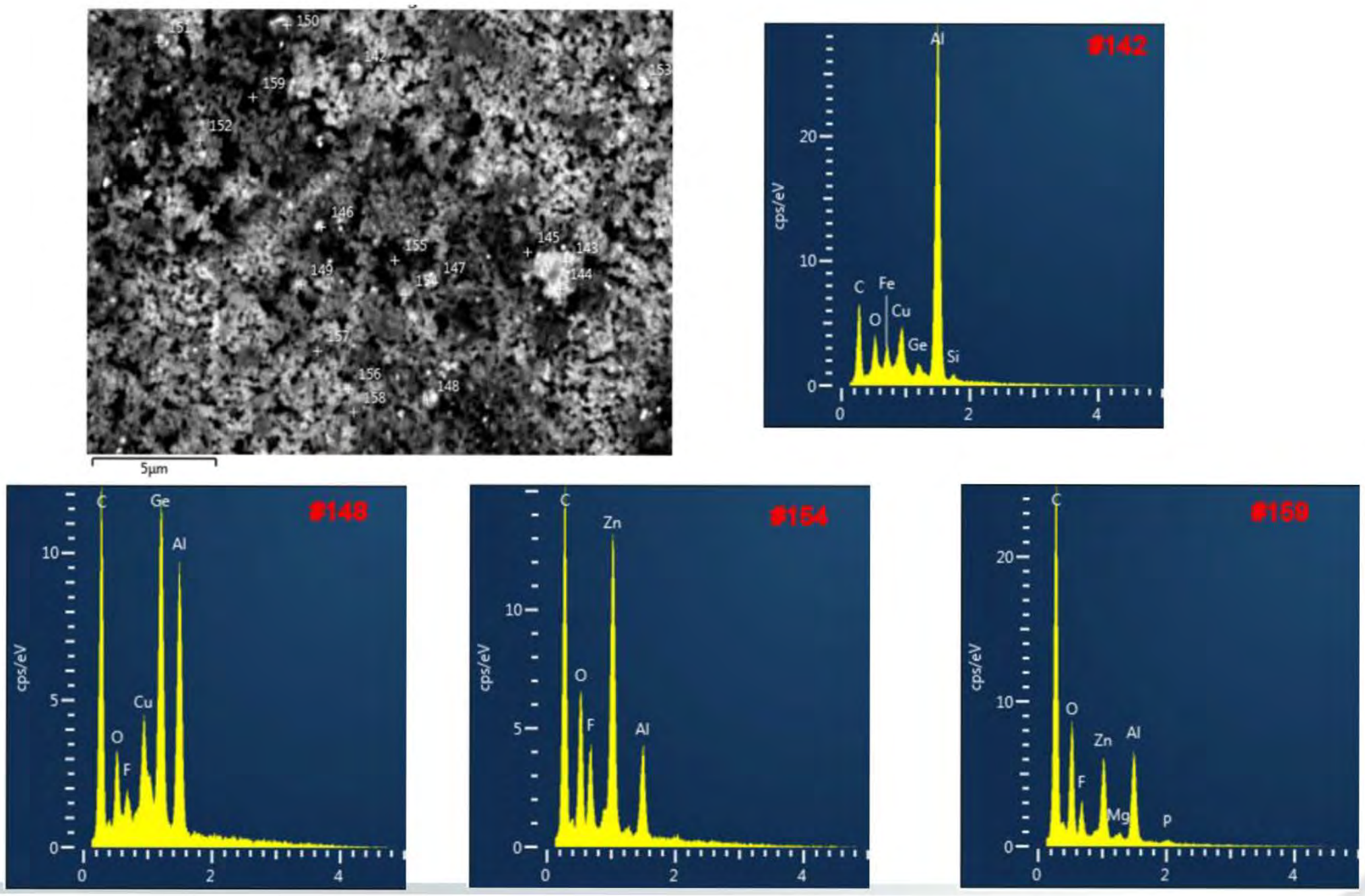

$\mathrm{C}$ is ubiquitous - $\mathrm{Al}, \mathrm{Zn}, \mathrm{Ge}, \mathrm{F}$ and $\mathrm{Cu}$ are common. 


\section{SEM Stub 14: Focused Ion Beam (FIB) Cross Section Secondary Electron SEM 2KX, $5 \mathrm{KX}$}
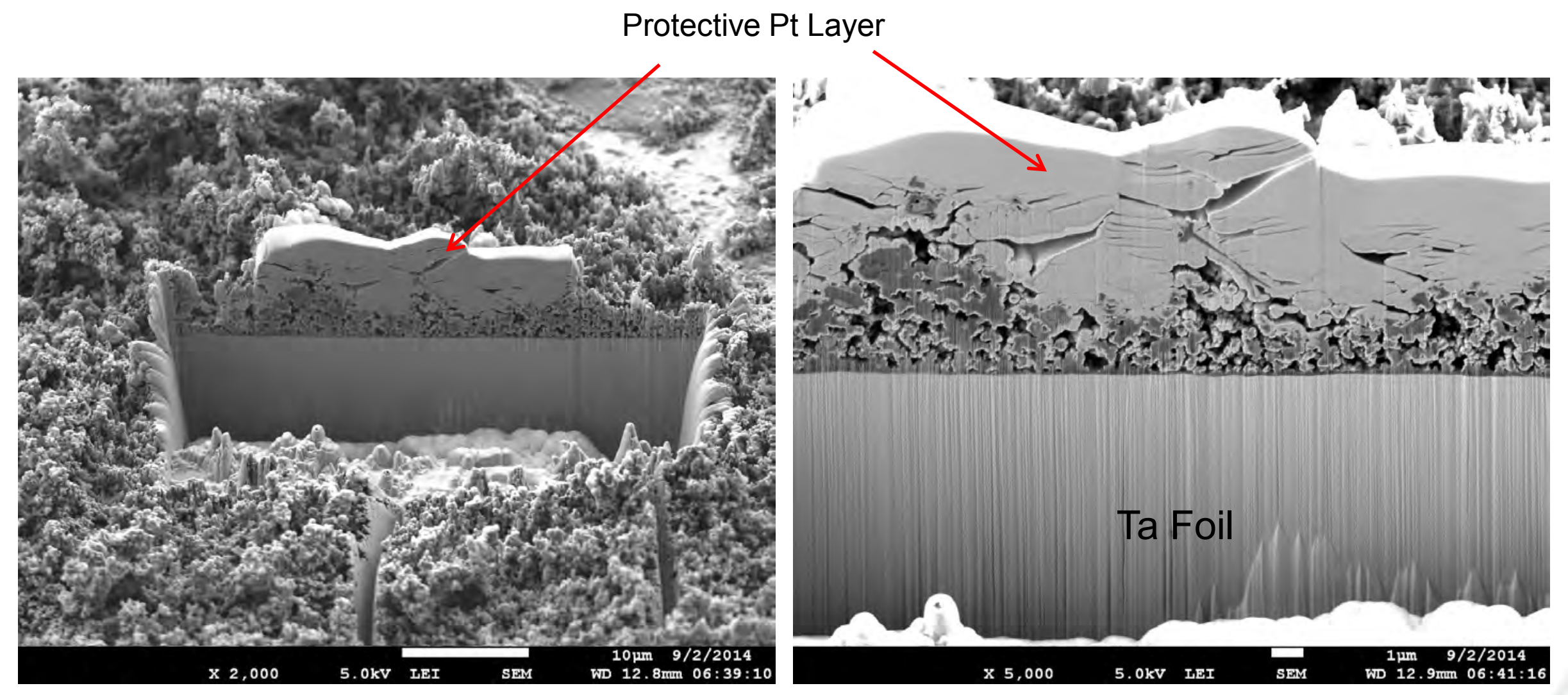

45 degree tilt

Deposit is several microns thick consisting of loose debris which is 32 composed of agglomerates of nano particles. 


\section{SEM Stub 14: FIB Cross Section Backscatter Electron SEM 15KX, $20 \mathrm{KX}$}

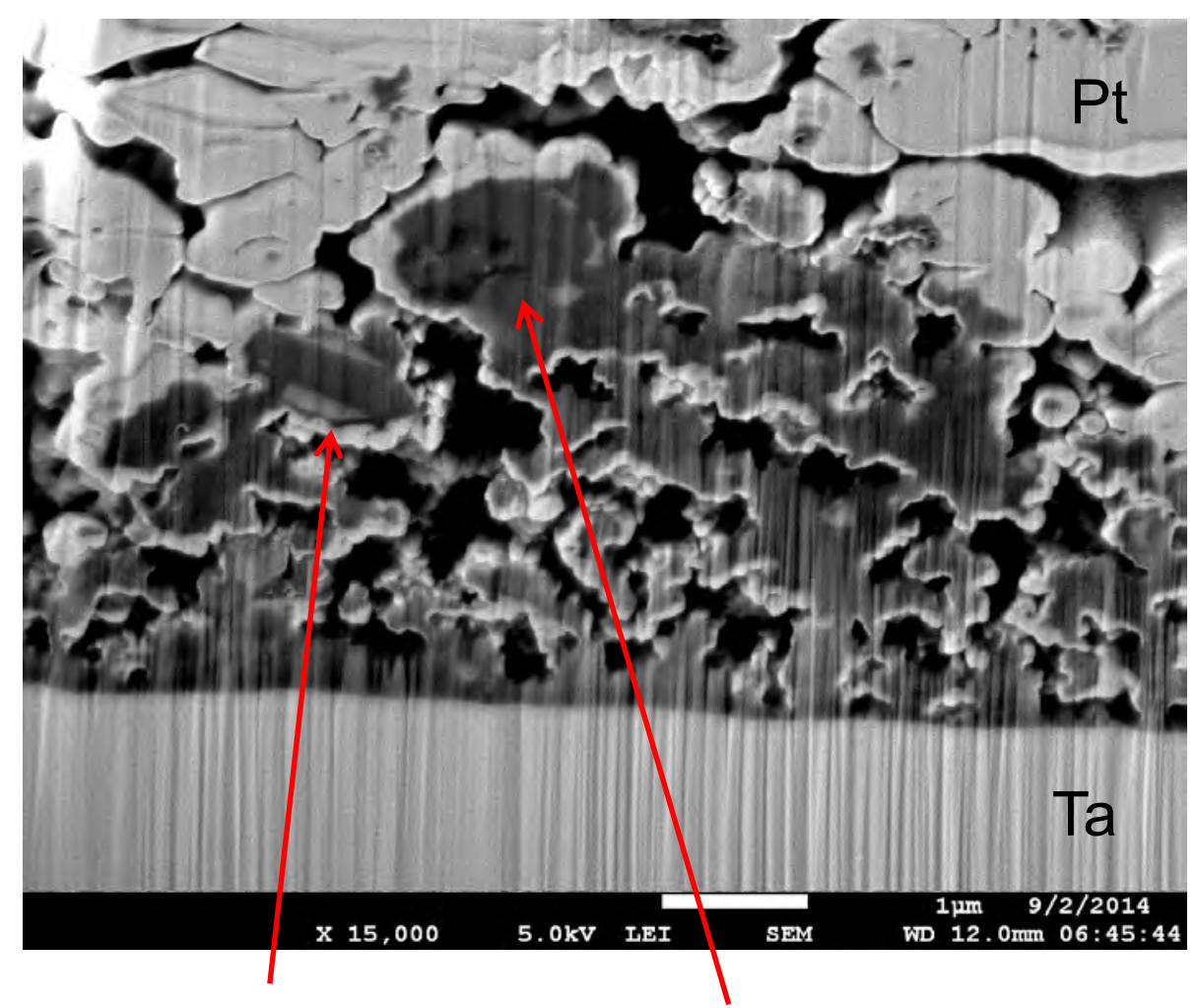

Higher $\mathrm{Z}$ fragments in carbonaceous matrix

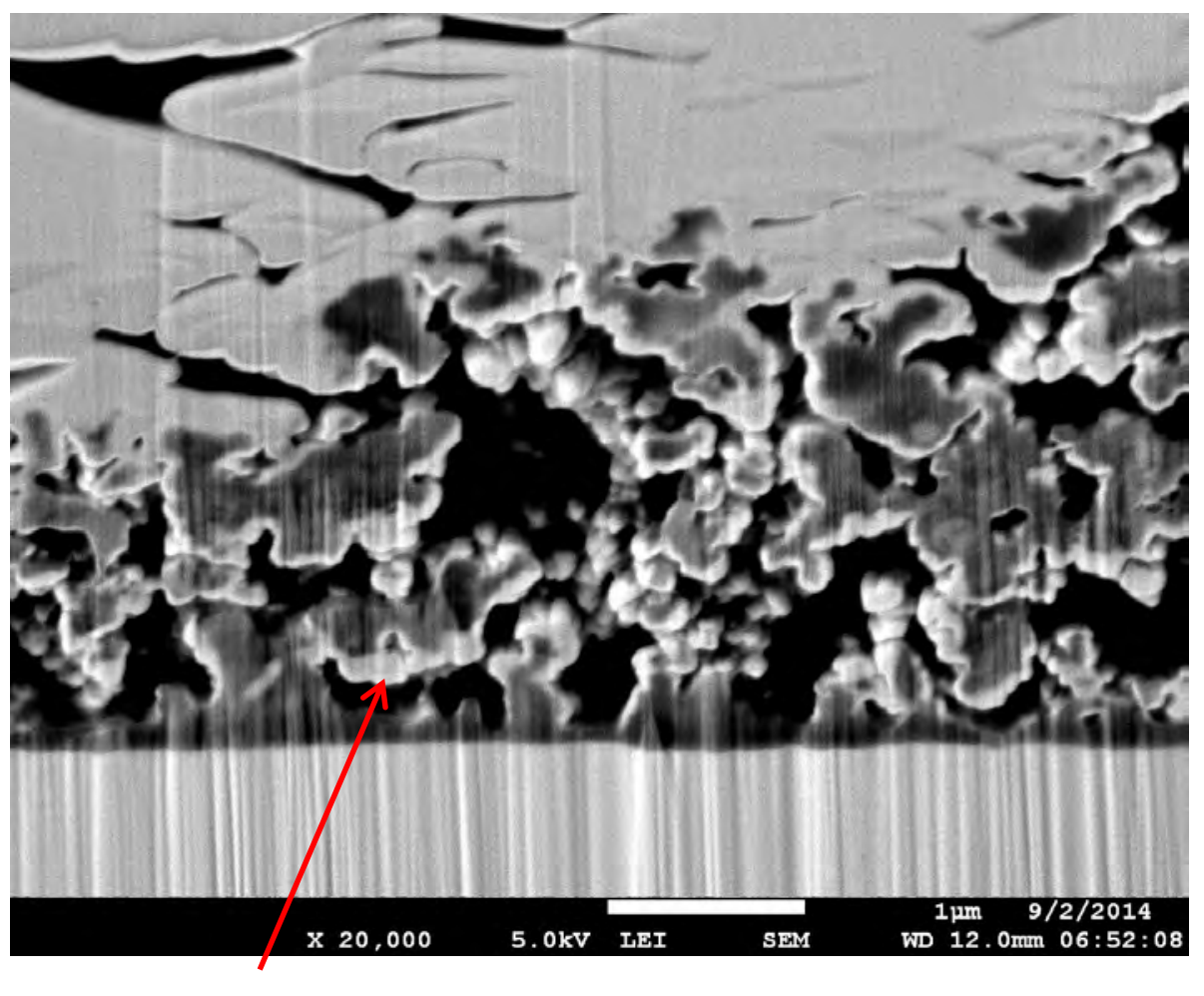

Light rind on particles is probably Ta ejected into cavities during the trenching operation or infusion of Pt.

EDS analysis was hampered by relatively large sampling volume and introduction of significant $\mathrm{Pt}, \mathrm{Ta}$ and $\mathrm{Ga}$. C, O and some Al detected. 


\section{SEM Stub 20}

\section{Secondary Electron SEM 5KX, 10KX}
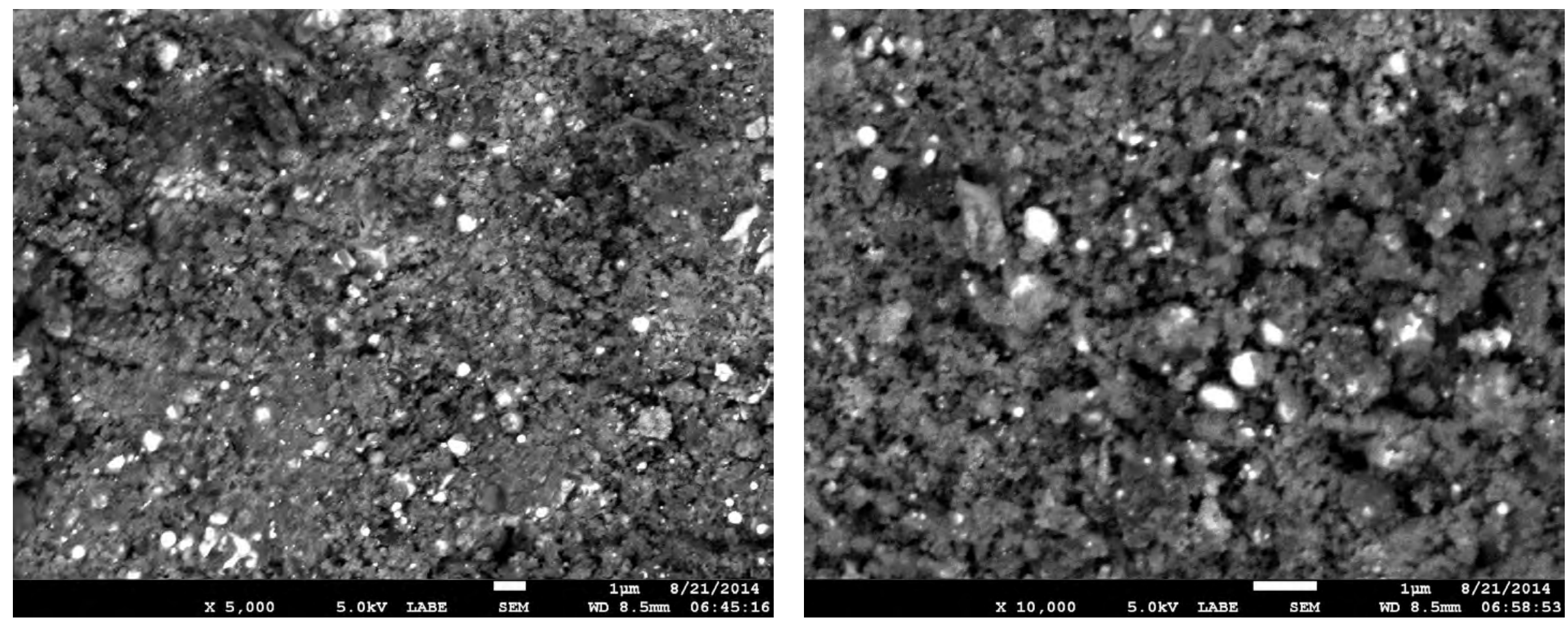

Material on surface consists of nano-sized agglomerates.

Darker areas are carbon rich. Bright spots contain $\mathrm{Fe}, \mathrm{Cu}, \mathrm{Zn}, \mathrm{Ge}$ and represent solidified molten droplets partially covered with carbonaceous nano particles.

Located on down range back wall. 


\section{Summary of Area EDS Analyses}

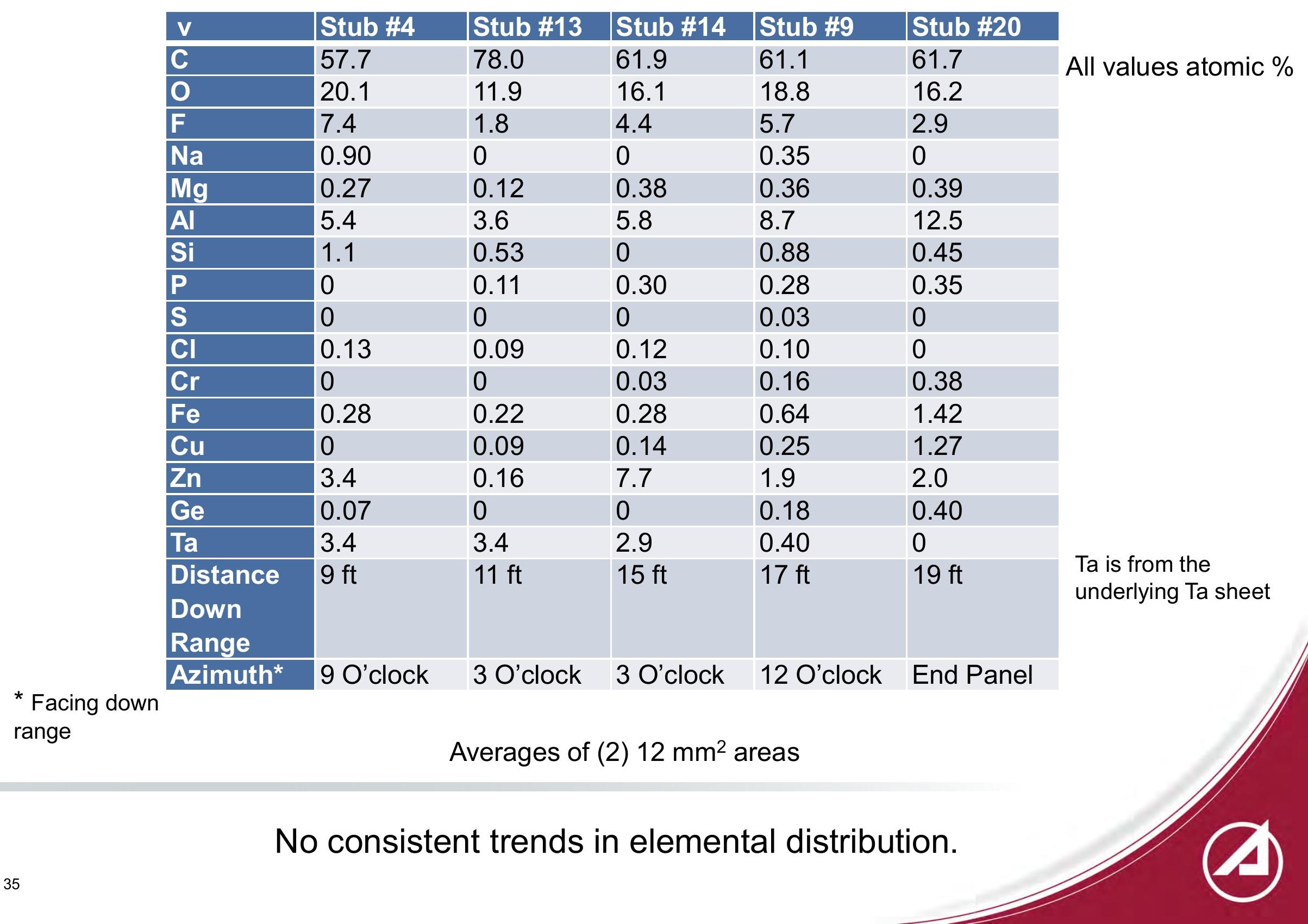




\section{Summary of Area EDS Analyses}

- The majority of the deposits consist of carbon and oxygen (77-89 at\%).

- Primarily from pyrolyzed soft catch (based on Debris-LV results).

- Some contribution form MLI and C-C composite face sheet.

- Fluorine (1.8 - 7.4 at\%) is from Teflon wire insulation and?

- Metal nano particles are common

- Aluminum (3.6 - 12.5 at\%) is from the aluminum honeycomb panels, structural core, nadir-zenith panels and COPV tank.

- Zinc (0.2 - 7.7 at\%) is from an unidentified source.

- Iron (0.2 - 1.4 at\%) is from stainless steel tubing and solenoids.

- Copper (0.09 - 1.3 at\%) is from wiring and solenoids.

- Germanium $(0.07-0.40$ at $\%)$ is from the solar cells. 
SBU Marking:
Post Test: SEM Stubs

\section{FTIR - Qualitative Diffuse Reflectance}

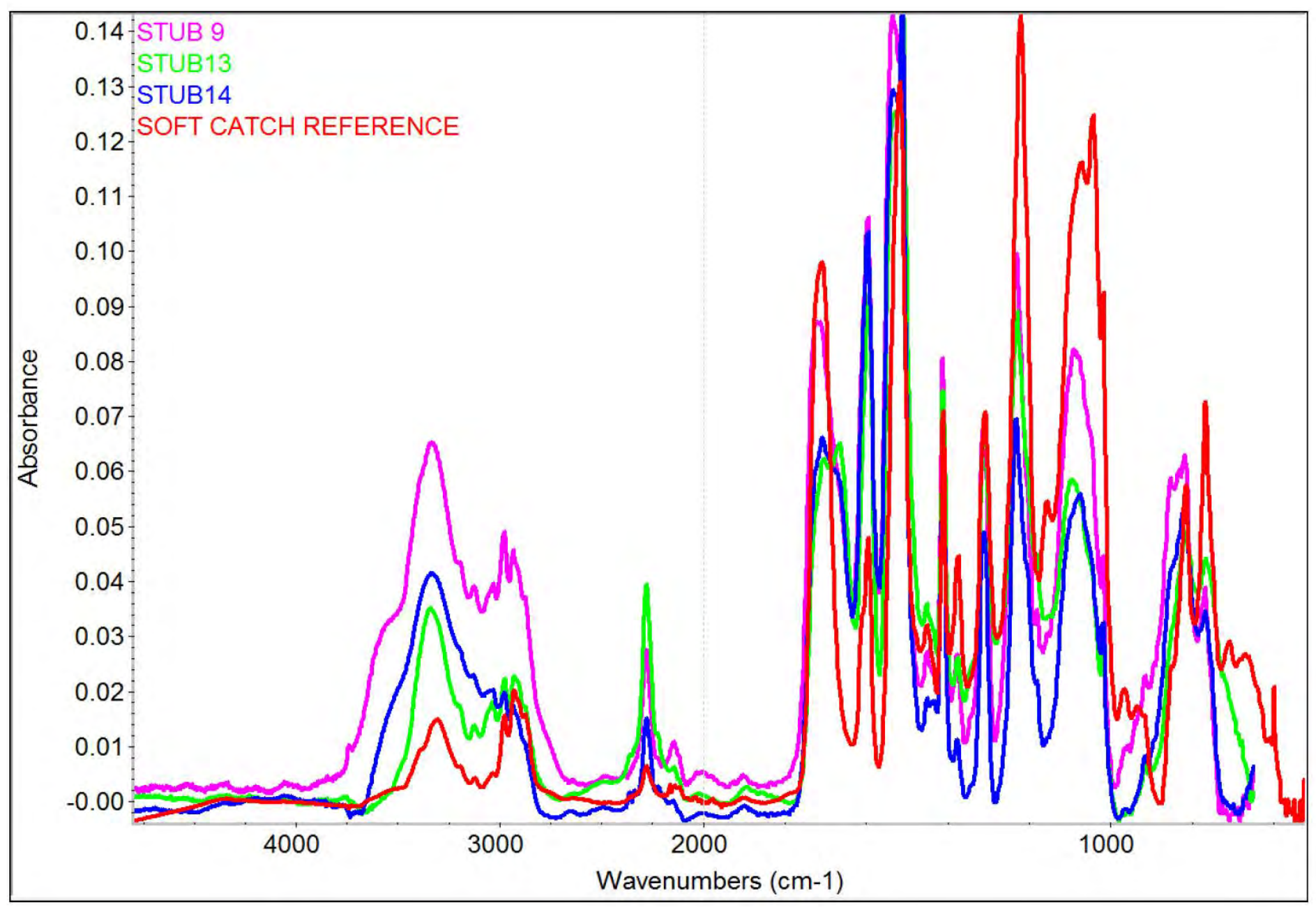

Significant soft catch signature is present on SEM stubs. Some, but not all, is in the form of soft catch foam fragments which give samples a sparkly appearance. 


\section{Laboratory Foam Pyrolysis Experiment}

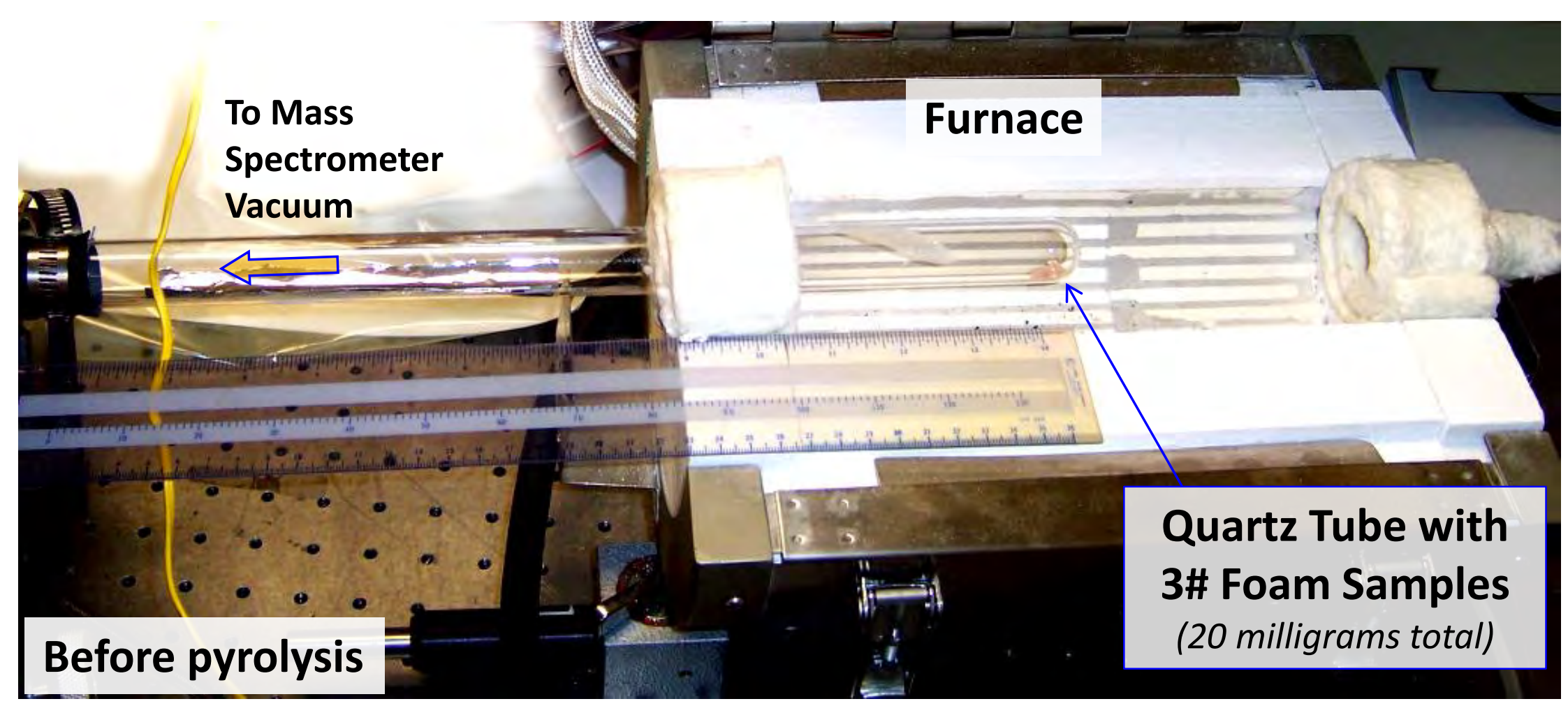

$\sim 0.001$ Torr Throughout Pyrolysis $\Rightarrow \lambda \sim 10$ inches

30 milligram pieces of $3 \#$ foam pyrolyzed in a quartz tube under vacuum in order to simulate exposure to plasma from hypervelocity impact.

Condensate residues in cool portion of tube outside the furnace were analyzed by FTIR . 


\section{Laboratory Foam Pyrolysis Experiment}

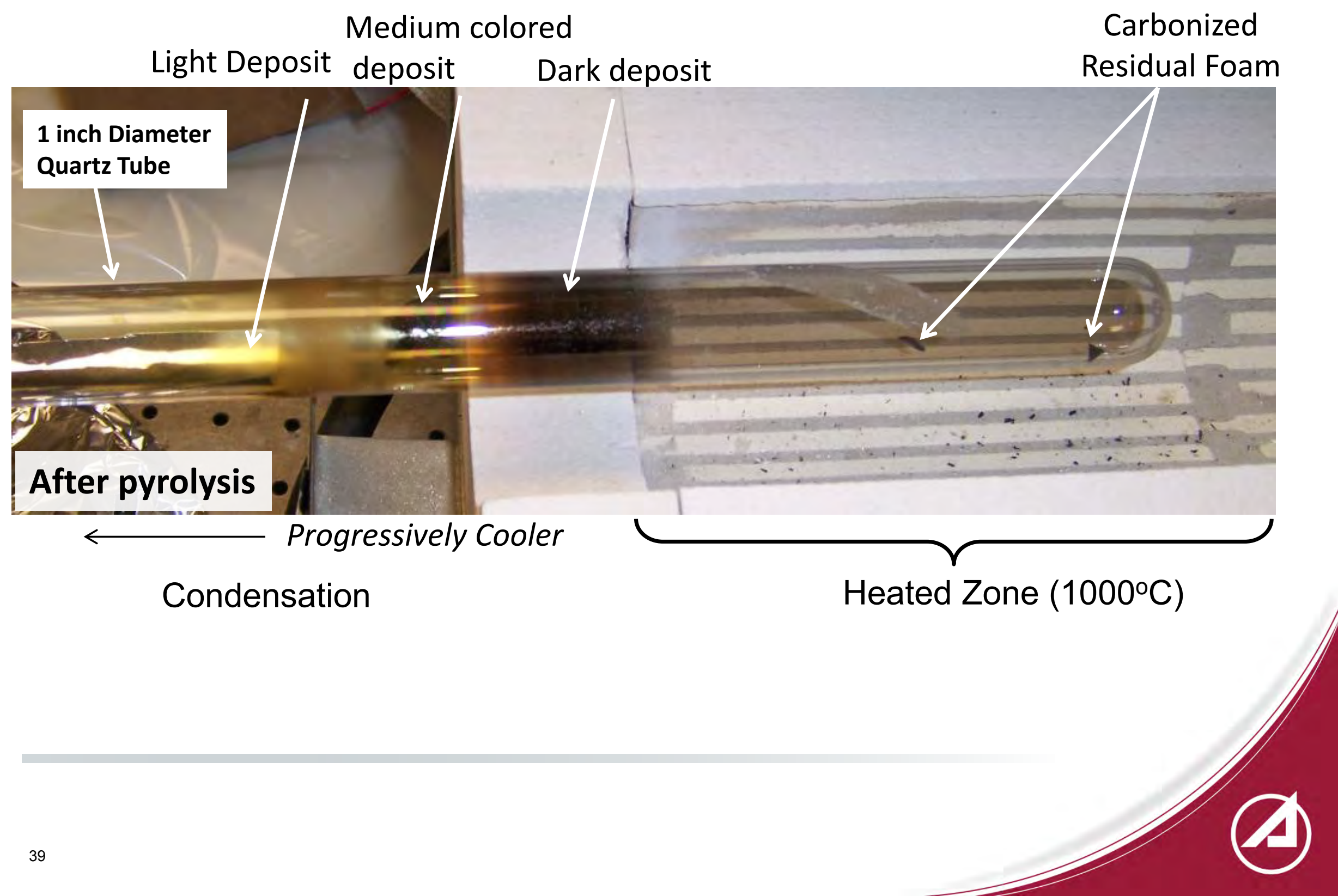




\section{Condensate Removed from Tube}

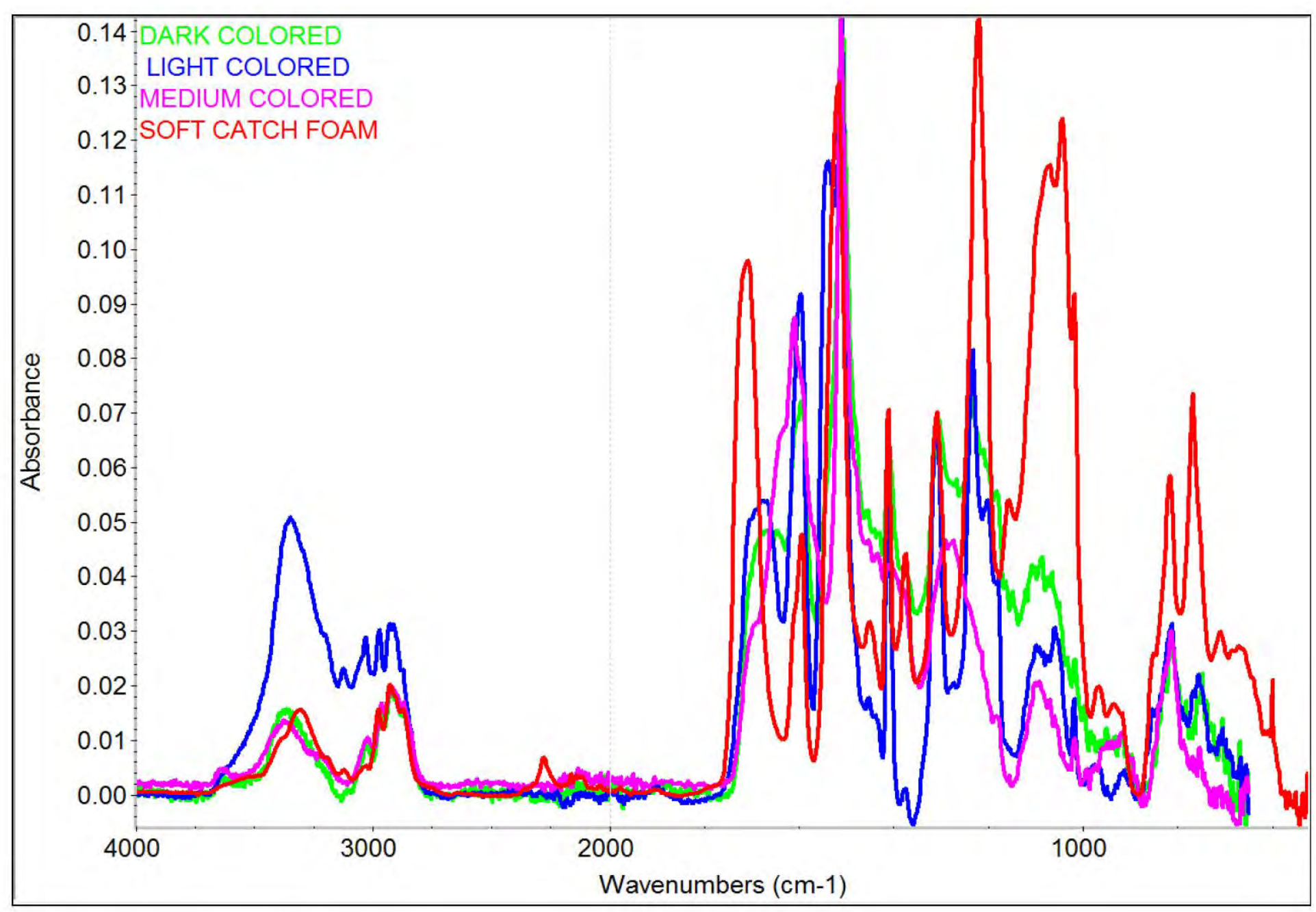

Various colors of condensate have similar but slightly different spectra that resemble soft catch foam. 


\section{Debris-LV Stub 10 vs. Pyrolysis Condensate}

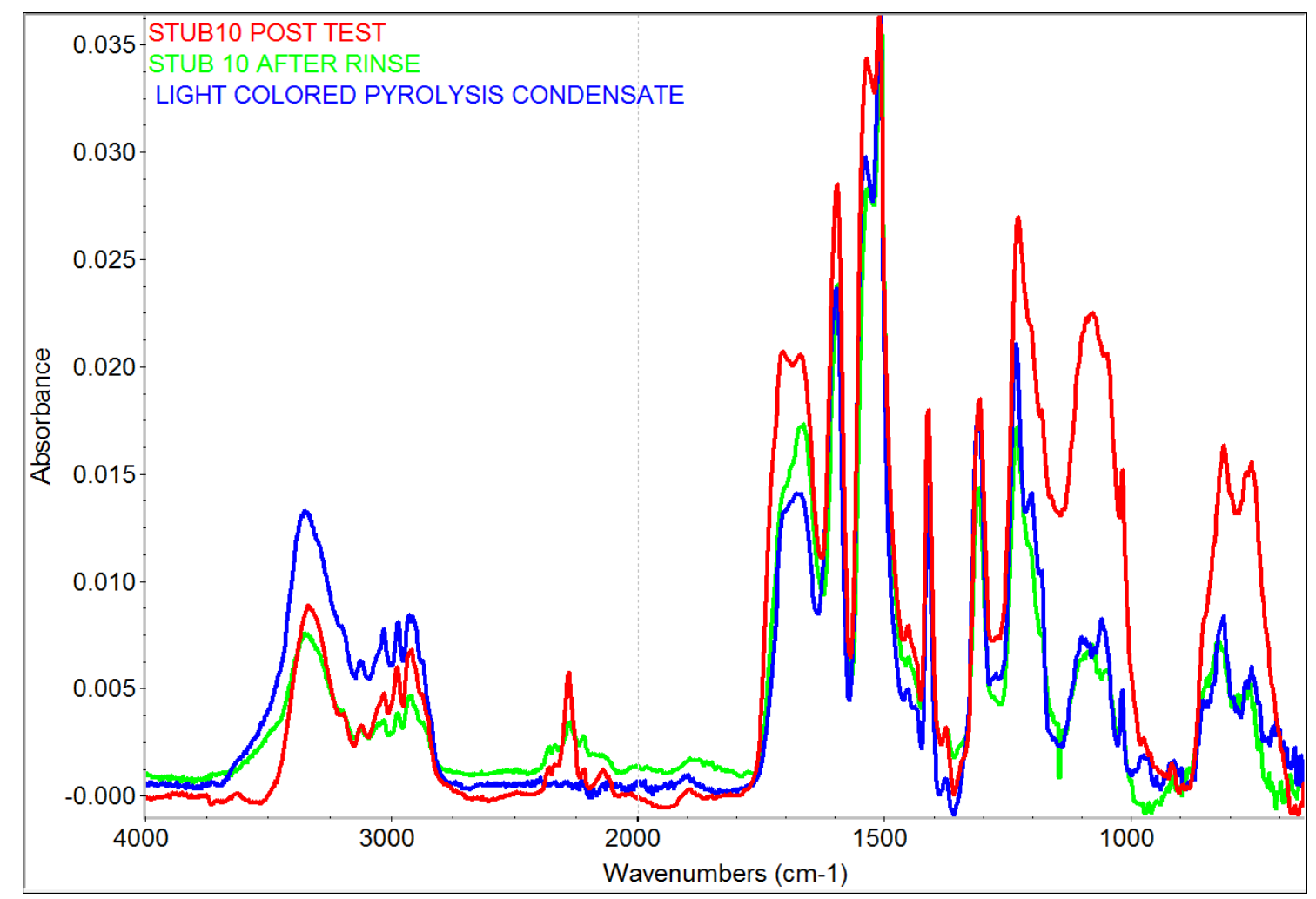

- Spectrum of soft catch condensate is similar to that on SEM stubs, before and after rinsing stubs with isopropyl alcohol (IPA). Alcohol rinse only removed loose fragments.

-SEM stubs are covered with a thin layer of soft catch condensate in addition to fragments. Probably a result of close proximity to soft catch panels exposed to plasma.

Since DebriSat also used soft catch - SEM stubs are probably also covered with a thin layer of soft catch vapor condensate. DebriSat stubs were not rinsed with IPA. 


\section{SEM Stubs: Raman Spectroscopy}

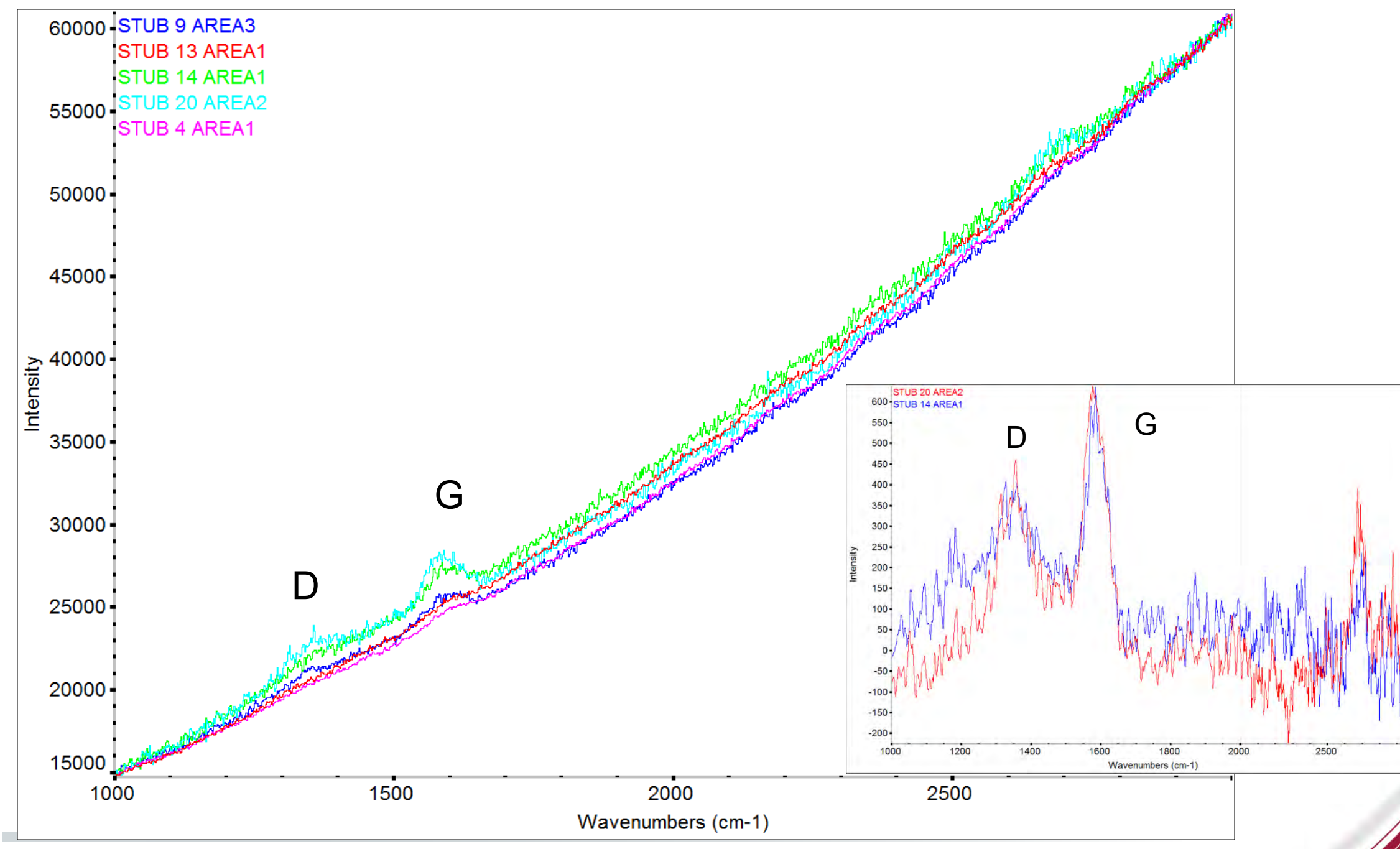

Disordered (D) and crystalline graphite $(G)$ bands observed in some areas. Graphitic bands also seen in Debris-LV deposits. 


\section{Witness Plate: Post Test}

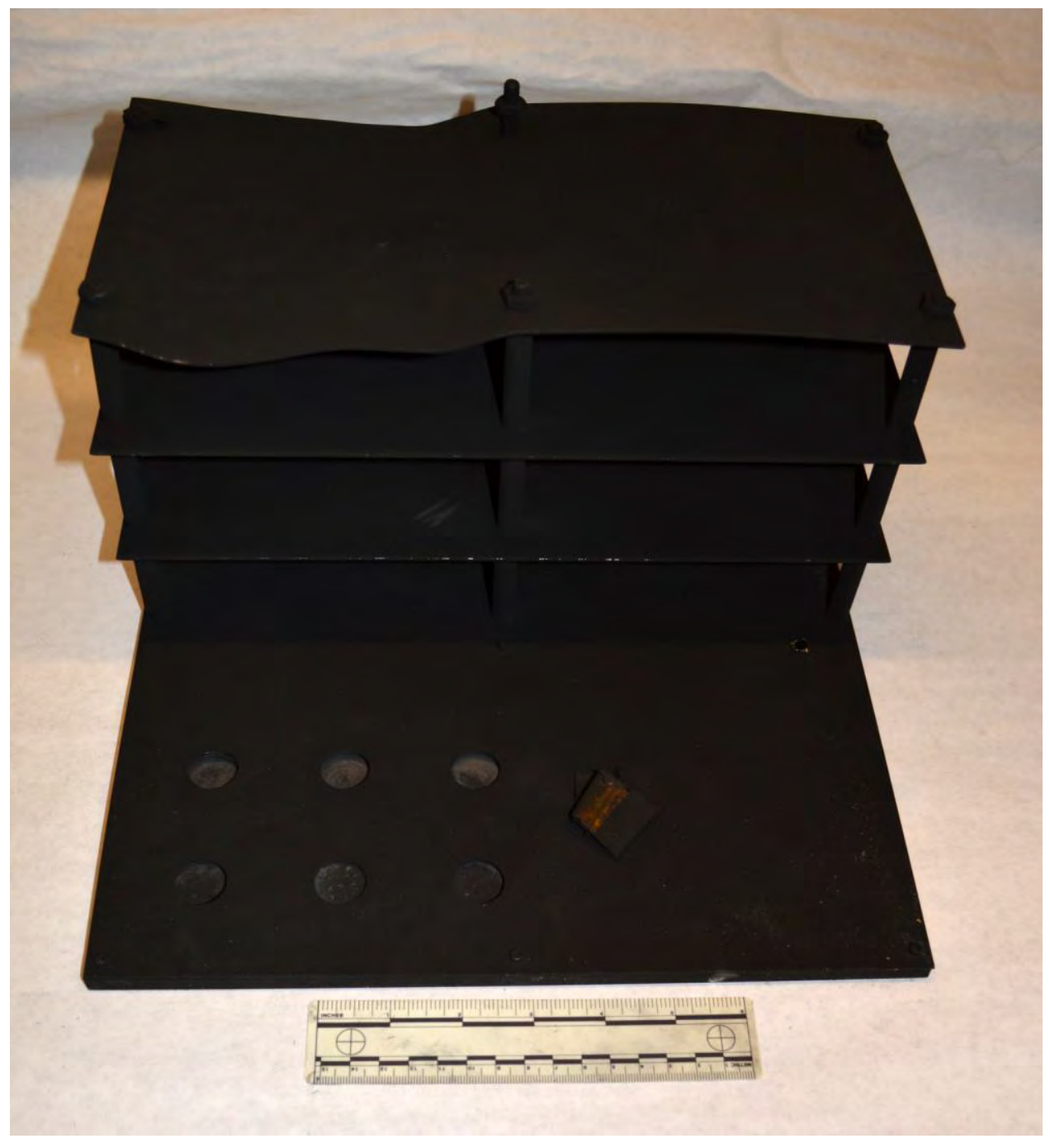

Witness Plate Samples:

Direct Exposure

(4) 1" fused silica (D)

(1) 1" Z-93 painted Al

(1) 1" Aluminum

Multi layer insulation

Protected Under Whipple Plates

(2) 1" fused silica

(1) 1" Z-93 painted Al

(1) 1 " Aluminum

(1) $1 " \mathrm{NaCl}$ (cleaved)

(1) Cu sheet

Ge ATR crystal (D)

Solar cell

(D) = destroyed

Top Whipple plate received a significant impact. Assembly is completely covered with

black soot. Many witness plate samples were fractured/destroyed. 


\section{Witness Plate Post Test : Aluminum Disks}

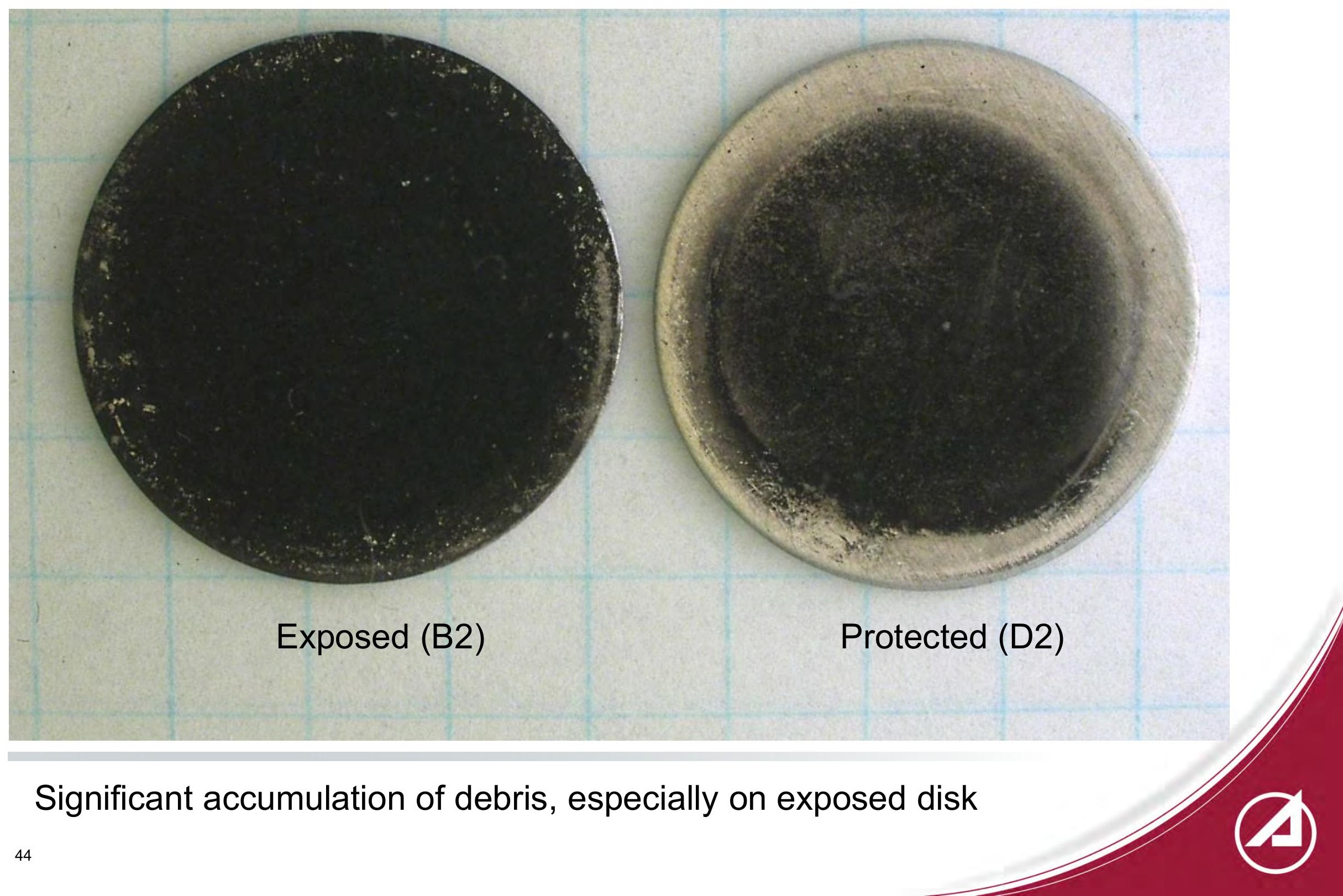




\section{Witness Plate Post Test : Aluminum Disk B2 (exposed) Secondary Electron SEM Images (250X, 1KX)}
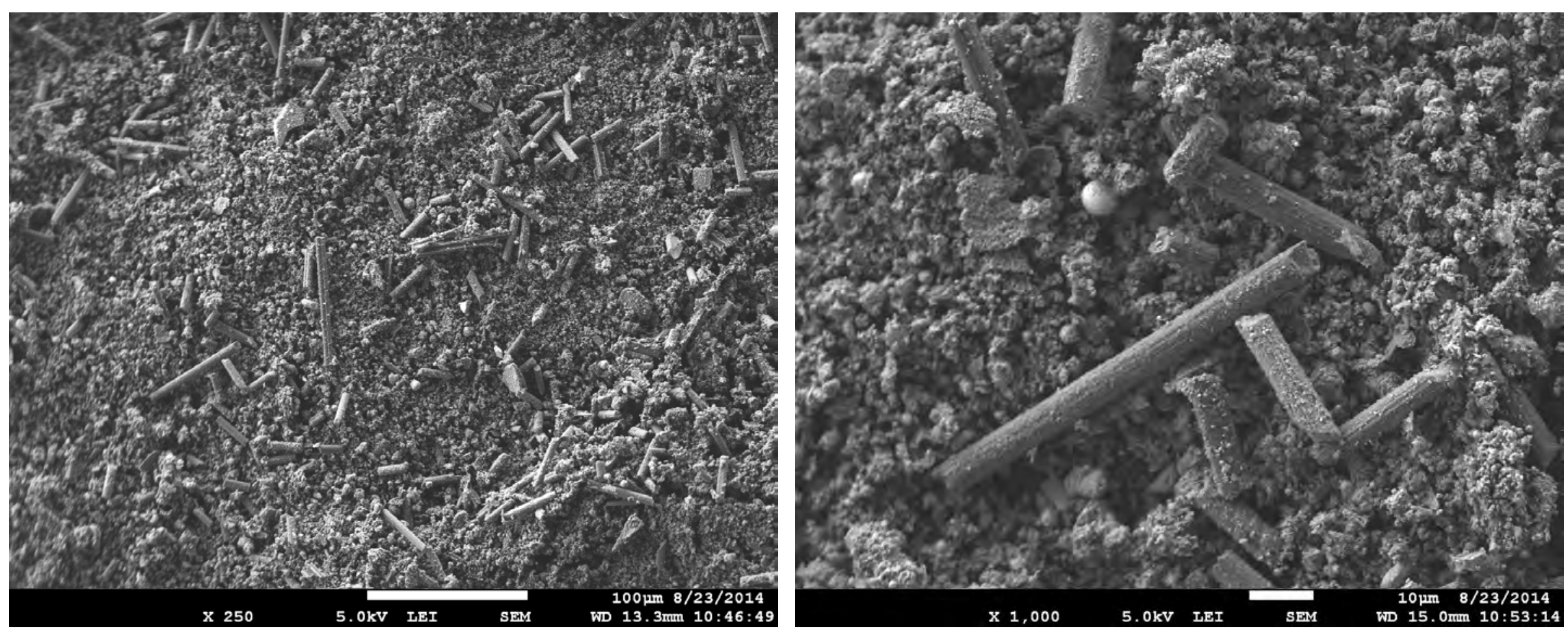

Note fragments of carbon fibers and round solidified droplets. Carbon fibers are from the composite face sheets on the honeycomb structural panels. 


\section{Witness Plate Post Test : Aluminum Disk B2 (exposed) Backscatter Electron SEM Images (2KX, 5KX)}
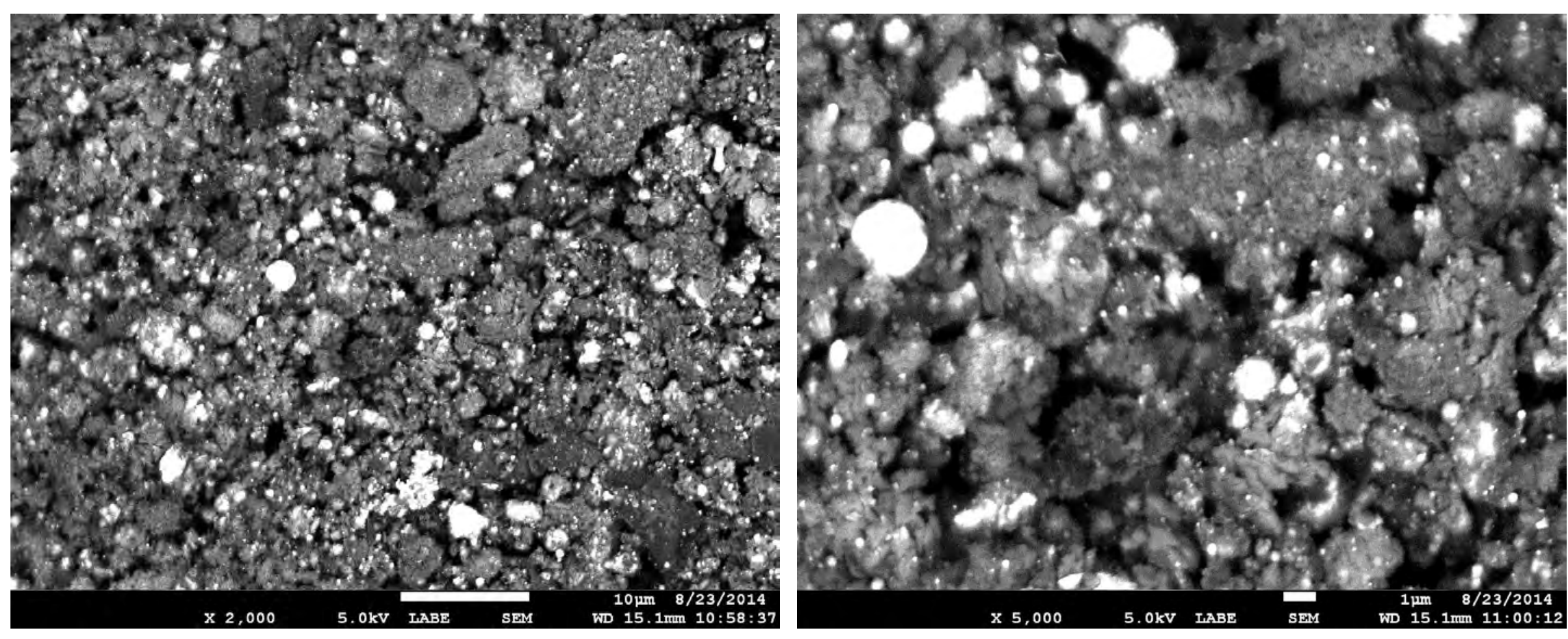

Round solidified droplets are higher Z (Al, Fe, Cu, Ge, Zn) and indicate melting of material as a result of impact. 
Witness Plate Post Test : Aluminum Disk B2 (exposed) SEM Images of particles suspended on lacey carbon films on Cu TEM grid
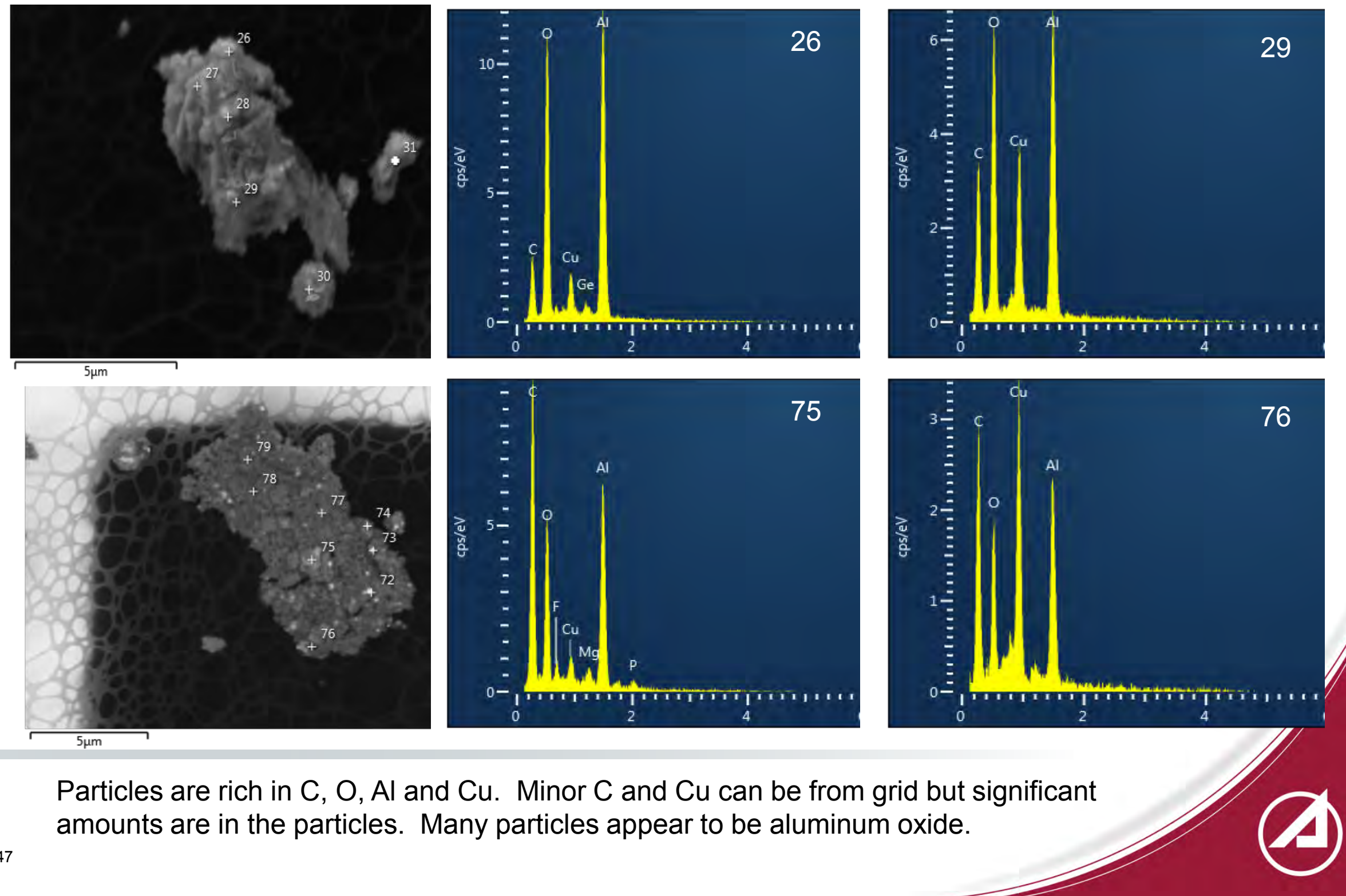

Particles are rich in $\mathrm{C}, \mathrm{O}, \mathrm{Al}$ and $\mathrm{Cu}$. Minor $\mathrm{C}$ and $\mathrm{Cu}$ can be from grid but significant amounts are in the particles. Many particles appear to be aluminum oxide. 
Witness Plate Post Test: Al Disk D2 Debris Transferred to TEM Grid: Bright Field (BF) - TEM

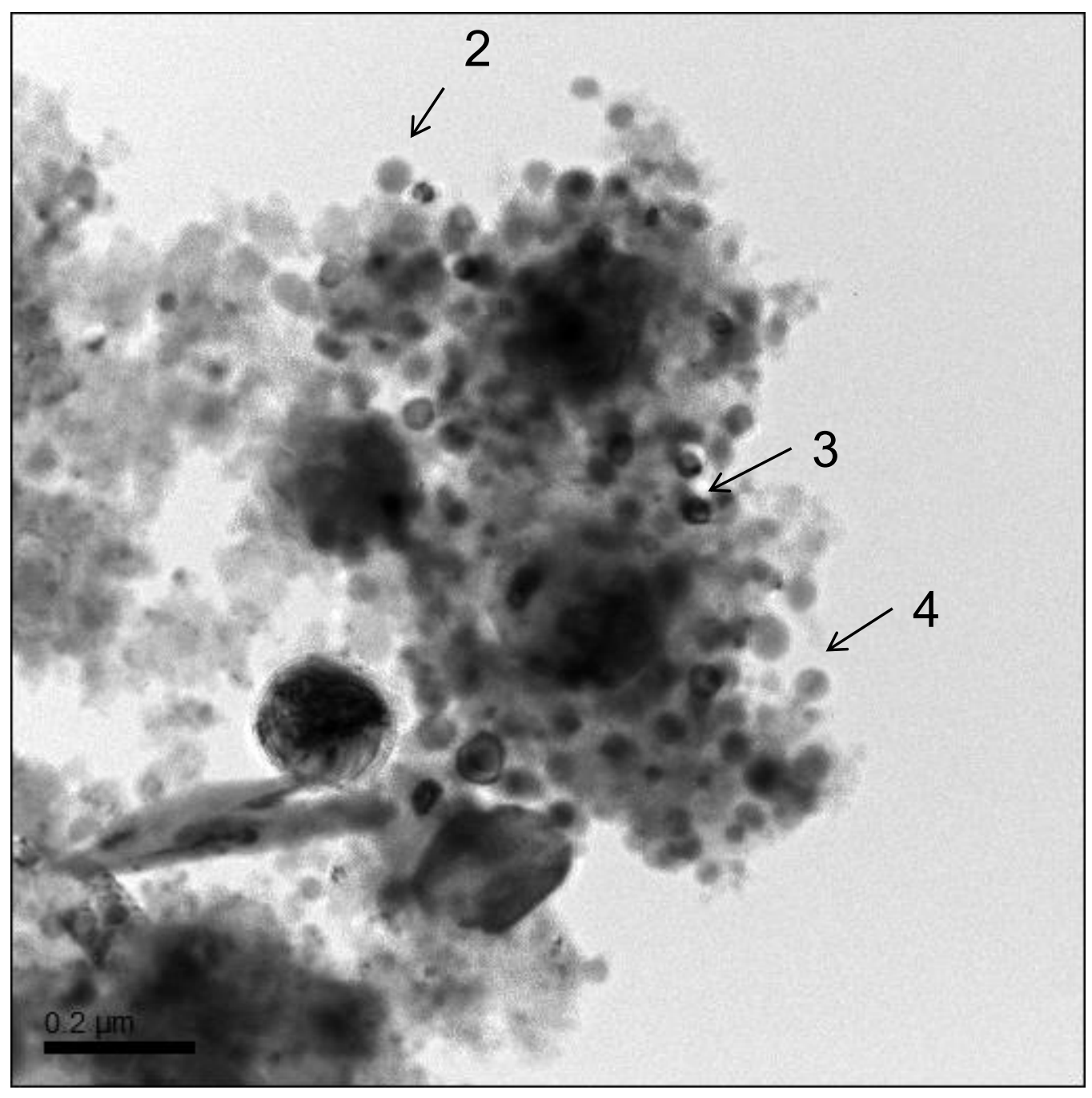

Material is an agglomeration of nano particles. Diffraction contrast in some particles indicates crystallinity. 


\section{Witness Plate Post Test D2: Area 3 BF-TEM}

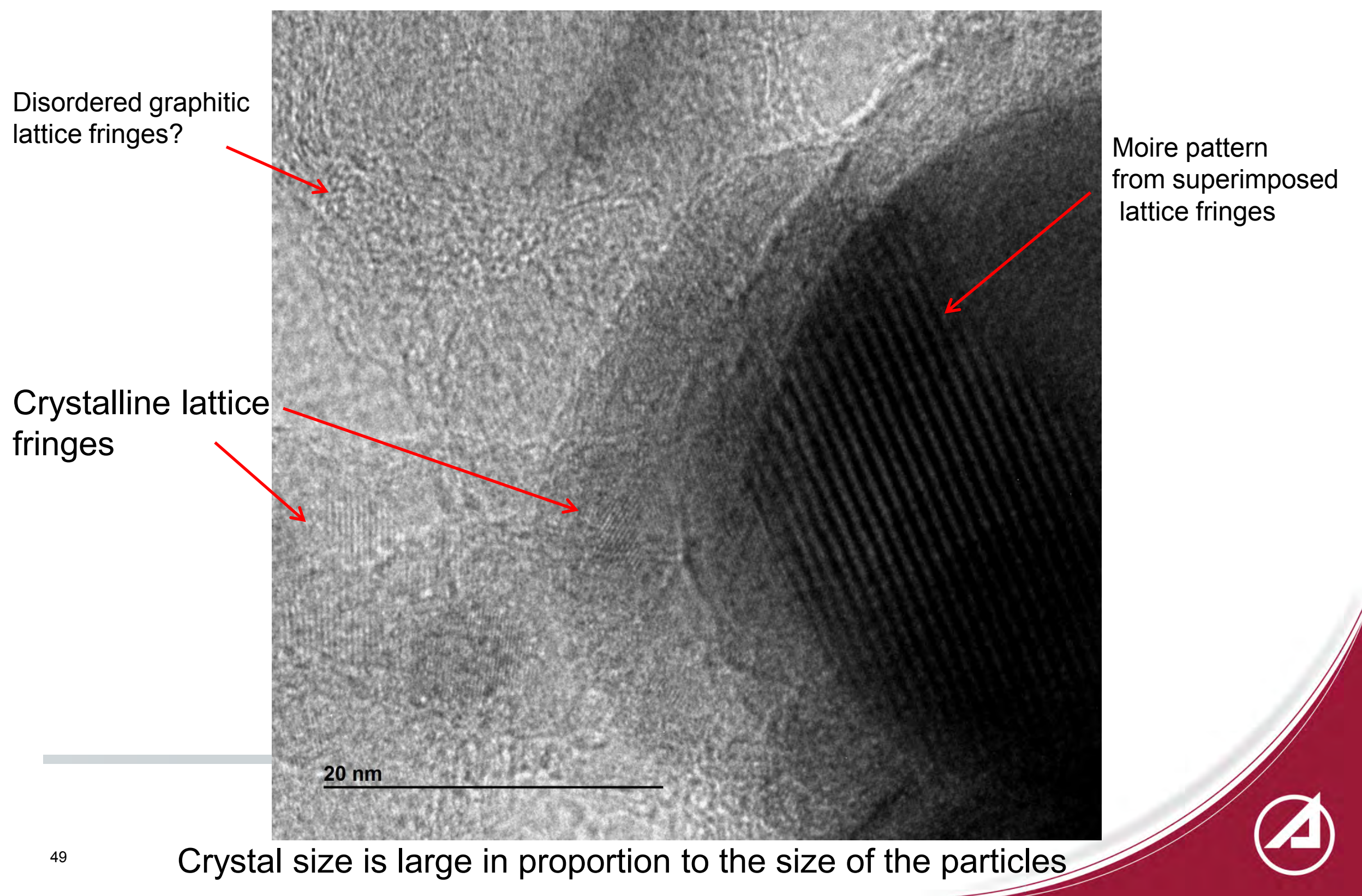




\section{Witness Plate Al Disk D2 : Location 4 Area 6 BF-TEM}

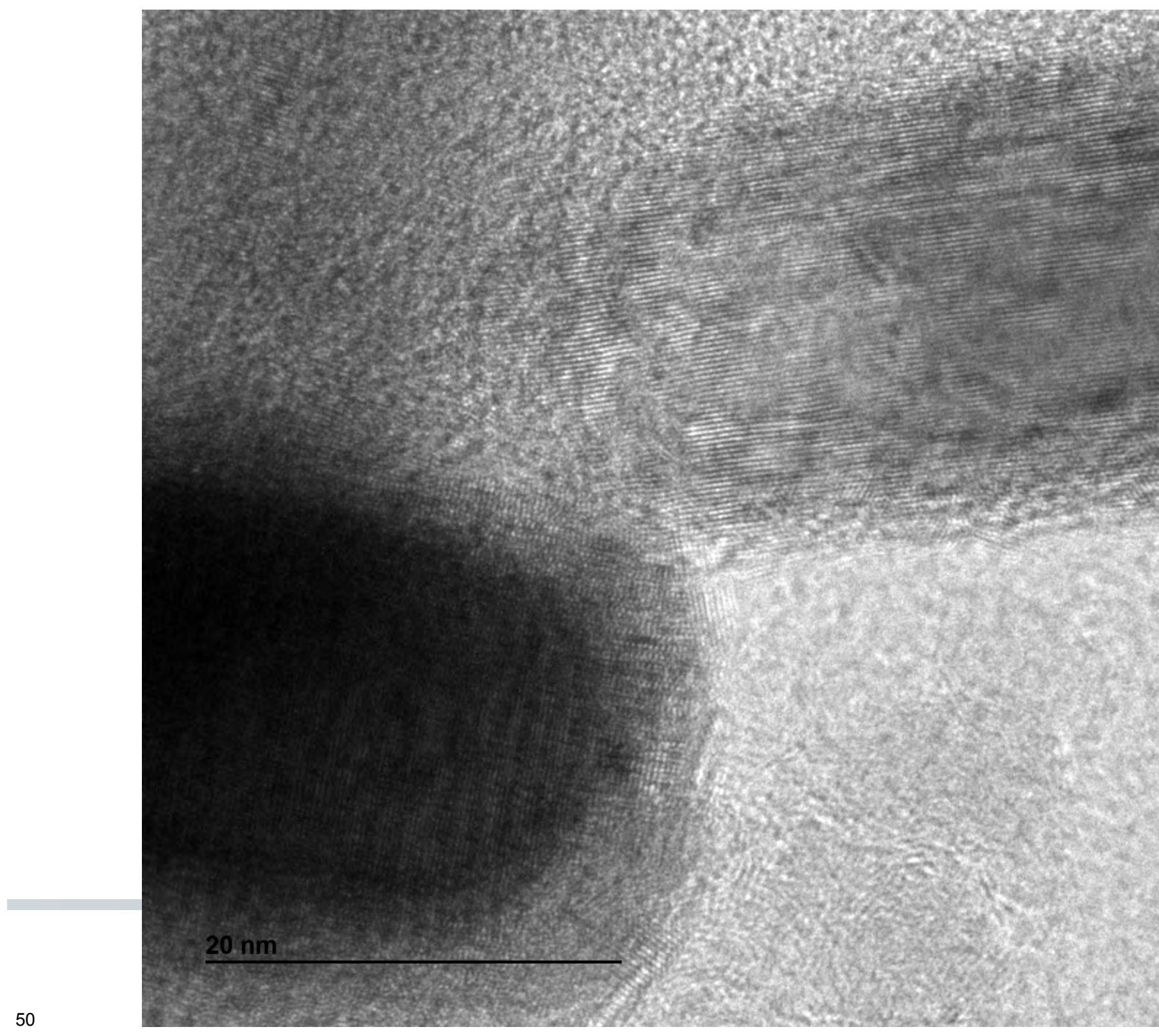

Crystalline lattice fringes $(0.256 \mathrm{~nm})$. $\mathrm{ZnO}(002)=0.260 \mathrm{~nm}$

Particle is nominally a single crystal. 


\section{Witness Plate Post Test: D2 Location 5 TEM - EDS}
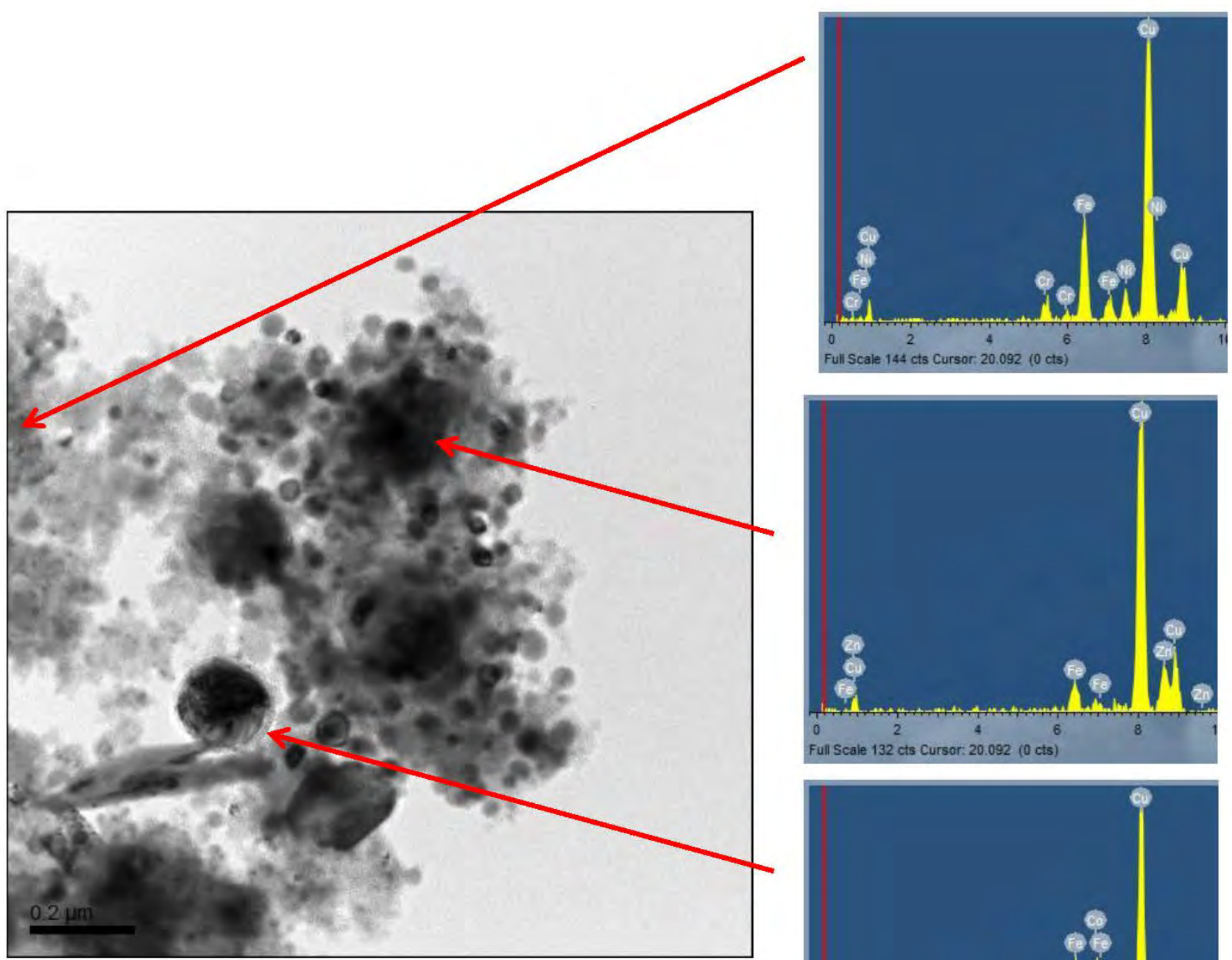

Particulates contain significant $\mathrm{Cu}, \mathrm{Fe}$ and $\mathrm{Co}$
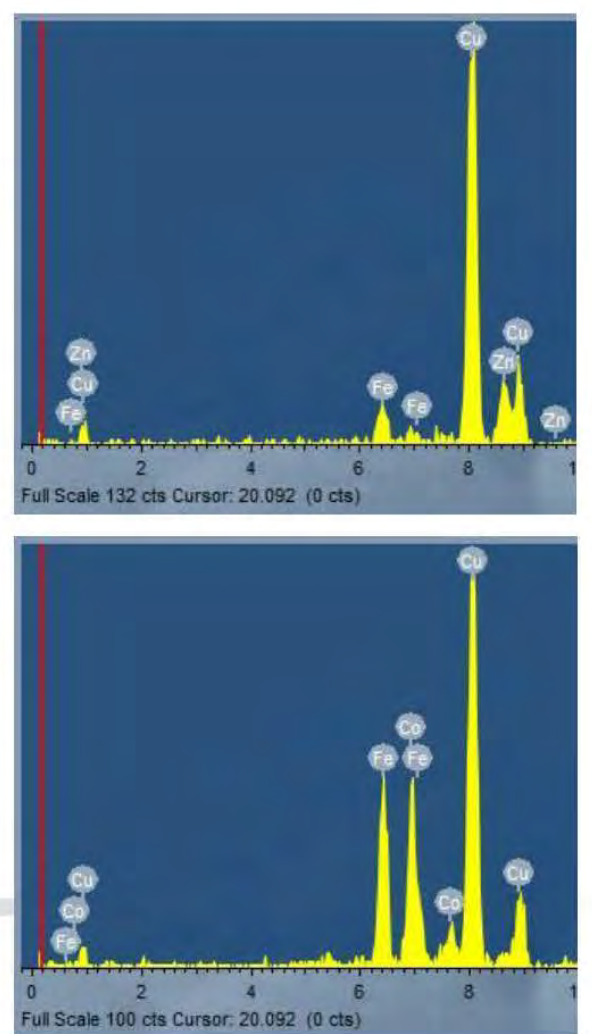


\section{Witness Plate Post Test: Aluminum Disks (B2, D2) \\ Quantitative LWIR FTIR Hemispherical Reflectance}

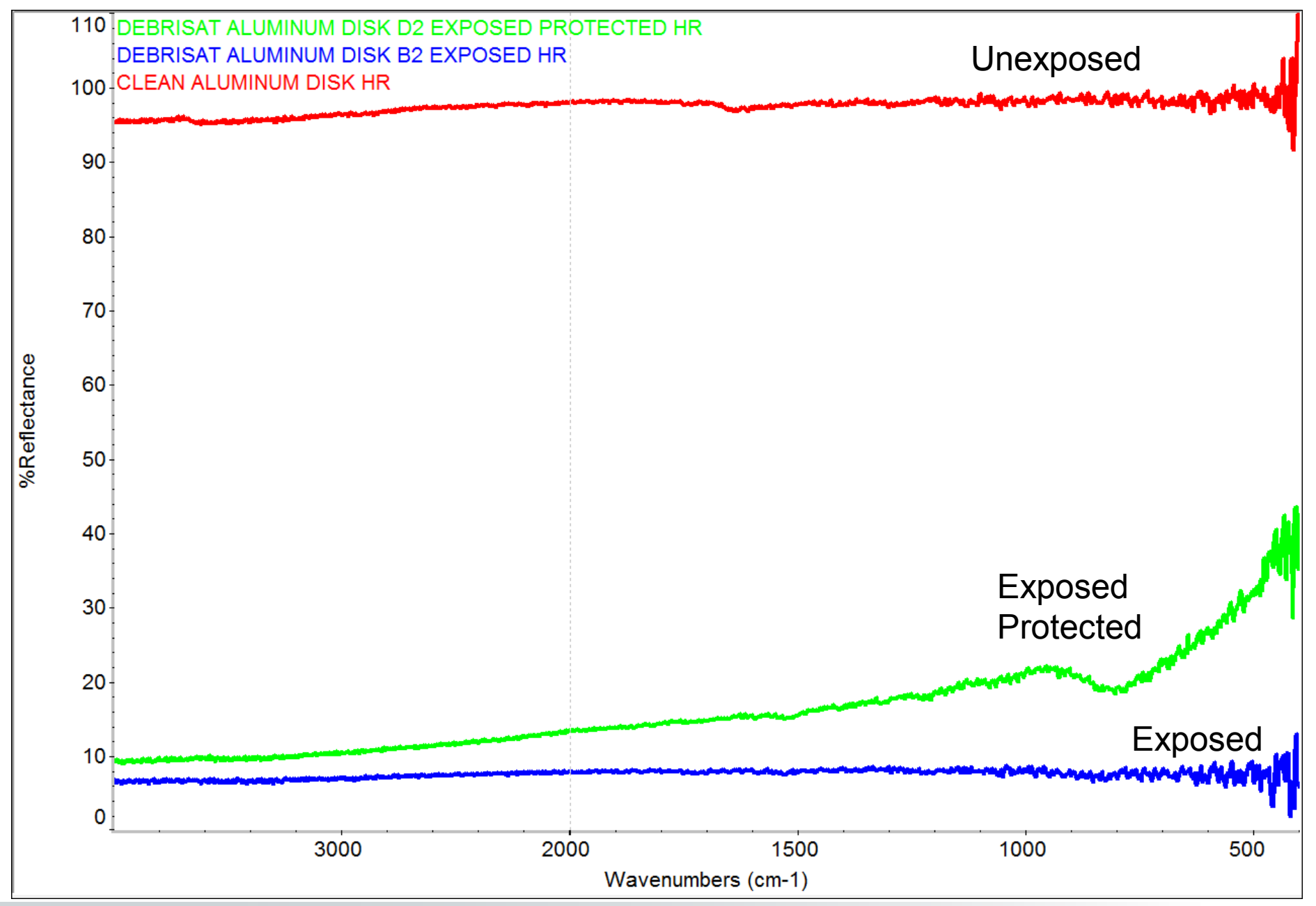

Significant darkening from $95 \%$ to $6 \%$ reflectance. 


\section{Witness Plate}

Qualitative LWIR FTIR Biconical Reflectance

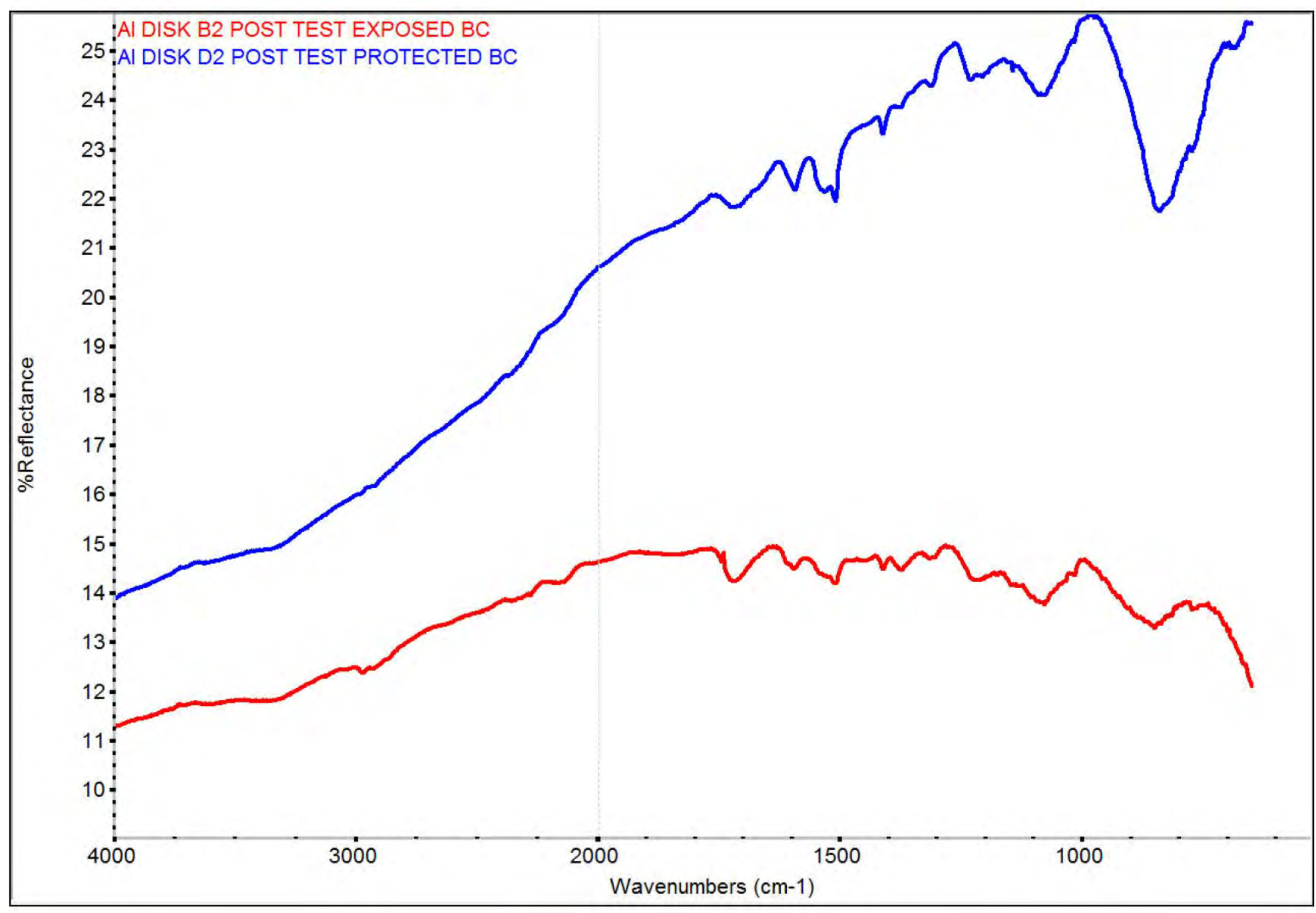

Soft catch contamination plus additional "oxide" band at $800 \mathrm{~cm}^{-1}$. May be an aluminum oxide. Similar band seen in Debris-LV. 


\section{Post Test: Protected $\mathrm{NaCl}$ Disk}

\section{LWIR FTIR Transmission}

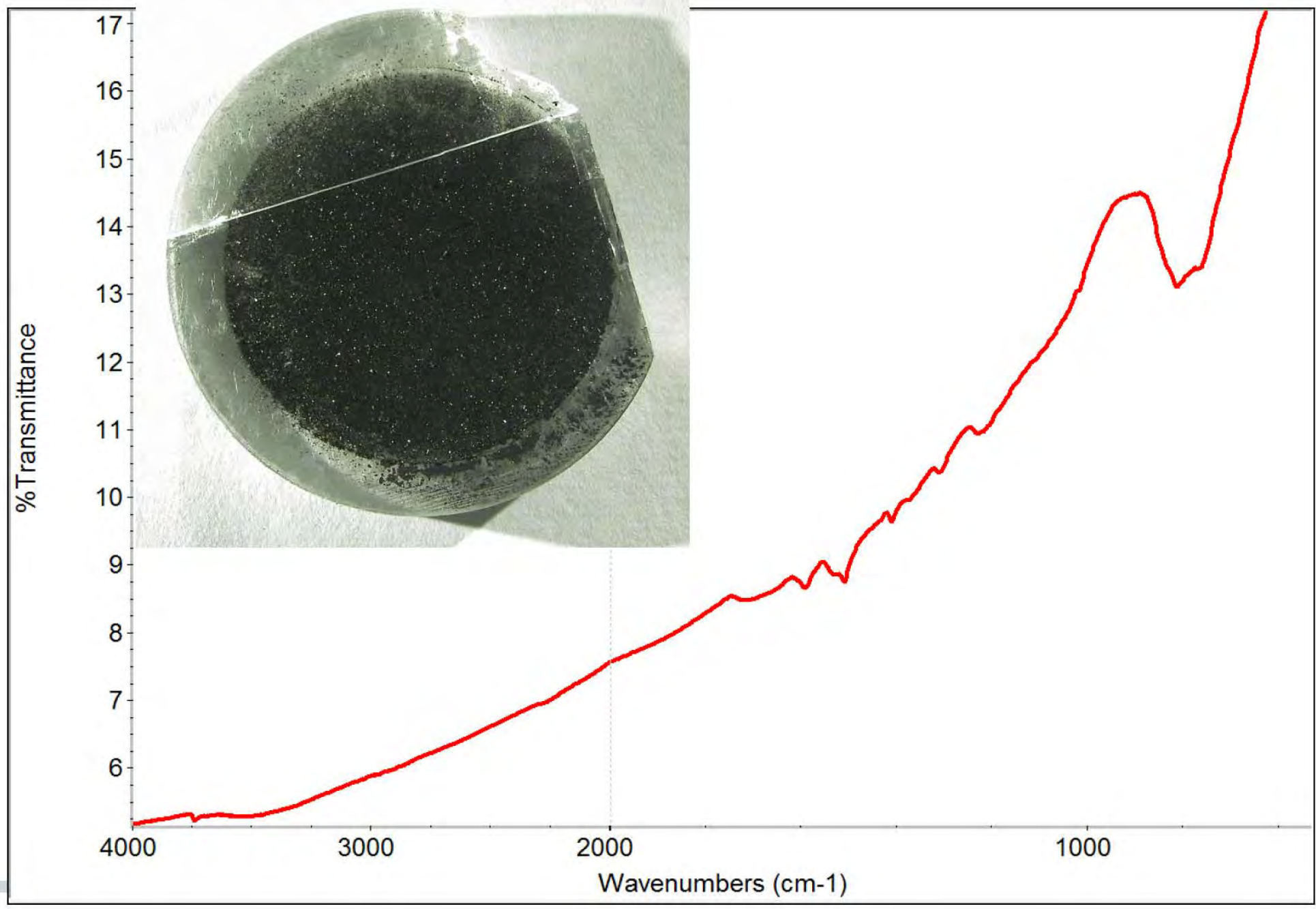

Significant darkening with absorption band at $815 \mathrm{~cm}^{-1}$ similar to band seen by biconical reflectance. 


\section{Witness Plate Post Test Al Disks \\ Raman Spectroscopy}

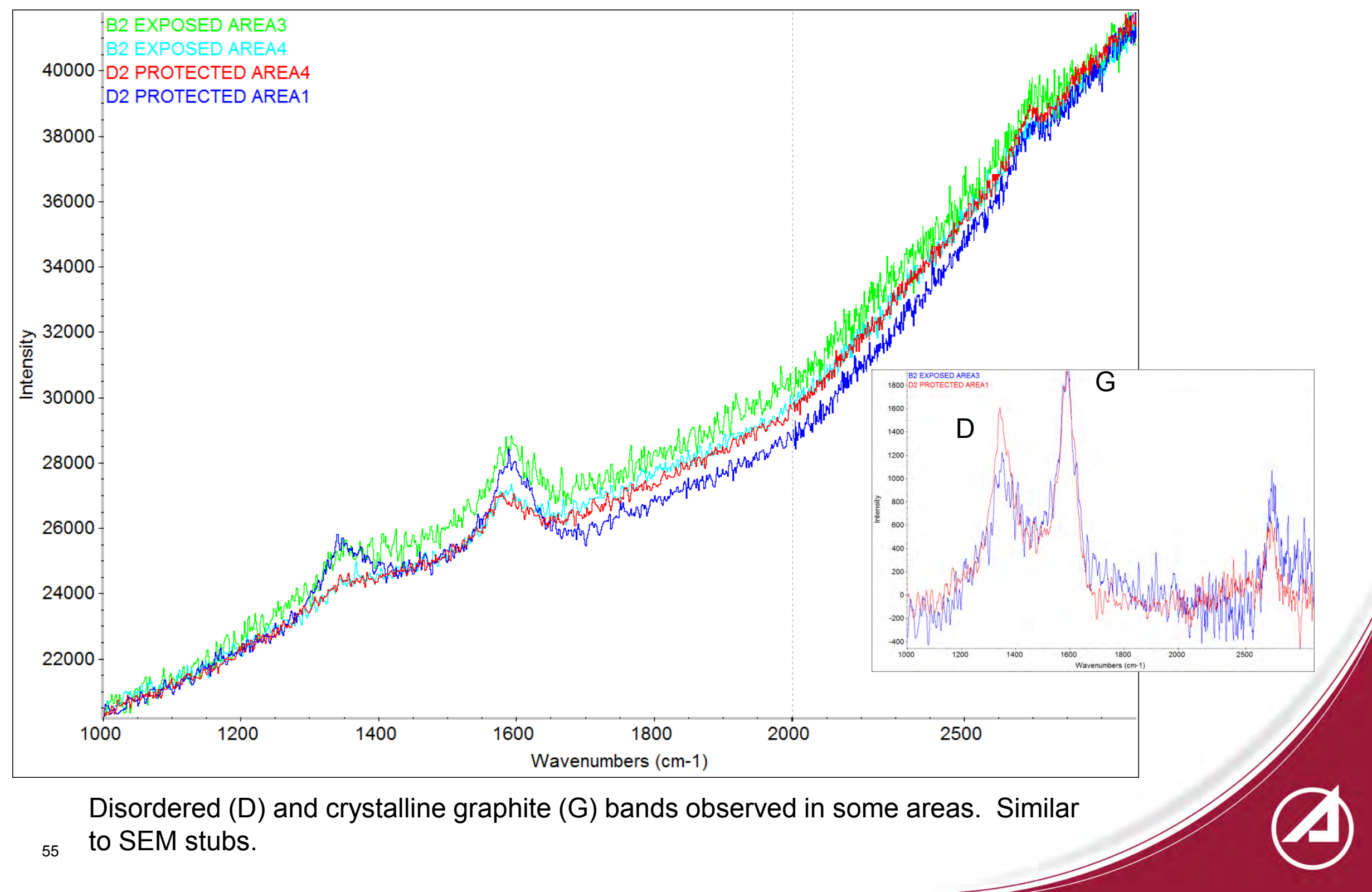




\section{Witness Plate Whipple Plate Support Posts}

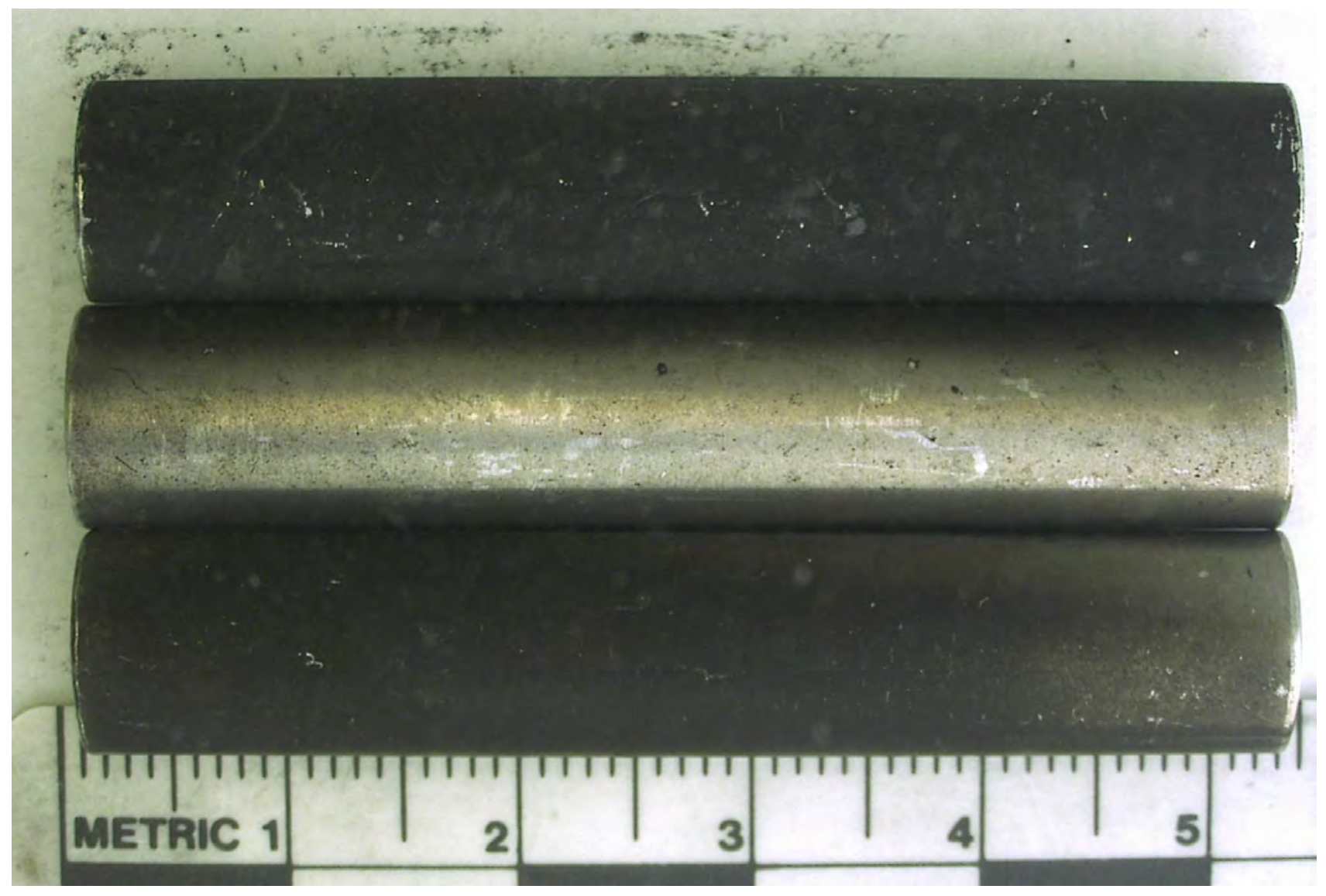

Unrinsed covered with black soot

Rinsed Side 1

Rinsed Side 2

After rinsing with isopropyl alcohol the loose black soot is removed. One side is relatively clean but a resistant black coating remains on one side indicating directional deposition. 


\section{Rinsed Whipple Plate Support Post (surface) Backscatter SEM 5KX, 10KX}
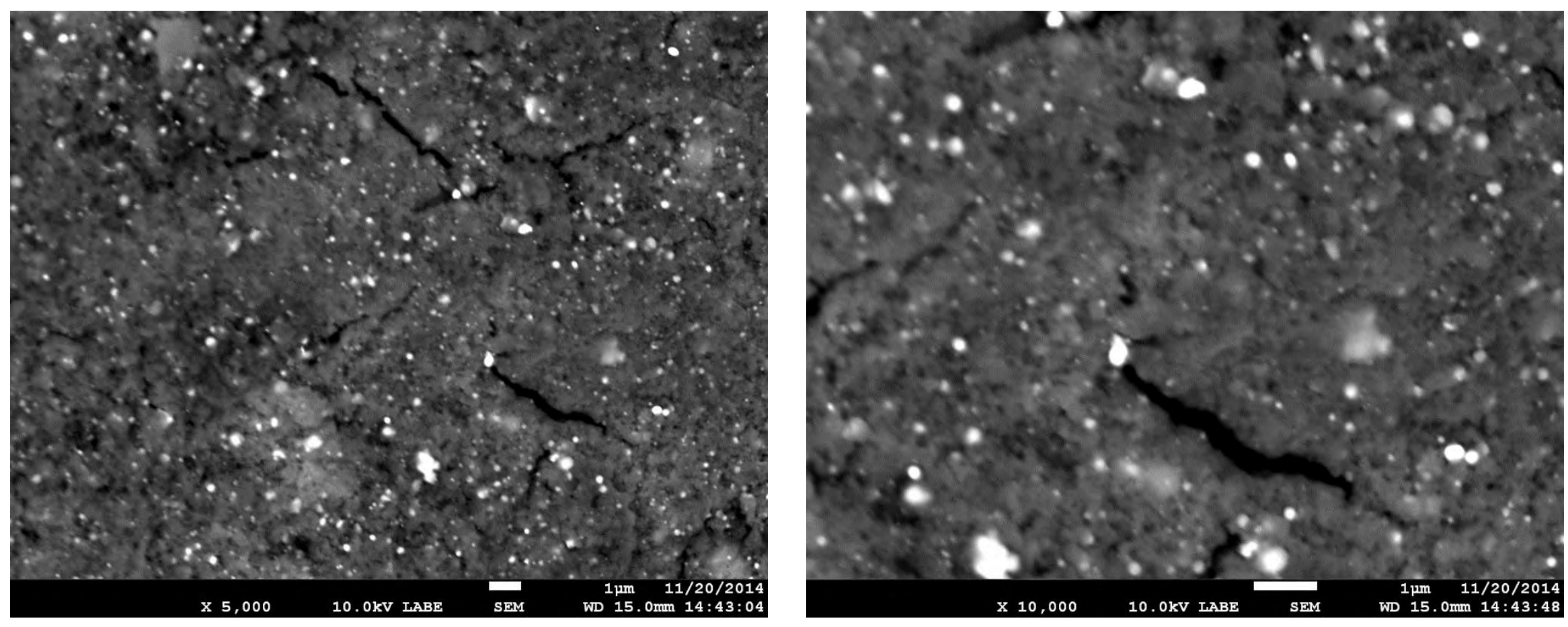

High Z ( $\mathrm{Al}, \mathrm{Fe}, \mathrm{Cu})$ nanoparticles embedded in carbonaceous matrix. 


\section{Rinsed Whipple Plate Support Post (polished cross section)}

Backscatter SEM 5KX, 10KX

\section{Epoxy}

Steel

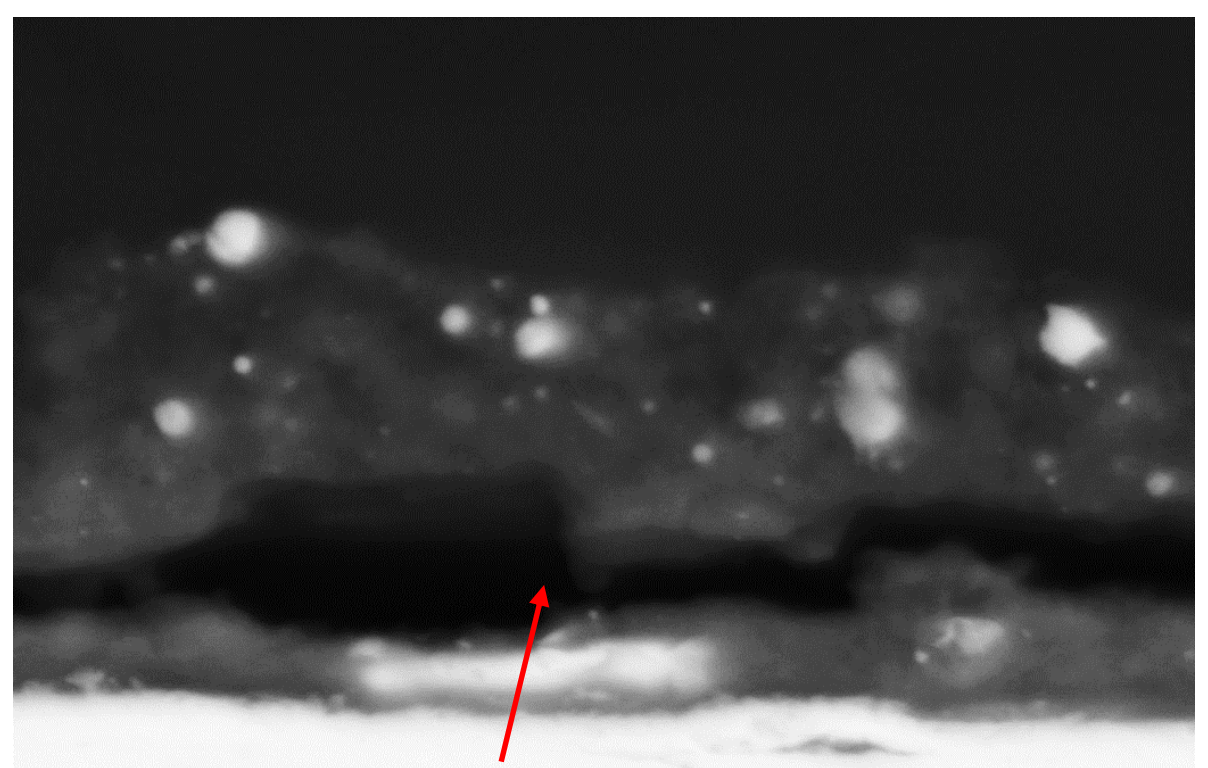

Shrinkage crack polishing artifact

Metal nano droplets in a carbonaceous matrix 2-3 microns thick. 


\section{Rinsed Whipple Plate Support Post Deposit}

Backscatter SEM EDS Spectra
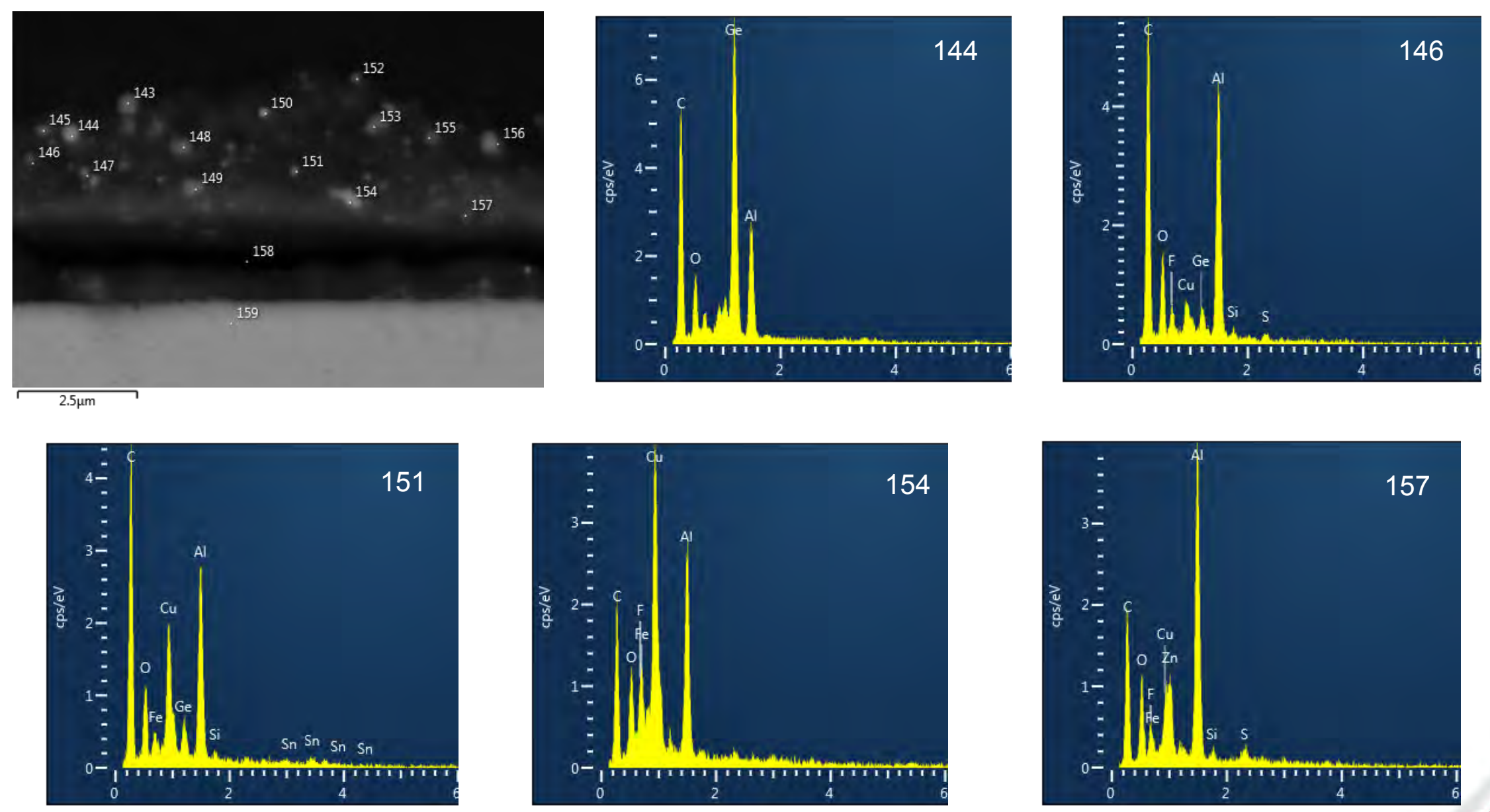

High Z nano particles in carbonaceous matrix contain $\mathrm{Al}, \mathrm{Cu}, \mathrm{Ge}, \mathrm{Fe}$ and $\mathrm{Zn}$. 


\section{Rinsed Whipple Plate Support Post Deposit} Backscatter SEM and EDS maps
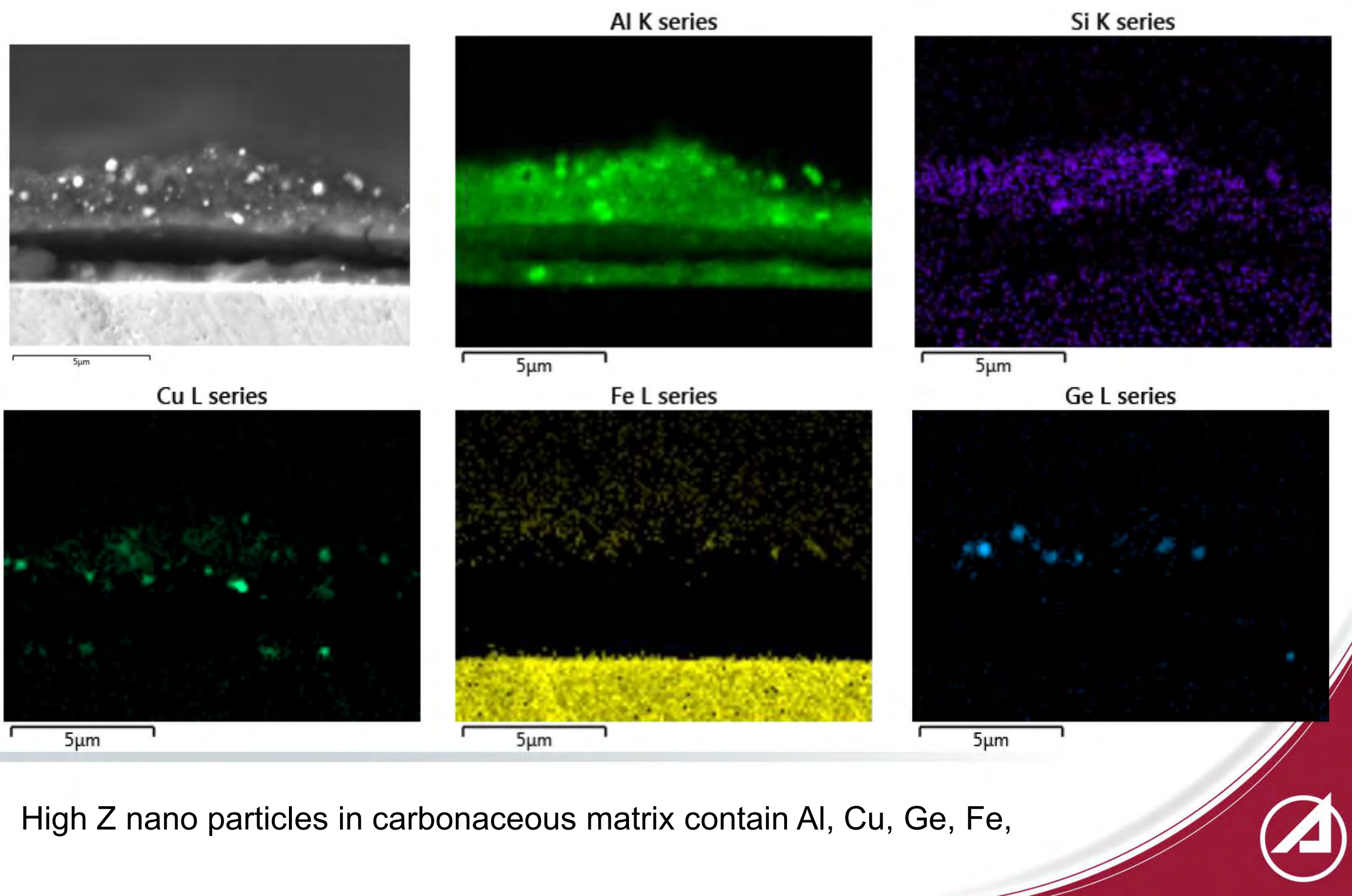

High Z nano particles in carbonaceous matrix contain Al, Cu, Ge, Fe, 


\section{Witness Plate Spacer: Raman Spectroscopy}

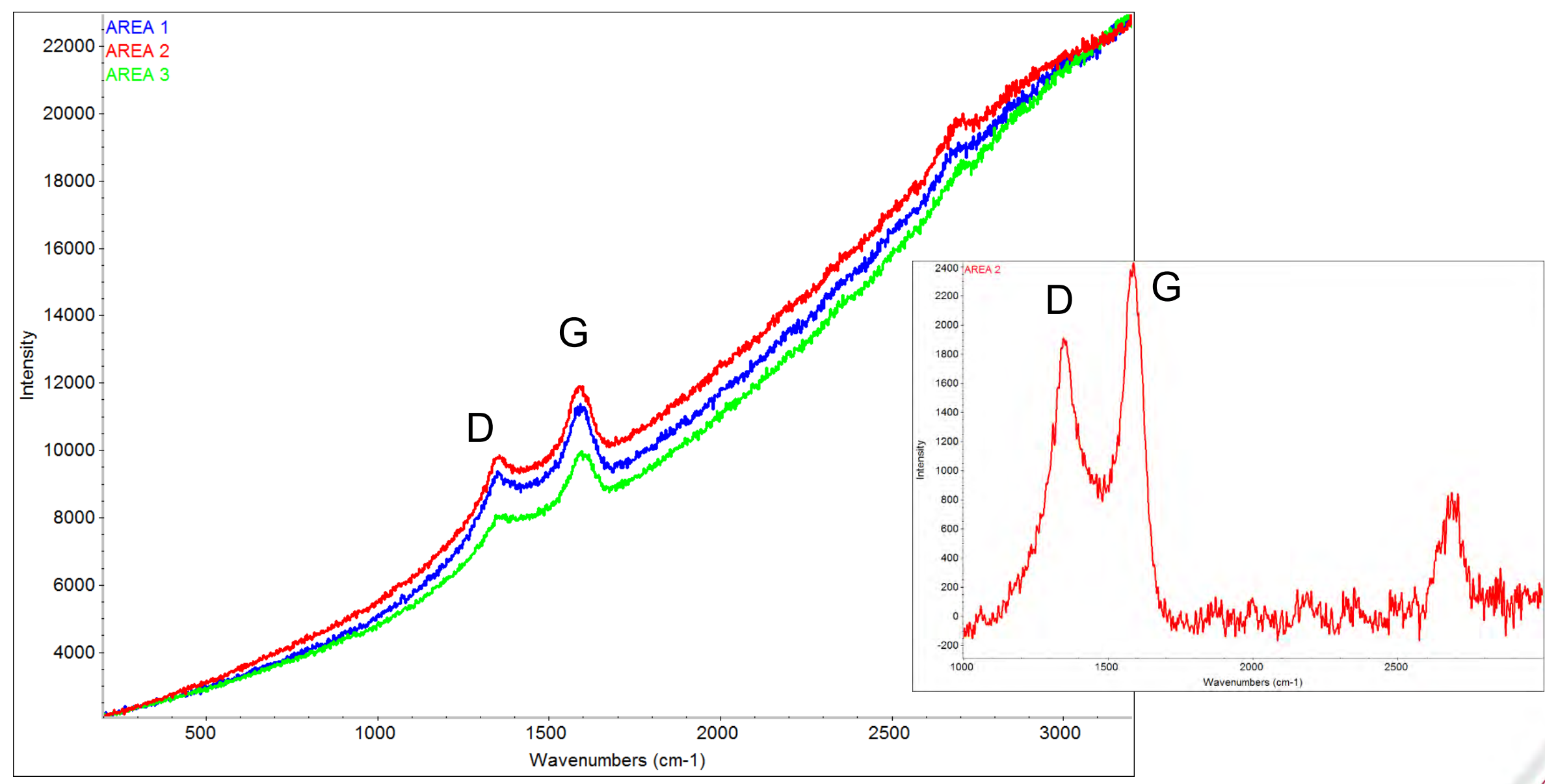

Disordered (D) and crystalline graphite (G) bands observed on dark side of spacer. 


\section{Summary of Observations}

- SEM stubs, witness plate assembly and DebriSat fragments were contaminated with soft catch fragments.

- SEM stubs also had a thin film of condensed soft catch vapor.

- Similar to Debris-LV.

- Deposits on SEM stubs and witness plate assembly are predominantly $C$ and $\mathrm{O}$ and consist of agglomerates of nano carbonaceous material.

- Deposits are primarily from the soft catch - similar to Debris-LV

- C-C composite honeycomb face sheets and MLI are also possible sources.

- Disordered graphitic carbon is present based on Raman spectra and TEM lattice fringe images. Similar to Debris-LV.

- The witness plate assembly was covered in a layer of loose "soot", even under the protective Whipple plates.

- Removal of the loose material by rinsing with isopropyl alcohol revealed a thin adherent coating on one side of the support posts indicating early directional deposition from DebriSat.

- Coating was carbonaceous (disordered graphite) with nano metal particles. 


\section{Summary of Observations (cont.)}

- Fluorine from Teflon wire insulation is also common.

- Nano droplets of metallic materials (Al, $\mathrm{Fe}, \mathrm{Cu}, \mathrm{Zn}, \mathrm{Ge}$ ) are also present indicating melting as a result of impact. Nano metal droplets also seen in Pre Preshot and Debris-LV.

- Al is from the Al honeycomb, nadir and zenith panels, structural core and COPV liner.

- Aluminum oxide particles are also present.

- Al projectile is another source of aluminum.

- Fe is from SS tubing and solenoids.

- Ge is from the solar cells

- Cu is from wiring and solenoids

- Solidified molten nano metal droplets are crystalline based on TEM lattice fringes and consist of only a few crystallites. 


\section{Summary of Observations (cont.)}

- Witness plates show a significant decrease in reflectance (95\% to $6 \%)$

- Soft catch contamination seen in LWIR reflectance spectra of DebriSat fragments, SEM stubs and witness plate.

- Not possible to get a clean spectrum of the debris generated by the hypervelocity impact

- Additional "oxide" band at $800 \mathrm{~cm}^{-1}$ seen on some samples.

- Other laboratory analyses documented:

- Aerospace TOR-2014-03201, Time-resolved Spectroscopy of Hypervelocity Impact Flash on DebriSat, Gouri Radhakrishnan.

- Aerospace ATM-2014-03659, DebriSat Hypervelocity Impact Fragmentation Modeling, Naoki Hemmi 


\section{Appendix 1}

Supplemental Information and Analyses 


\section{Introduction (cont.)}

- Pre Preshot was conducted February 2014.

- Validated performance of projectile to meet velocity goal of $7 \mathrm{~km} / \mathrm{s}$.

- Confirmed operational status of test chamber and facility.

- Target was primarily designed to catch the projectile.

- Multi-shock shield supplied by NASA.

- Multiple bumper panels of fiberglass, stainless steel mesh and Kevlar.

- No "soft catch " panels were installed (unlike Debris-LV and DebriSat).

- Test conducted with a pressure of $\sim 1-2$ Torr nitrogen.

- A witness plate assembly was provided by Aerospace in order to catch and sample debris.

- Additional Documentation

- Aerospace TOR- 2014-03082, DebriSat Pre Preshot Laboratory Analyses, P. M. Adams and P. M. Sheaffer, December 23, 2014. 


\section{Introduction (cont.)}

- Debris-LV (Pre Shot) conducted 1 April 2014

- Further validated performance of projectile and facility and served as a dress rehearsal for the DebriSat test.

- The $15 \mathrm{~kg}$ target consisted primarily of empty tanks and was constructed by Patti Sheaffer from materials representative of a launch vehicle (LV) upper stage.

- Primarily aluminum and titanium with lesser amounts of copper and stainless steel.

- Test chamber was lined with "soft catch" foam panels to trap fragments for size distribution analysis.

- A witness plate assembly was constructed by Aerospace in order to catch and sample debris and returned to Aerospace after the test for analysis.

- Aerospace also placed SEM stub witness plates into soft catch for post test retrieval and analysis.

- Additional documentation

- Aerospace TOR-2014-03577, Debris-LV Hypervelocity Impact Post-Shot Physical Results Summary, P. M. Sheaffer.

- Aerospace TOR-2015-00928, Debris-LV Laboratory Analyses, P. M. Adams, P. M. Sheaffer, Z. R. Lingley and G. Radhakrishnan. 


\section{Laboratory Instrumentation}

- Field Emission Scanning Electron Microscopy (FESEM)

- JEOL JSM-7600F SEM.

- In-lens secondary electron detector (SEI mode).

- High resolution imaging.

- Lower secondary electron detector (LEI mode).

- Less charging.

- Enhances topography.

- Backscatter electron detector (LABE mode)

- Atomic number (Z) image contrast.

- Energy Dispersive (X-ray) Spectroscopy (EDS) in the SEM/TEM

- Oxford X-Max silicon drift detector (SEM).

- Oxford SiLi detector (TEM)

- Transmission Electron Microscopy (TEM)

- JEOL JEM-3100F TEM.

- Oxford INCA EDS. 


\section{Laboratory Instrumentation (cont.)}

- Fourier Transform Infrared (FTIR) spectroscopy

- Nicolet 6700 spectrometer.

- Harrick Scientific "praying mantis" diffuse reflectance accessory.

- Qualitative reflectance.

- Mercury cadmium telluride (MCT) detector.

- Fast analysis with excellent signal to noise.

- Can only analyze small samples (<1").

- Labsphere hemispherical reflectance accessory.

- Quantitative reflectance.

- Long scan time with poor signal to noise.

- Raman Spectroscopy

- Renishaw inVia Raman microscope.

- UV-VIS-NIR Spectroscopy

- Perkin Elmer Lambda 900 Spectrometer

- Diffuse transmission and reflectance with integrating sphere. 


\section{Considerations for SEM and EDS Analyses}

- A preliminary look at Debris-LV and DebriSat SEM stubs indicated that a thin coating, containing low atomic number $(Z)$ materials (carbon), was present.

- This presented challenges and options for SEM-EDS analyses. Low vs. high voltage ( $5 \mathrm{KV}$ vs. $15 \mathrm{KV})$.

- Advantages of $5 \mathrm{KV}$ : high resolution imaging of thin low $Z$ surfaces, EDS from surface material and not substrate.

- Disadvantages of $5 \mathrm{KV}$ : beam does not penetrate beneath the surface (subsurface is hidden), does not excite $X$-rays from medium $Z$ elements $(\mathrm{Cl}$ to $\mathrm{Ti})$, high $\mathrm{Z}$ element $\mathrm{K}$ series not excited but $\mathrm{L}$ series $\mathrm{X}$-rays are.

- Most medium Z elements not expected.

- Advantages of 15KV: Can see a limited distance beneath the surface, excites $\mathrm{X}$-rays from just about all elements.

- Disadvantages of $15 \mathrm{KV}$ : loss of detail in low $Z$ surfaces, for thin coatings may penetrate through to the substrate

Use both $5 \mathrm{KV}$ to $15 \mathrm{KV}$ to obtain more comprehensive information. 


\section{Electron Penetration into Materials}
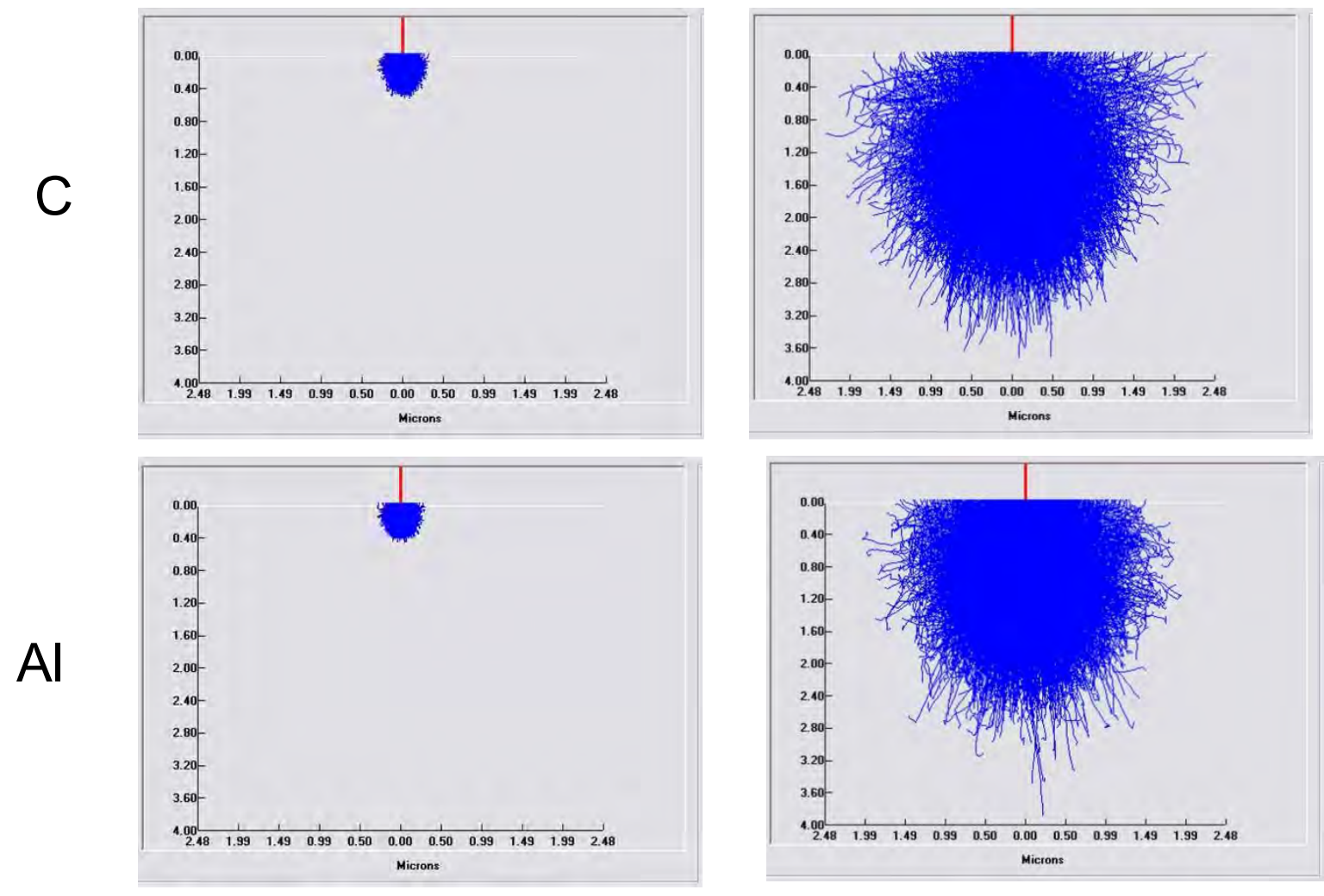

\section{$5 \mathrm{KV}$}

\section{$15 \mathrm{KV}$}

-Electron penetration influences depth of X-ray generation (EDS).

-Secondary emitted electrons have low energy and image primarily the surface.

-Backscattered emitted electrons have greater energy and image partially into the surface and have atomic number information. 


\section{SEM Stubs}

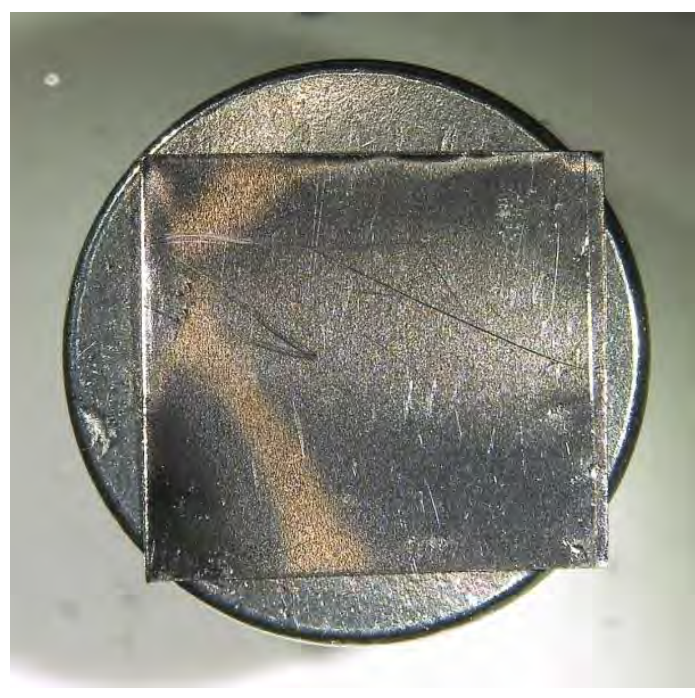

Unexposed

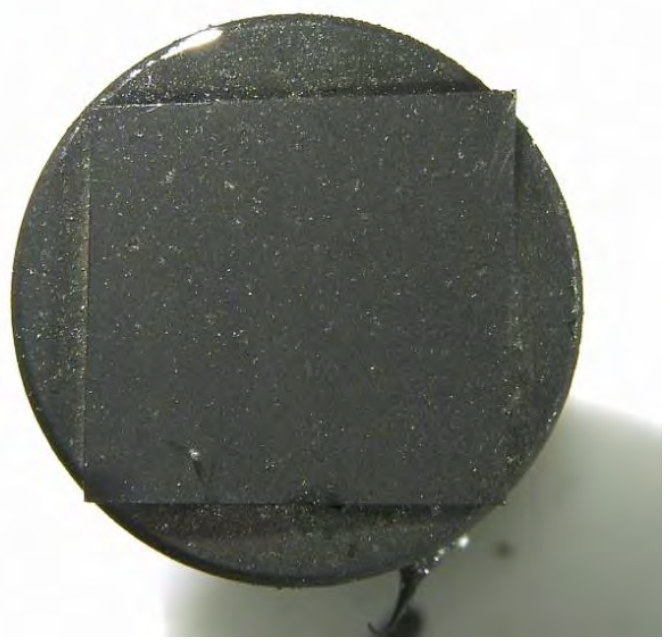

Exposed \#13

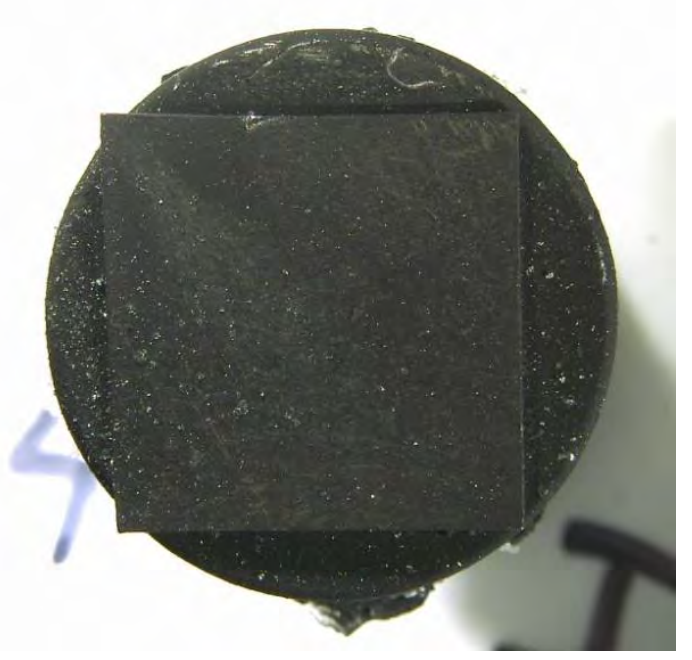

Exposed \#14

Note significant darkening of post test stubs 


\section{SEM Stub 4: Backscatter Electron SEM (5 KX)}

Brighter areas are higher atomic number (Z).

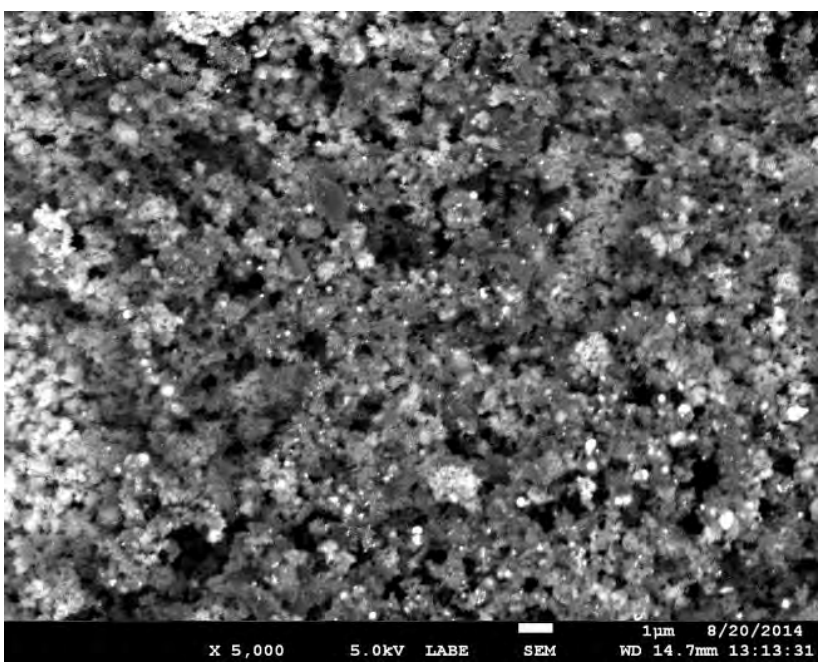

$5 \mathrm{KV}$

$10 \mathrm{KV}$
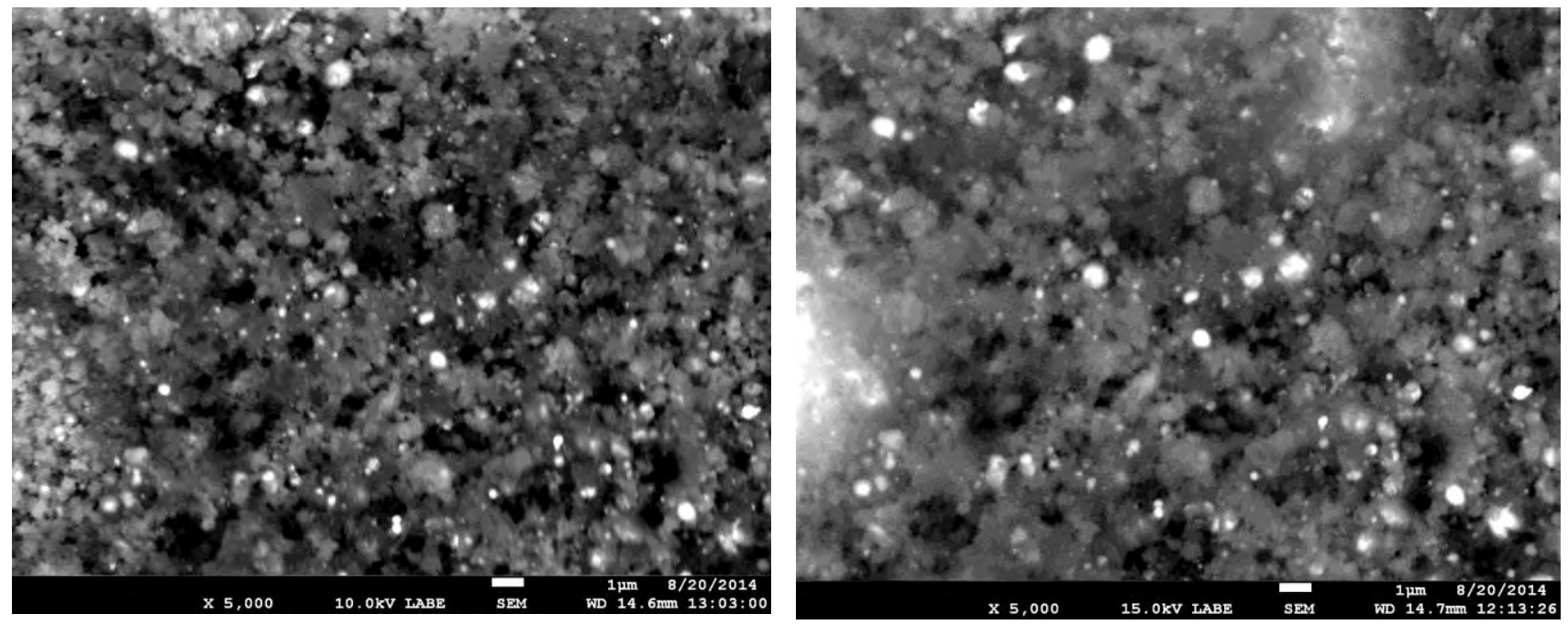

$15 \mathrm{KV}$

Images are from the same area.

${ }_{73}$ Greater penetration and less surface detail with increasing energy. 


\section{SEM Stub 4: Secondary Electron SEM (5KX)}

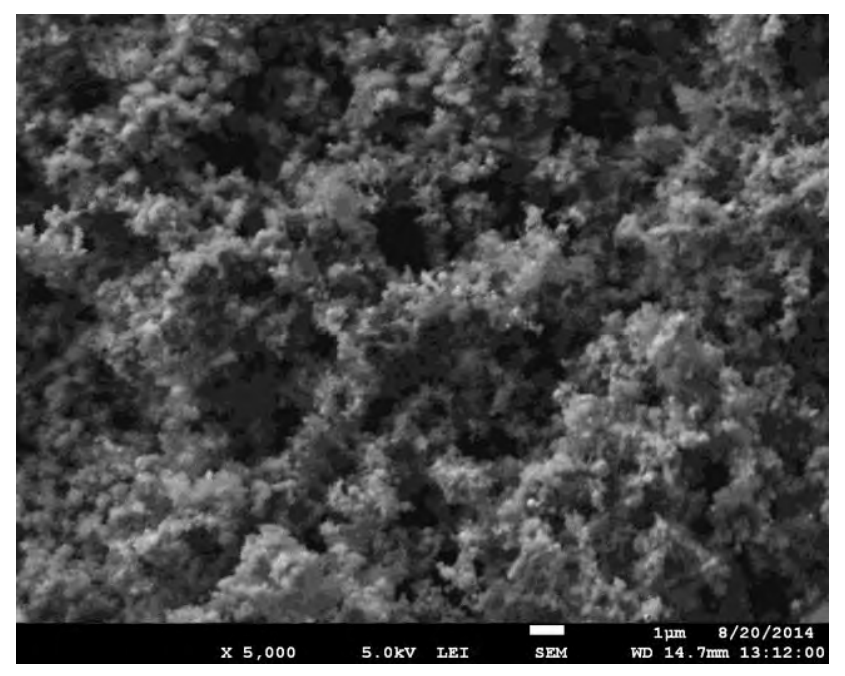

$5 \mathrm{KV}$

$10 \mathrm{KV}$
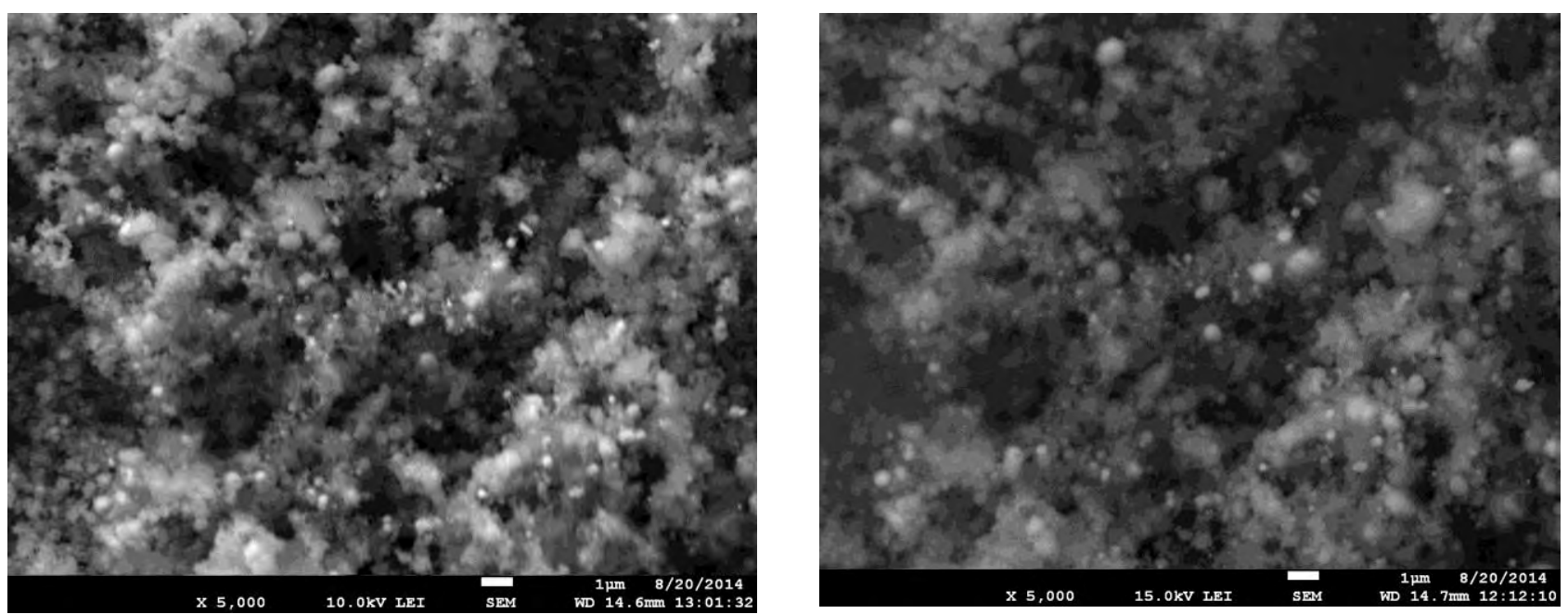

$15 \mathrm{KV}$

Images are from the same area as previous slide.

${ }_{74}$ Greater penetration and less of surface detail with increasing energy. 


\section{SEM Stub 13 \\ Backscatter SEM (5KX, 10KX)}

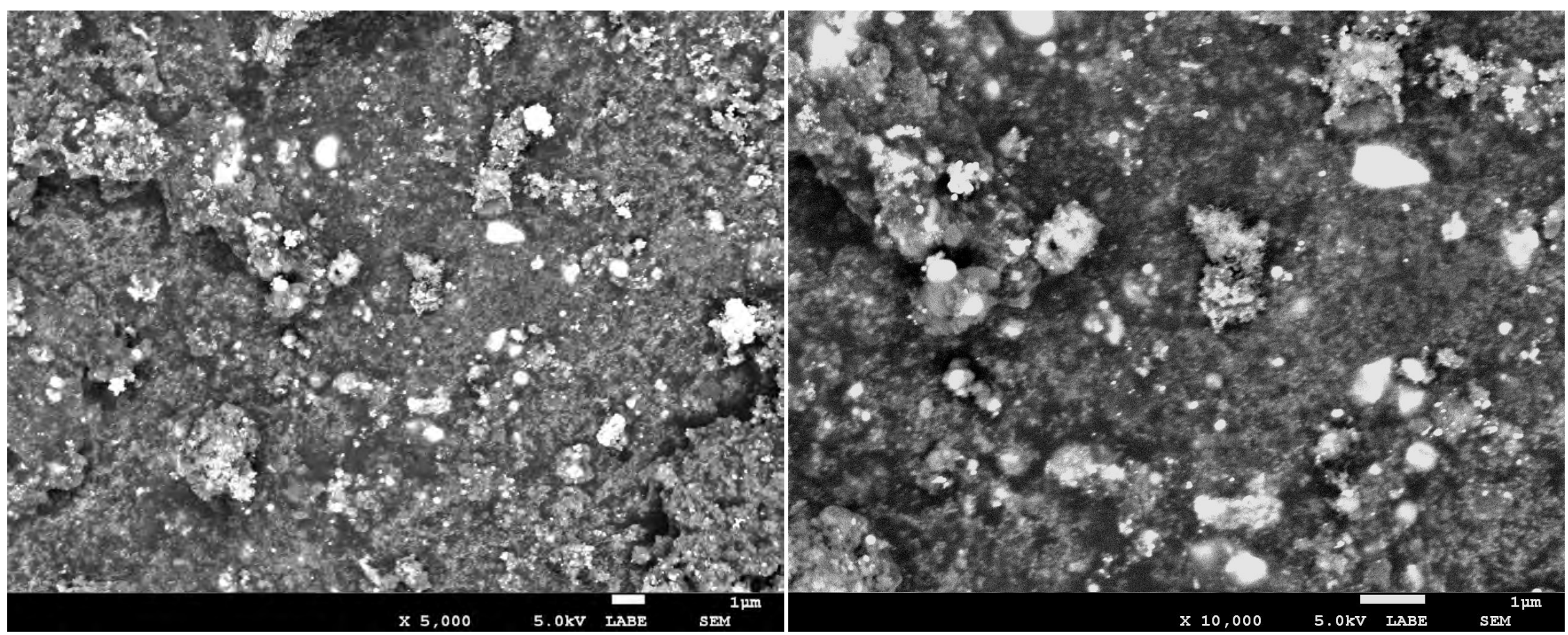

Material on surface consists of nano-sized agglomerates

Located 11 feet down range - 3 O'clock 


\section{SEM Stub 13}

\section{Secondary Electron SEM (10KX, 20KX)}
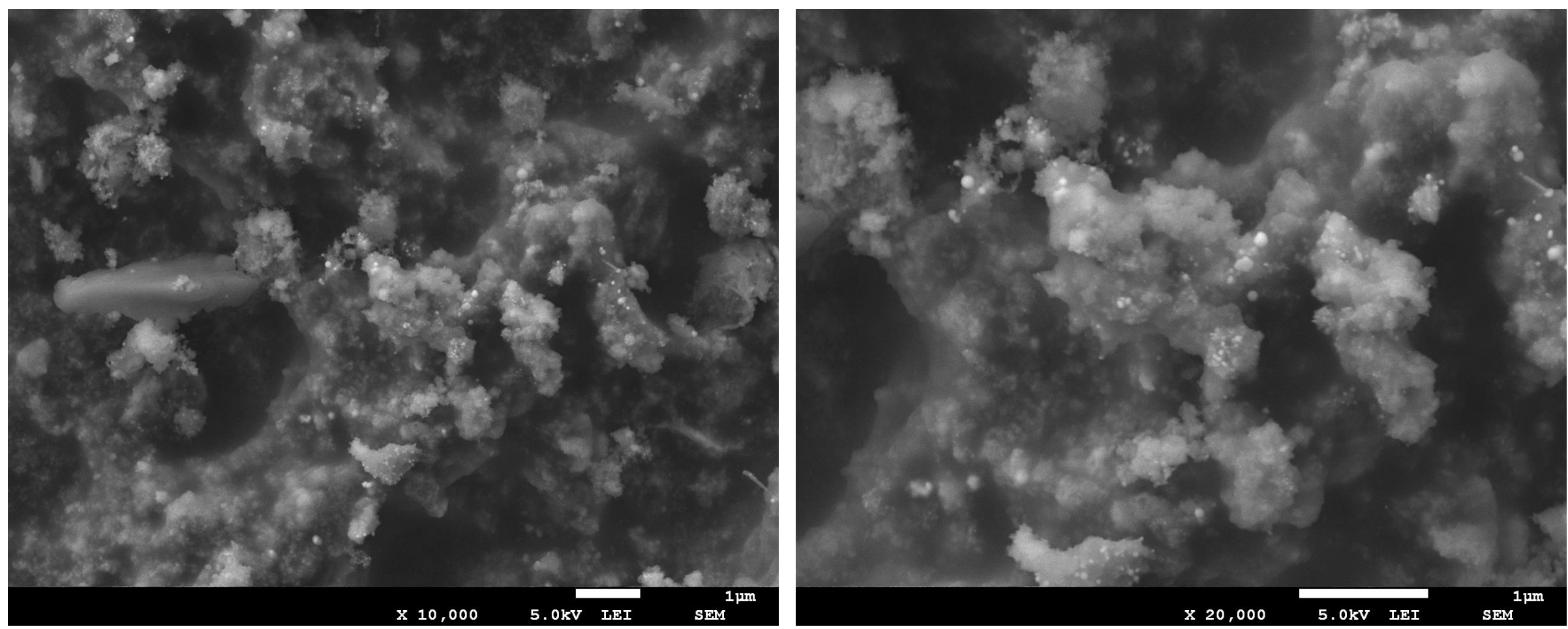

Note nano-scale structures 


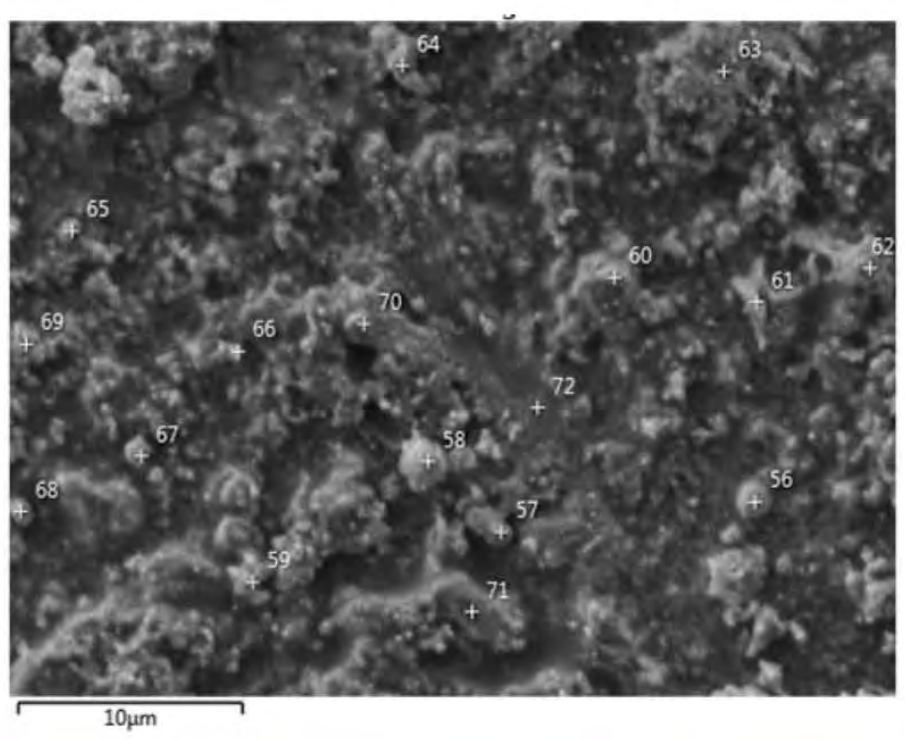

SEM EDS
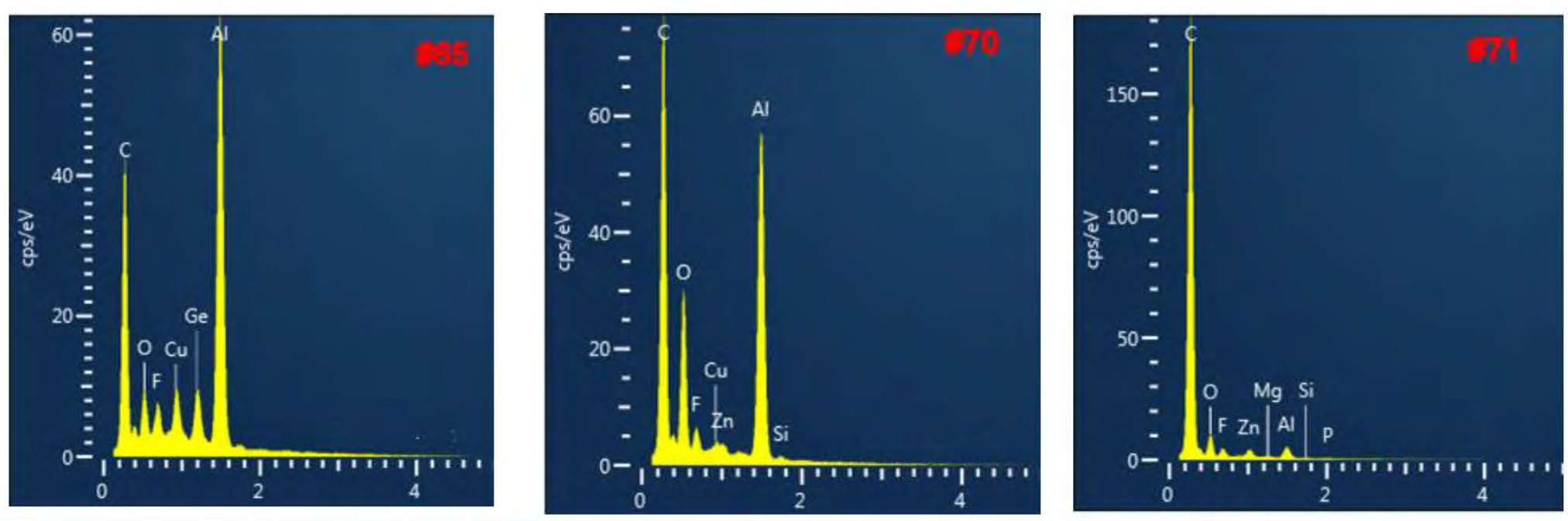

$\mathrm{Al}, \mathrm{C}, \mathrm{Cu}, \mathrm{O}, \mathrm{Fe}$, and $\mathrm{Ge}$ are common.

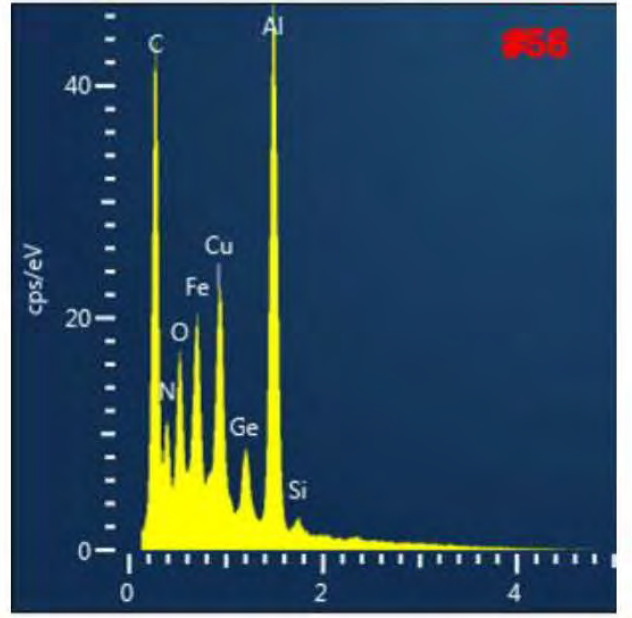




\section{SEM Stub 14 \\ Backscatter SEM 5KX, 10KX}
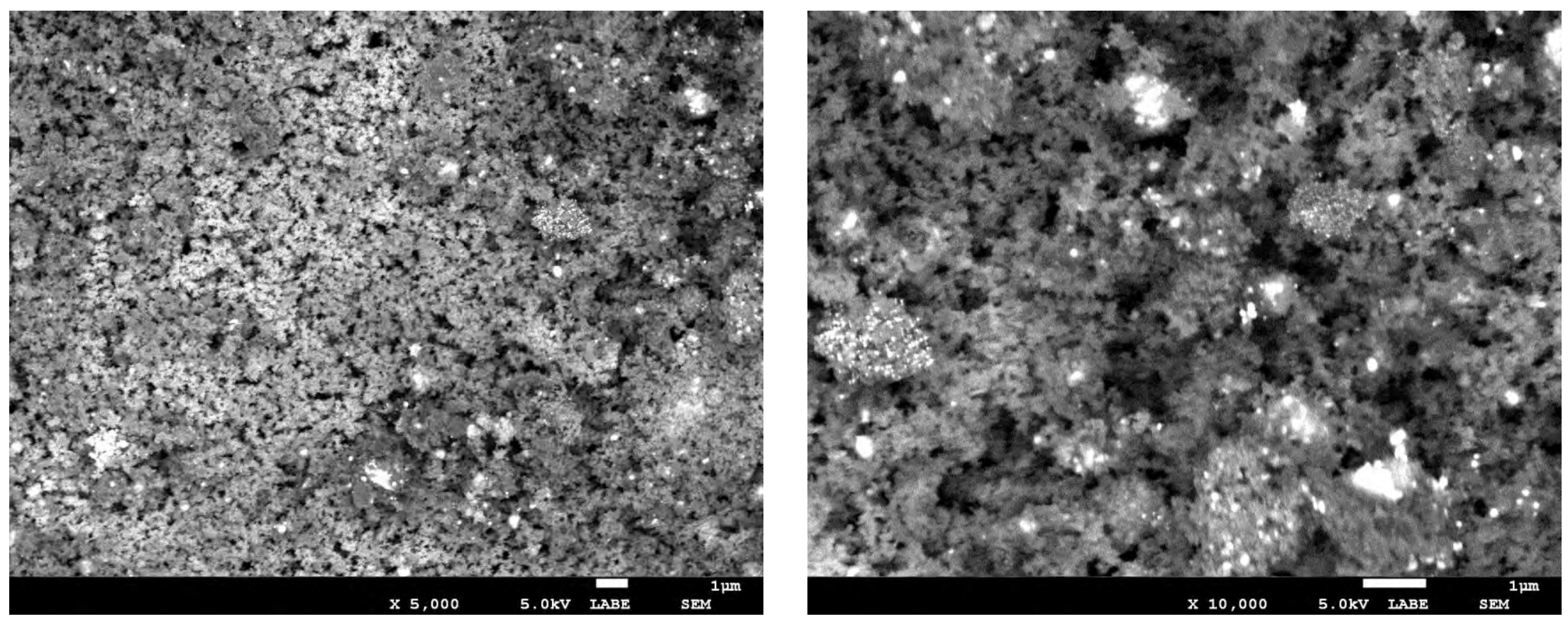

Material on surface consists of nano-sized agglomerates

Located 15 feet down range -3 O'clock 
SEM EDS (15 KV)
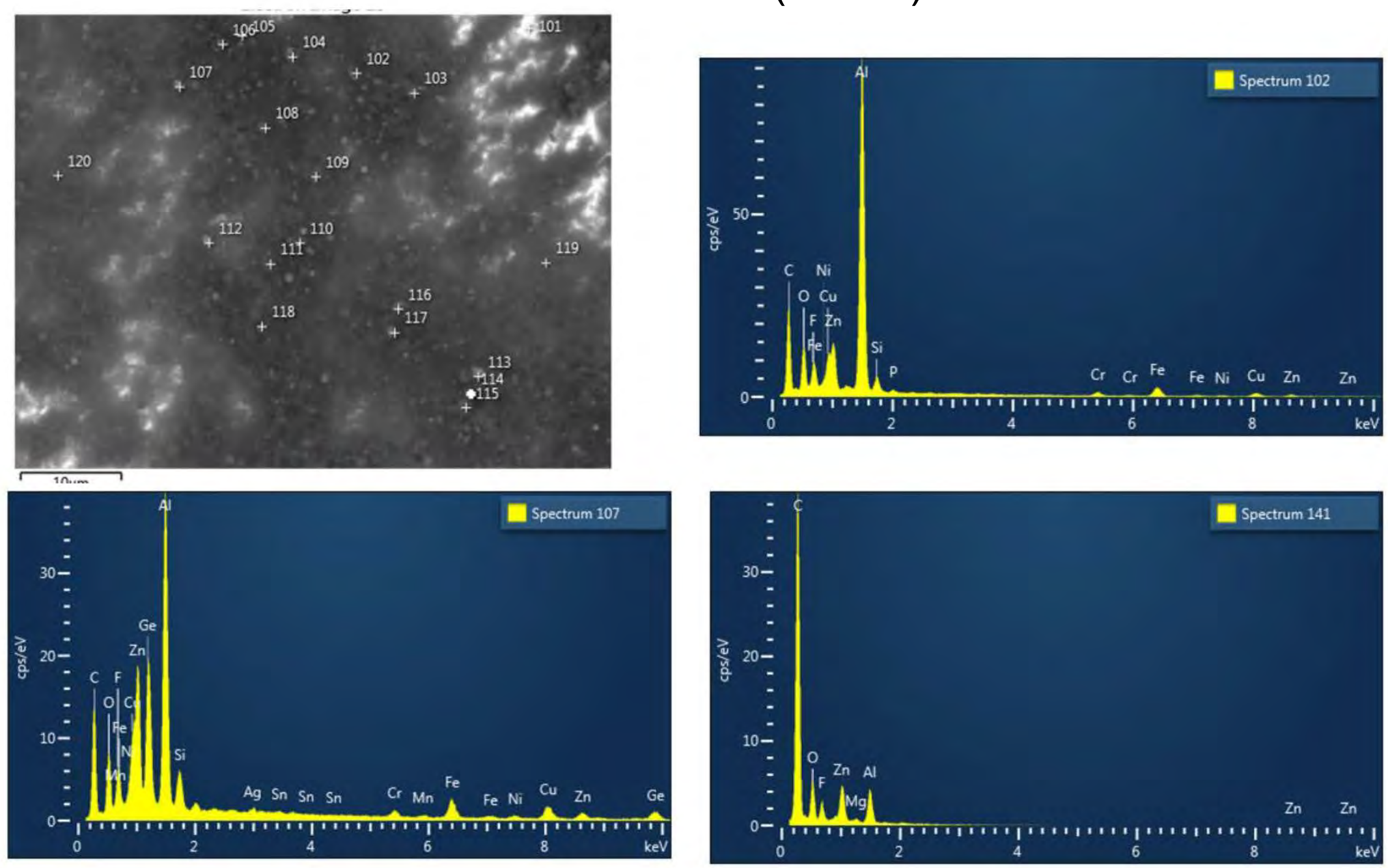

$\mathrm{Al}, \mathrm{C}, \mathrm{Cu}, \mathrm{O}, \mathrm{Fe}, \mathrm{Zn}$ and $\mathrm{Ge}$ are common. 


\section{SEM Stub 14: Focused Ion Beam (FIB) Cross Section Backscatter SEM}

Circle trenched down to Ta to facilitate site location

\section{Protective Pt layer deposition}
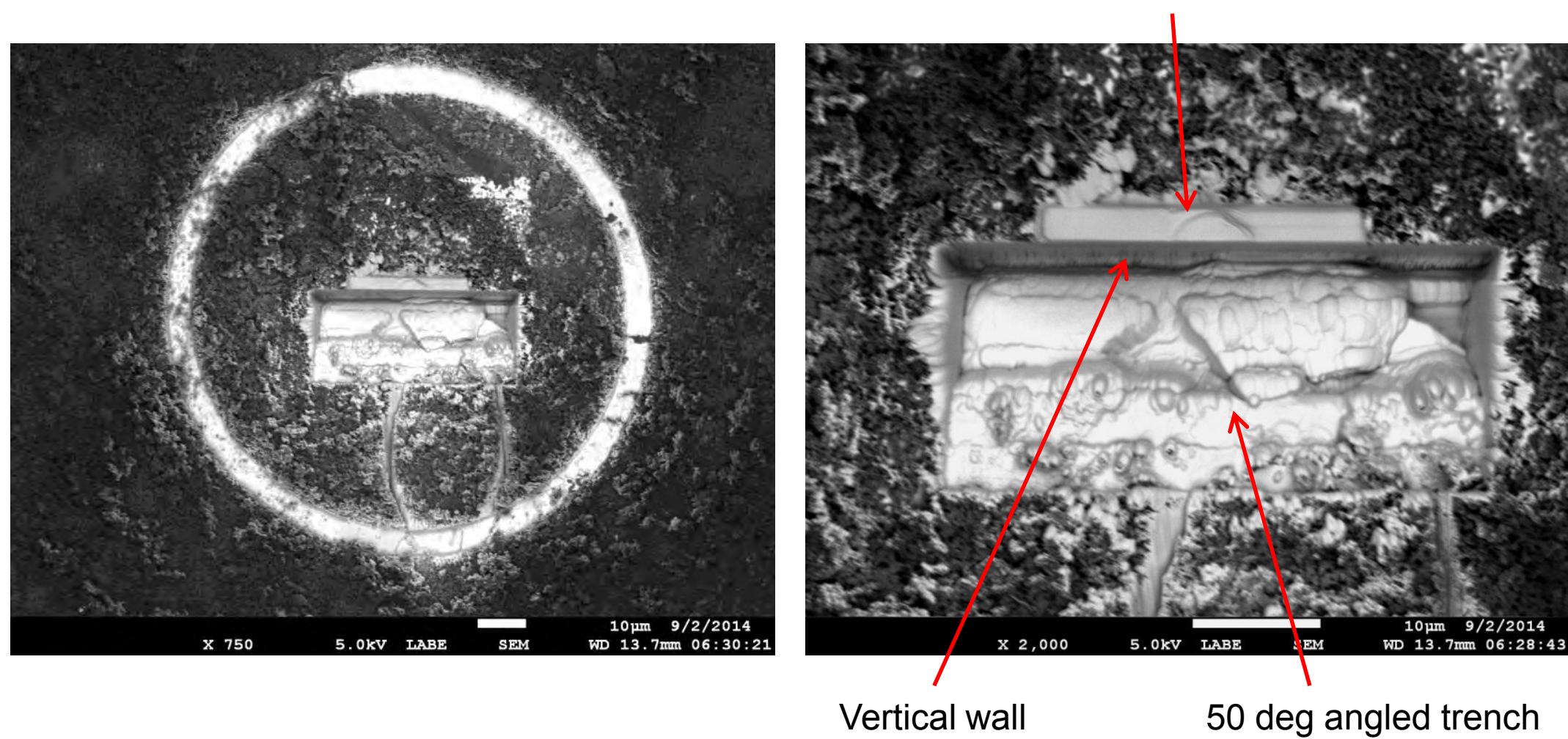

Plan View 


\section{SEM Stub 14: FIB Cross Section SEM $32.5 \mathrm{KX}, 50 \mathrm{KX}$}

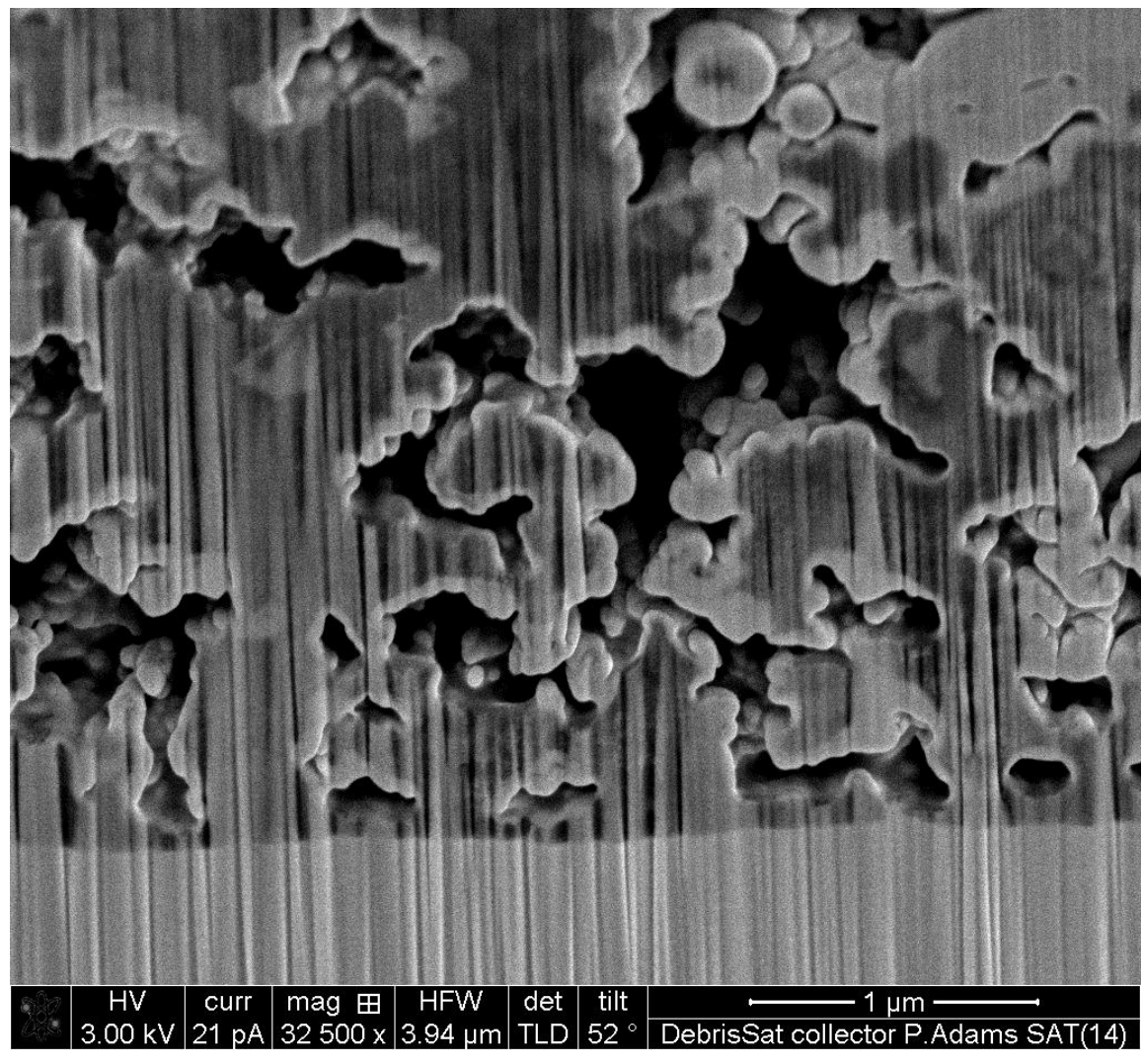

Striations (curtains) are artifacts of FIB preparation.

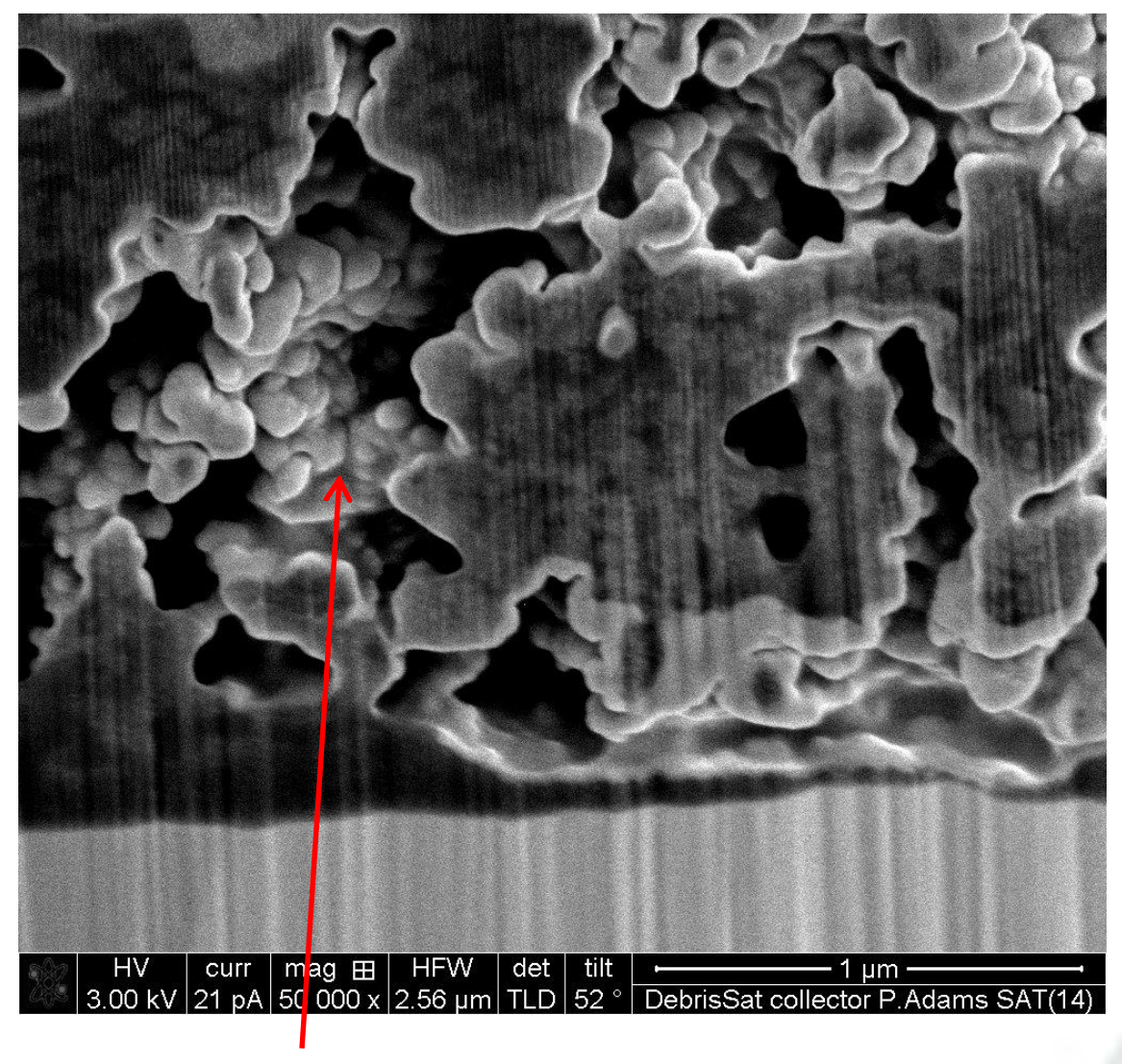

Back deposition of Ta from trenching into voids?

View of Side Wall 


\section{SBU Marking:
Post Test: SEM Stubs}

\section{FTIR - Qualitative Diffuse Reflectance}

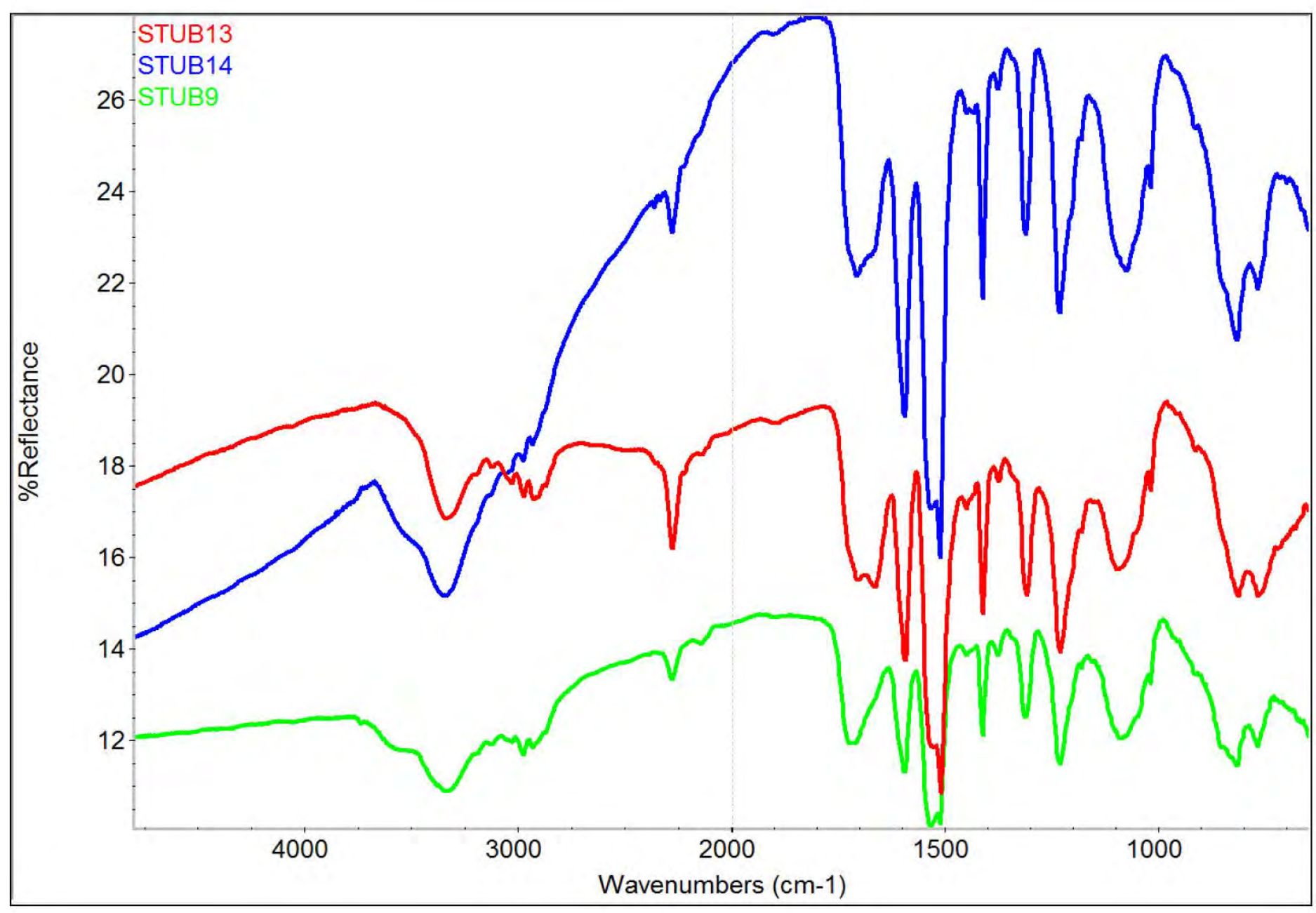

Significant soft catch signature is present on SEM stubs. 


\section{Witness Plau Makking
Pssembly: Post Test}

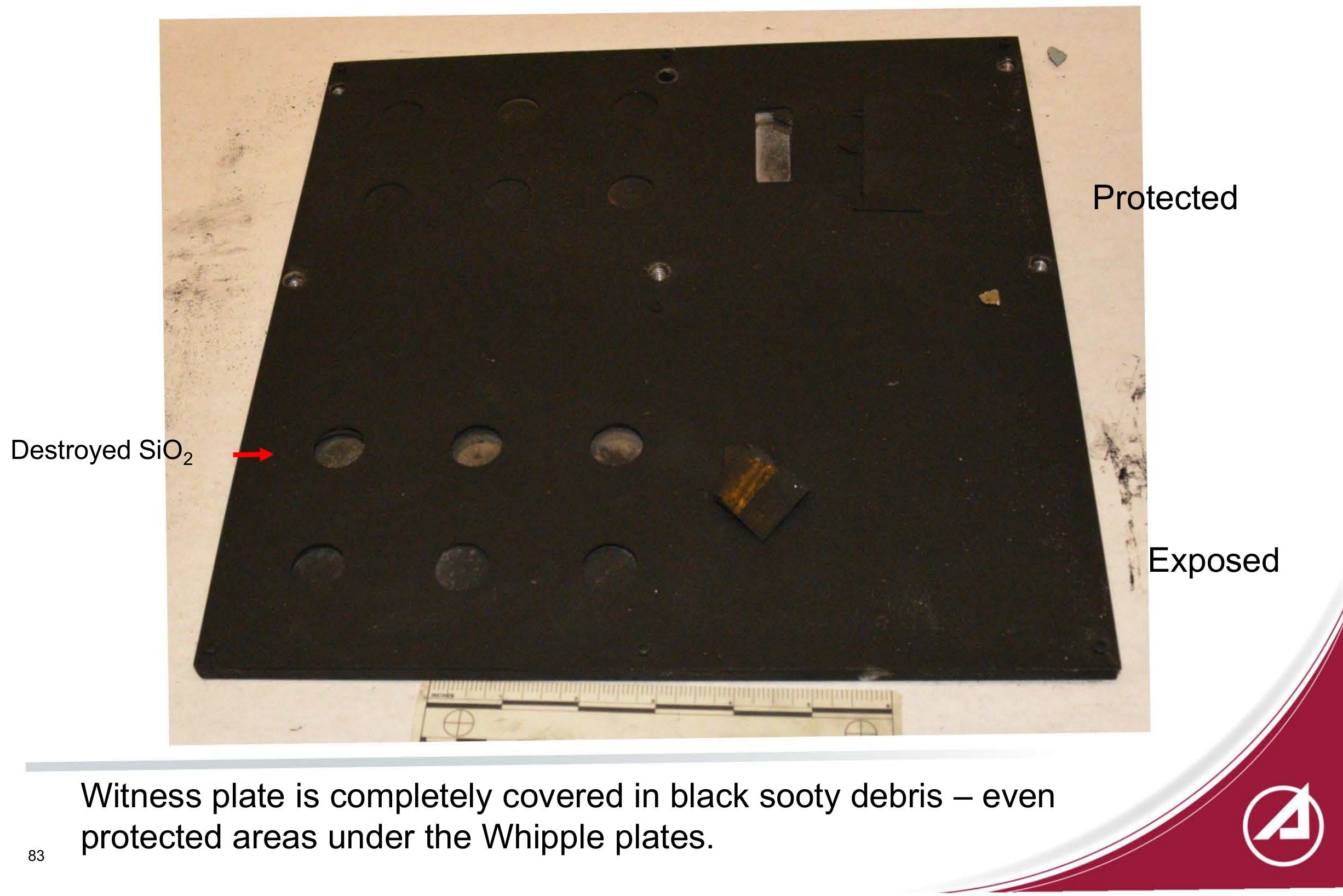




\section{Witness Plate Post Test : Aluminum Disk D2 (protected) Secondary Electron SEM Images (250X, 1KX)}
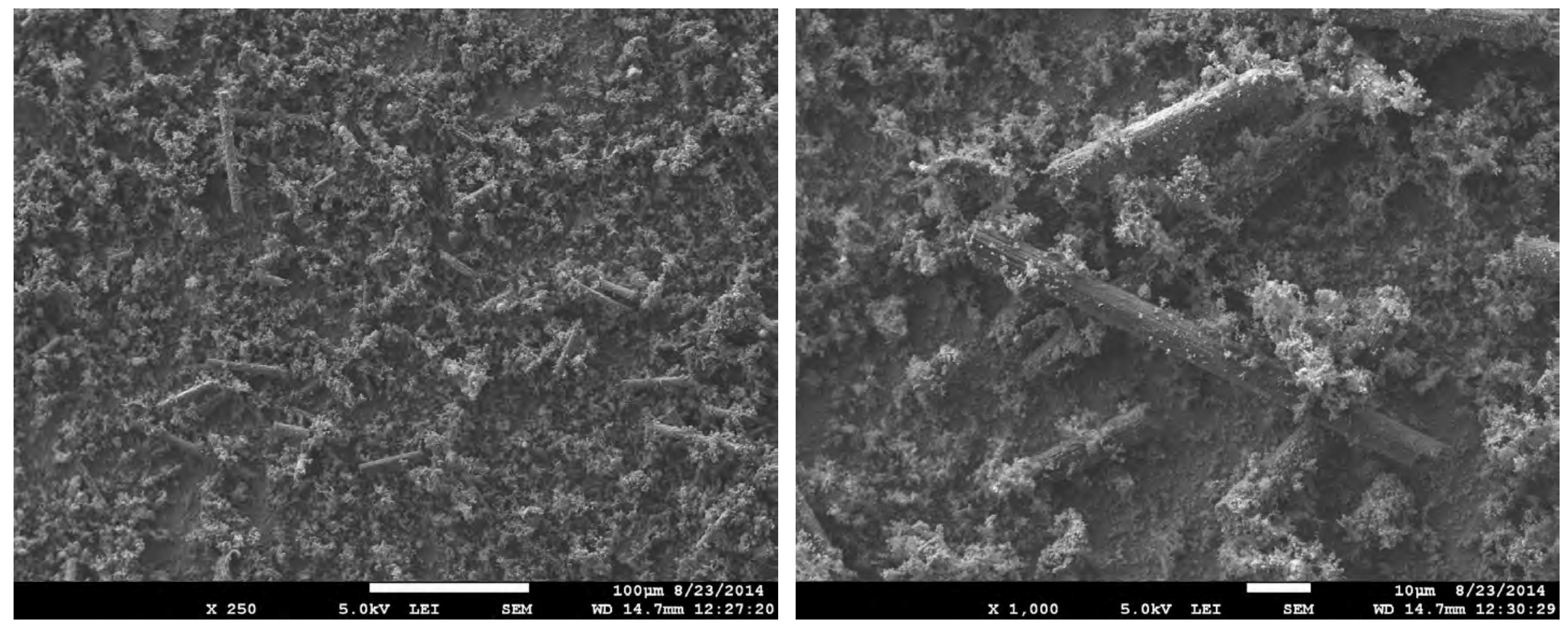

Note fragments of carbon fibers. 


\section{Witness Plate Post Test: Aluminum Disk D2 (protected) Backscatter Electron SEM Images (2KX, 10KX)}
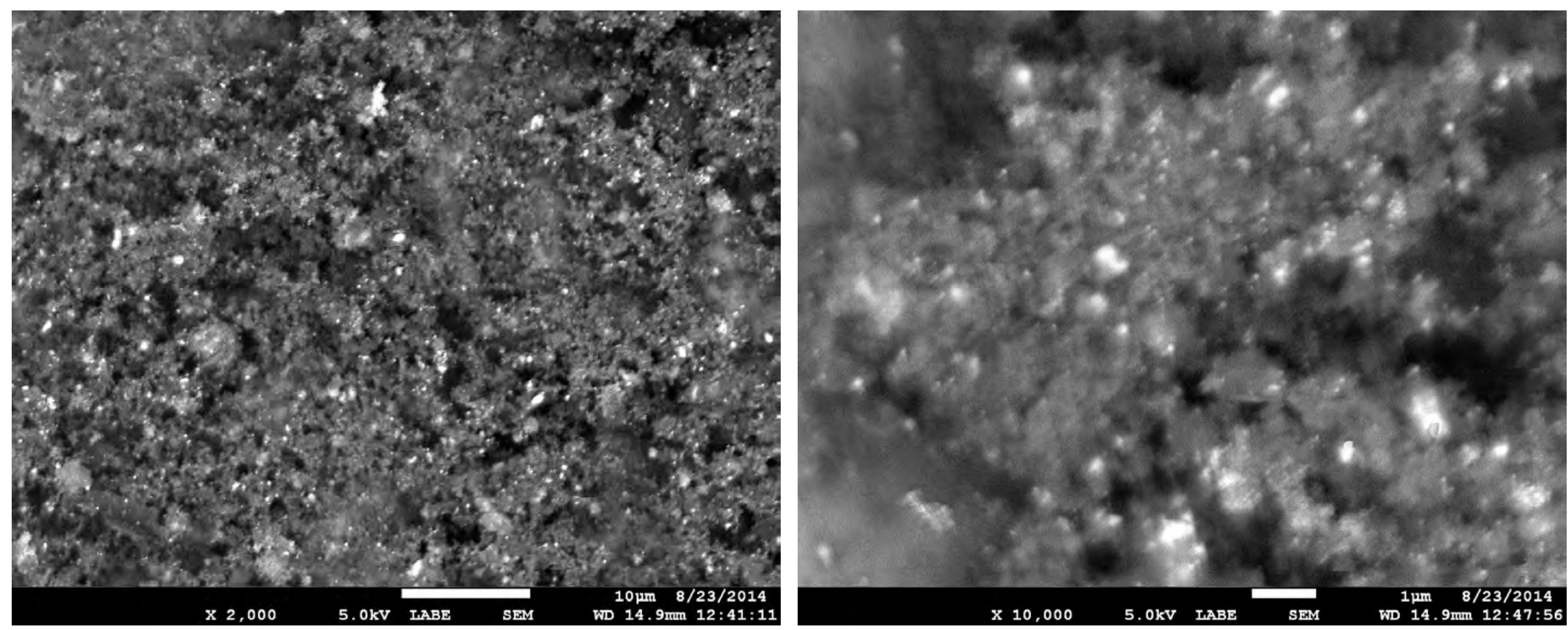

Agglomerates of nano carbonaceous material and solidified molten droplets of higher $Z$ material 


\section{Witness Plate Post Test : Aluminum Disk D2 (protected)}

SEM EDS Spectra (5KV)
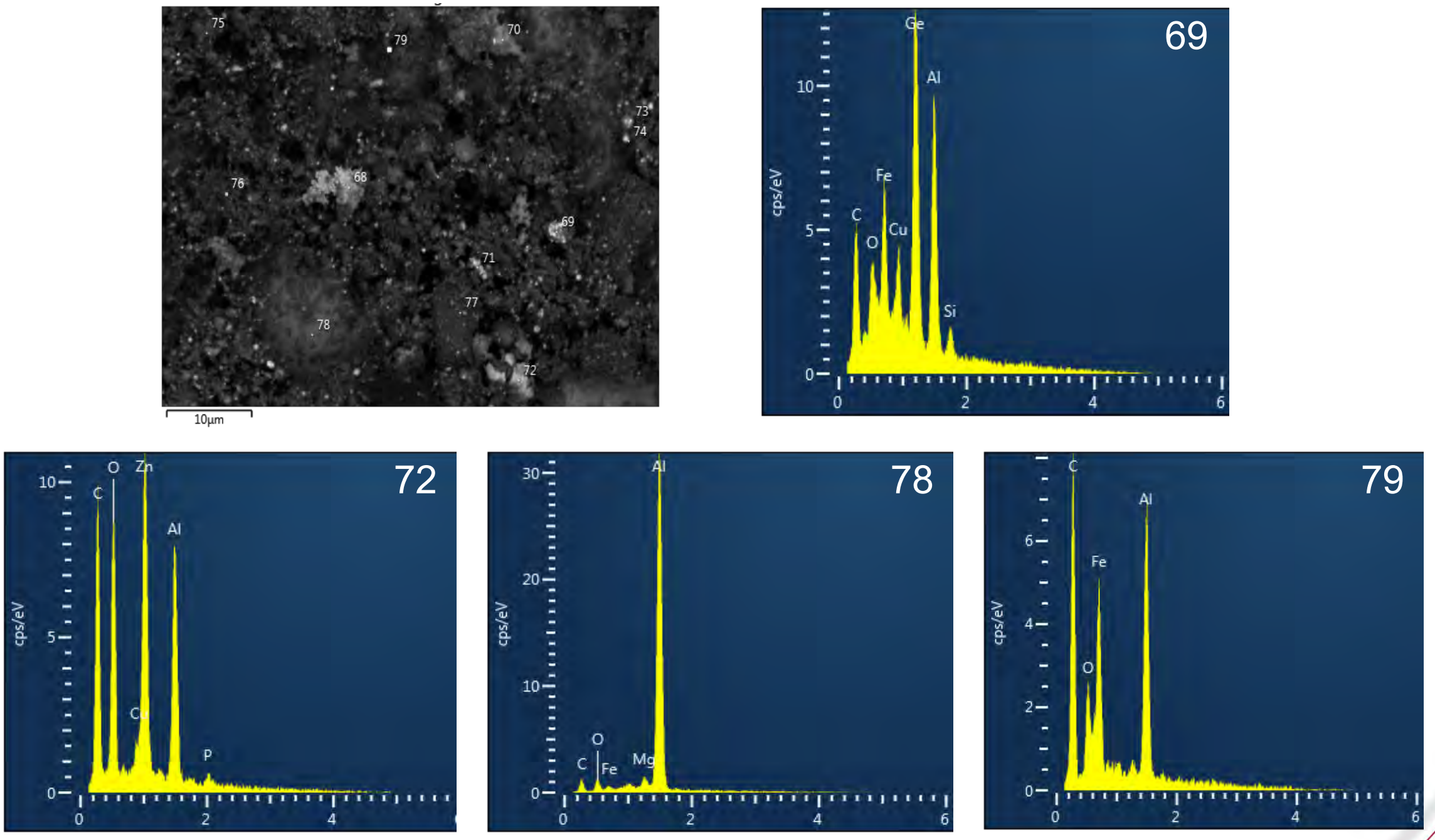

$\mathrm{Al}, \mathrm{C}, \mathrm{Cu}, \mathrm{O}, \mathrm{Fe}, \mathrm{Zn}$ and $\mathrm{Ge}$ are common. 
Witness Plate AI Disk D2: Loose Material on TEM Grid: BF TEM Location 4

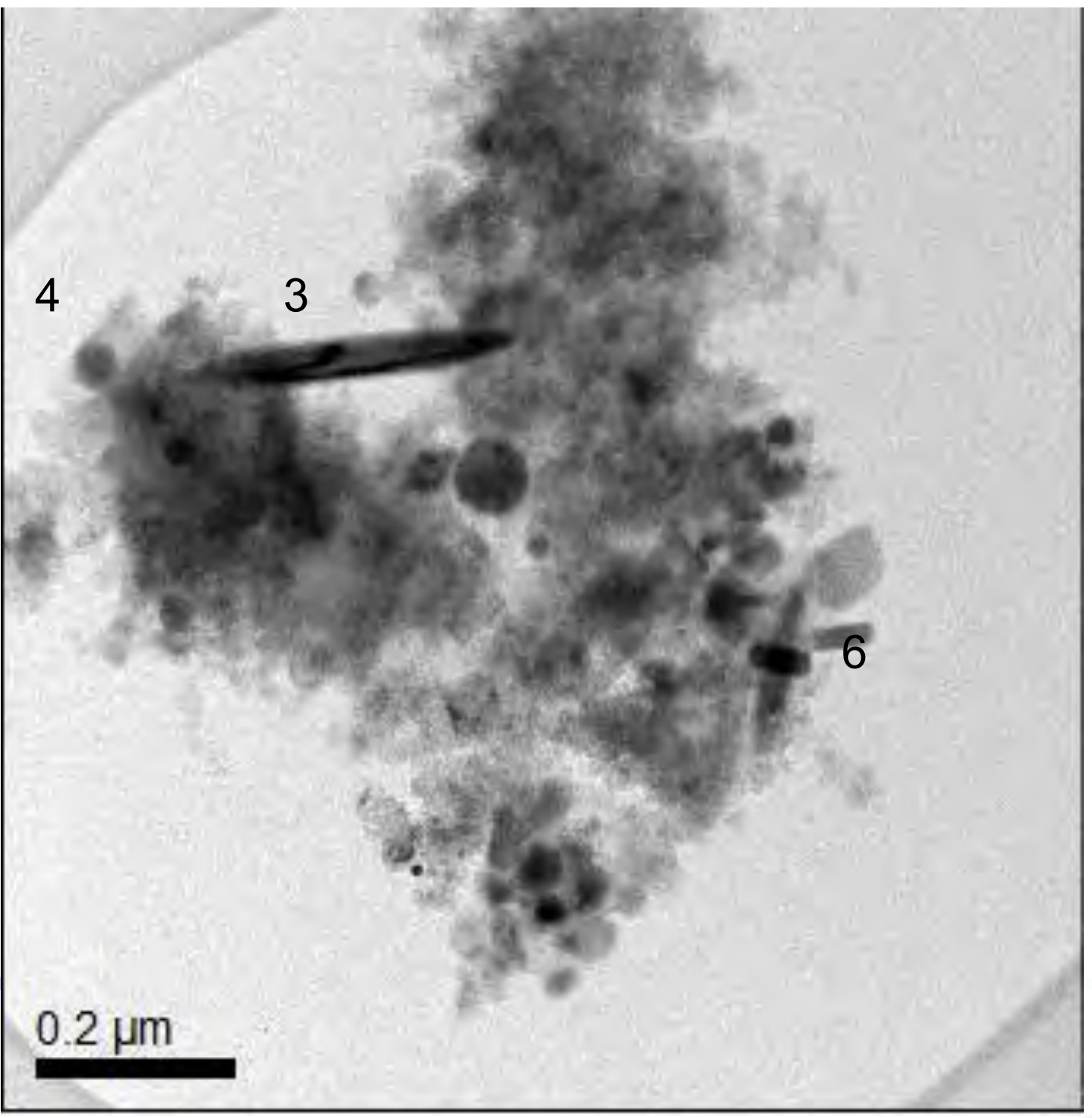




\section{Witness Plate Post Test D2: Area 2 BF-TEM}

Crystalline lattice fringes

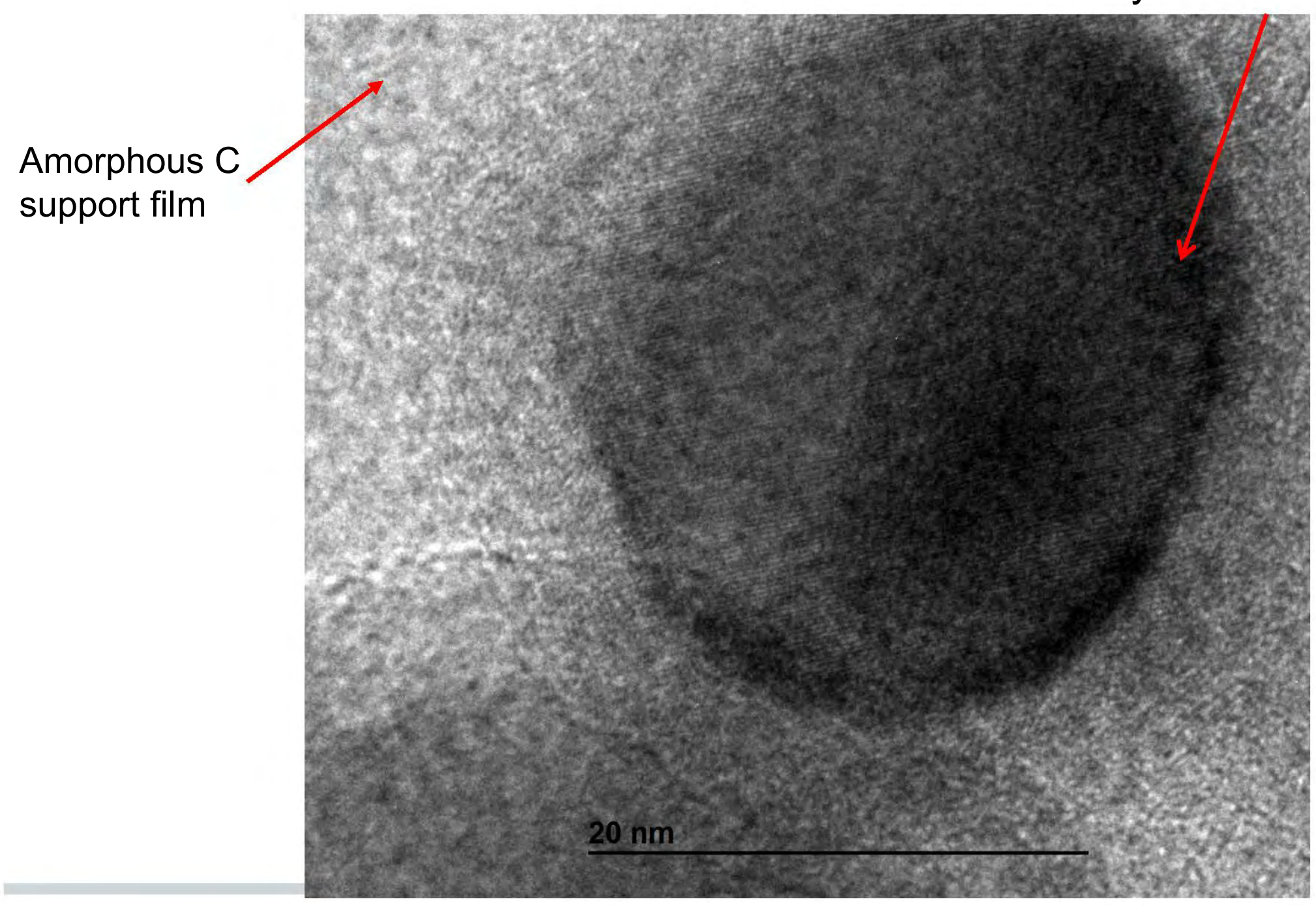

Particle is nominally a single crystal or consists of only a few crystalline grains. 


\section{Witness Plate Al Disk D2: Location 4 Area 3 BF-TEM}

Disordered graphitic carbon fringes?

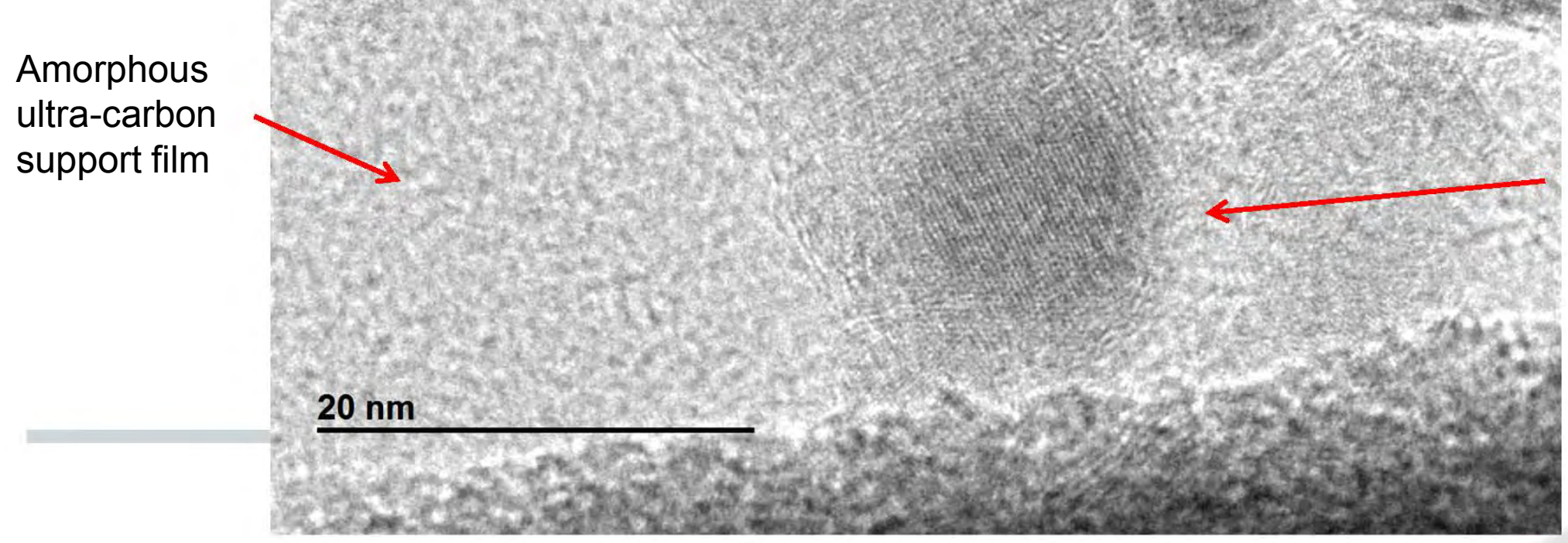

Crystalline lattice fringes 


\section{Witness Plate Al Disk D2 : Location 4 Area 4 BF-TEM}

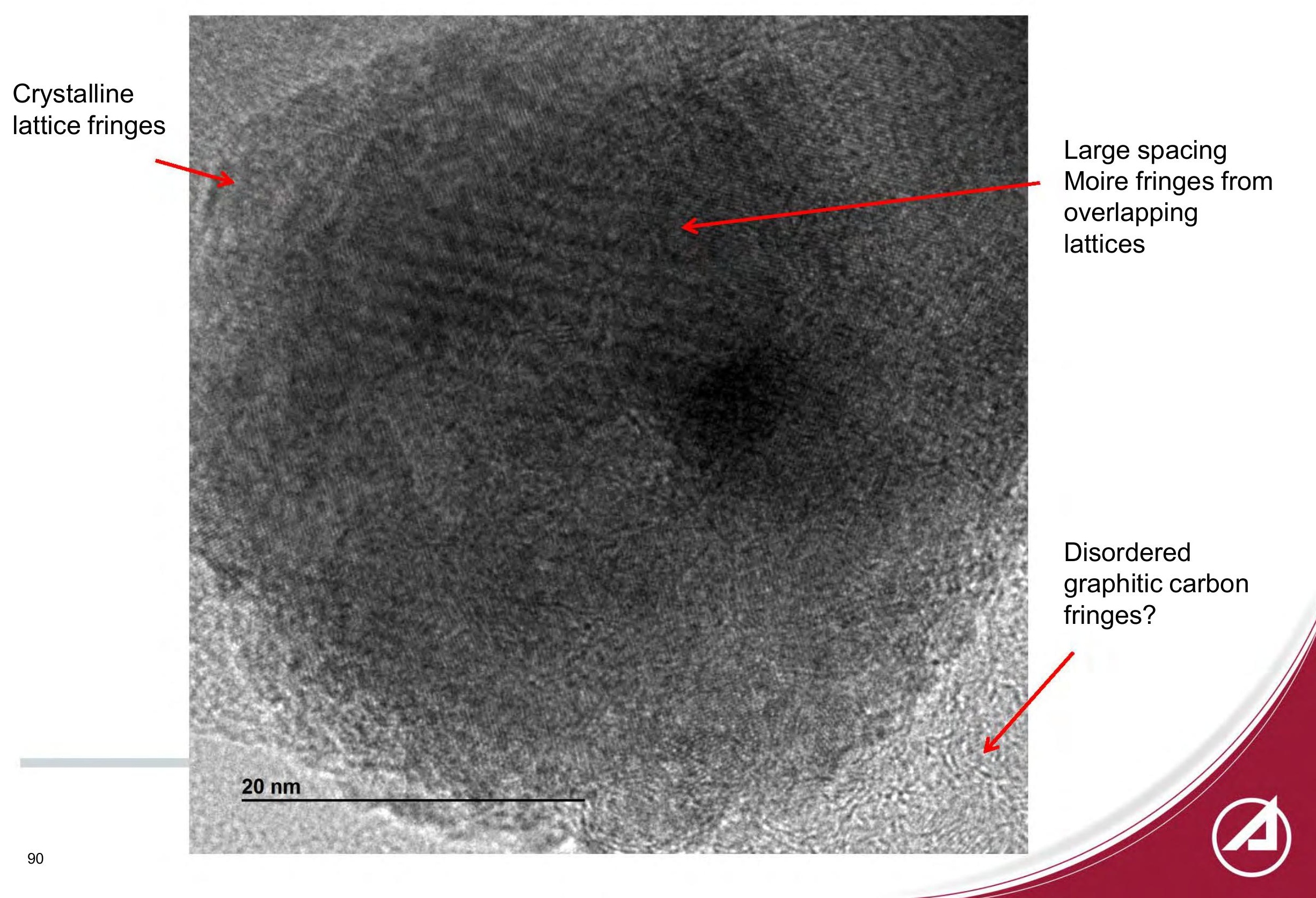




\section{Witness Plate Post Test: Al Plate D2: Area 4 BF-TEM}

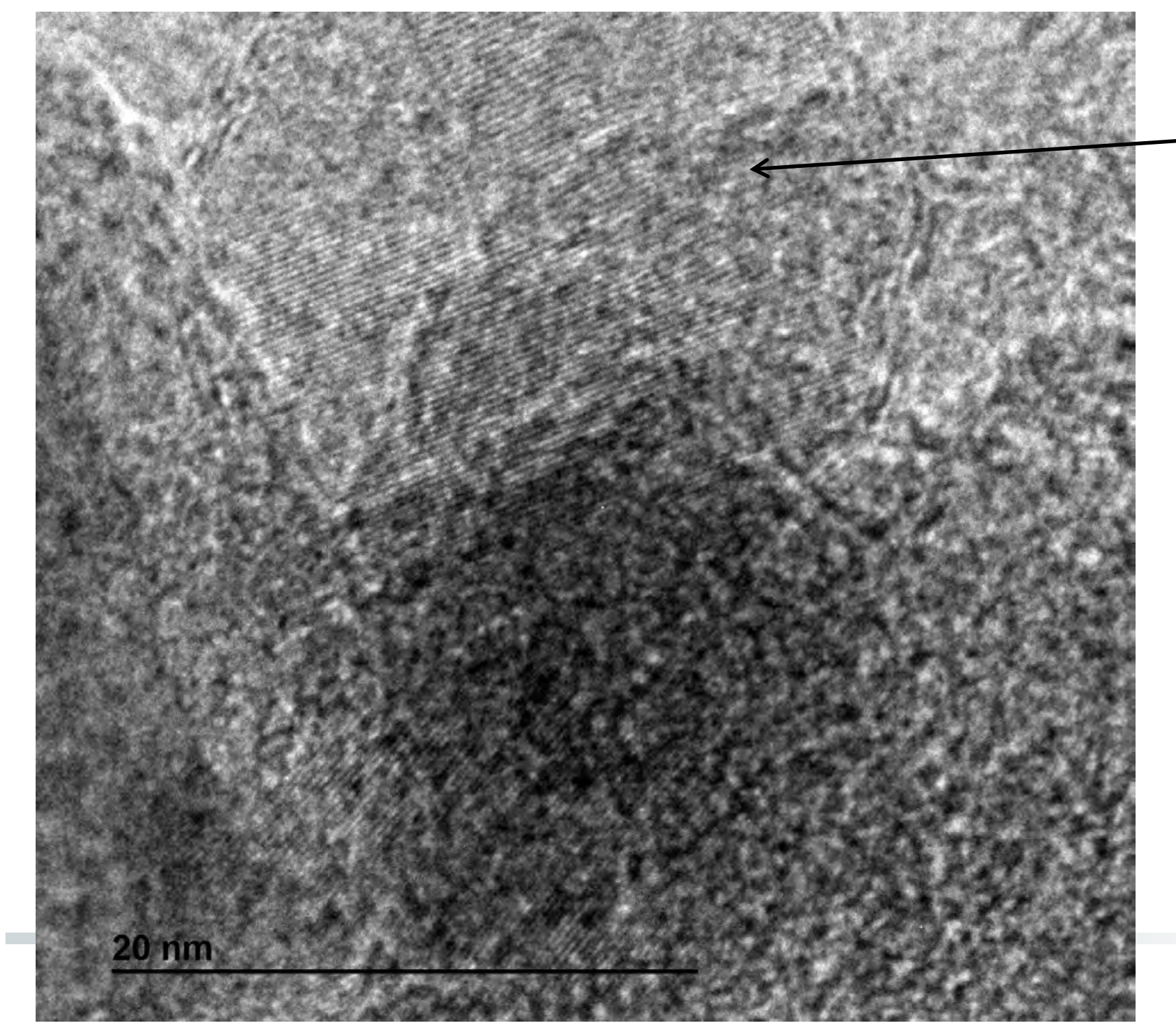

Crystalline lattice fringes

Particle is nominally a single crystal 
Witness Plate Al Disk D2 : Location 5 TEM Electron Diffraction
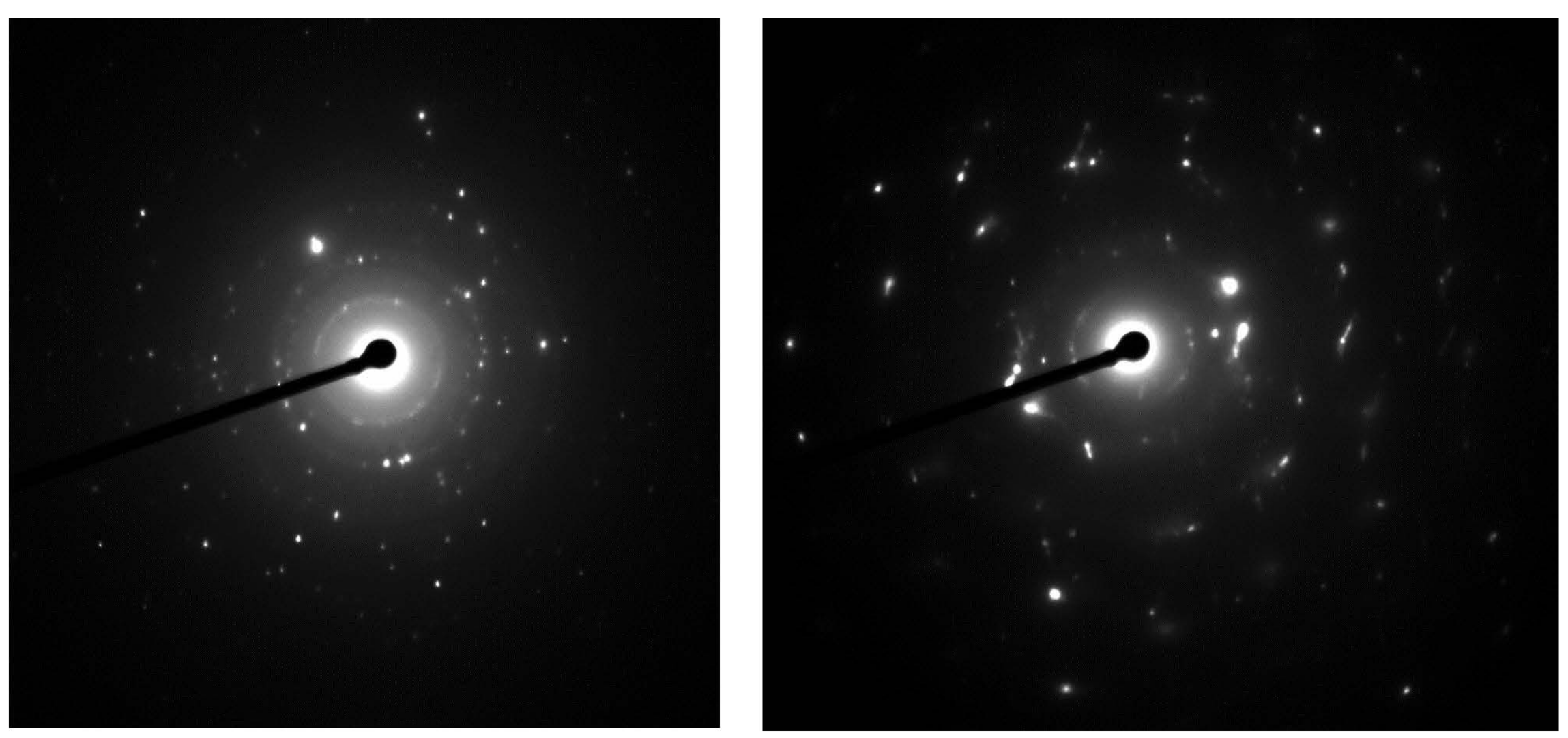

Spot patterns indicate crystallinity

Patterns cover about 0.7 micron diameter area 


\section{Witness Plate Al Disk D2 : Location 4 TEM-EDS}
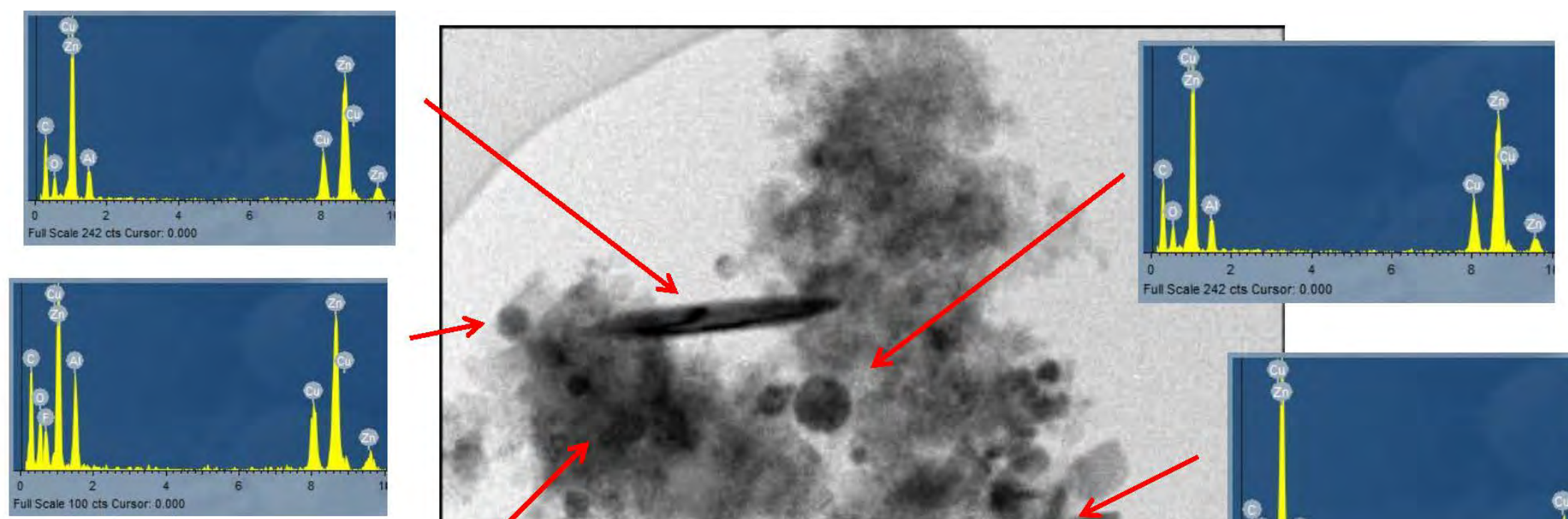

242 cts Cursor: 0.000
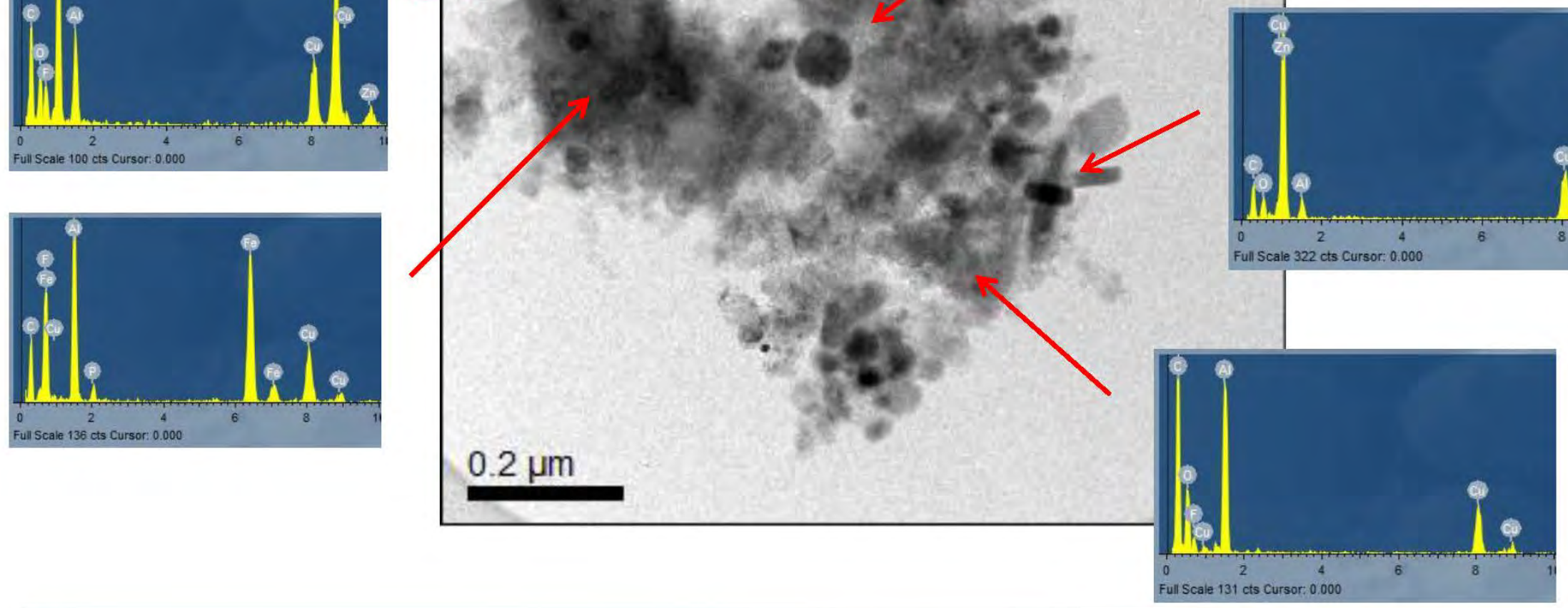

Discreet crystalline particles contain $\mathrm{Zn}$. Al and Fe also detected.

$\mathrm{Cu}$ is probably from $\mathrm{X}$-rays scattered from the microscope pole piece. 


\section{Witness Plate Post Test : Aluminum Disks (Optical Images - 150X)}

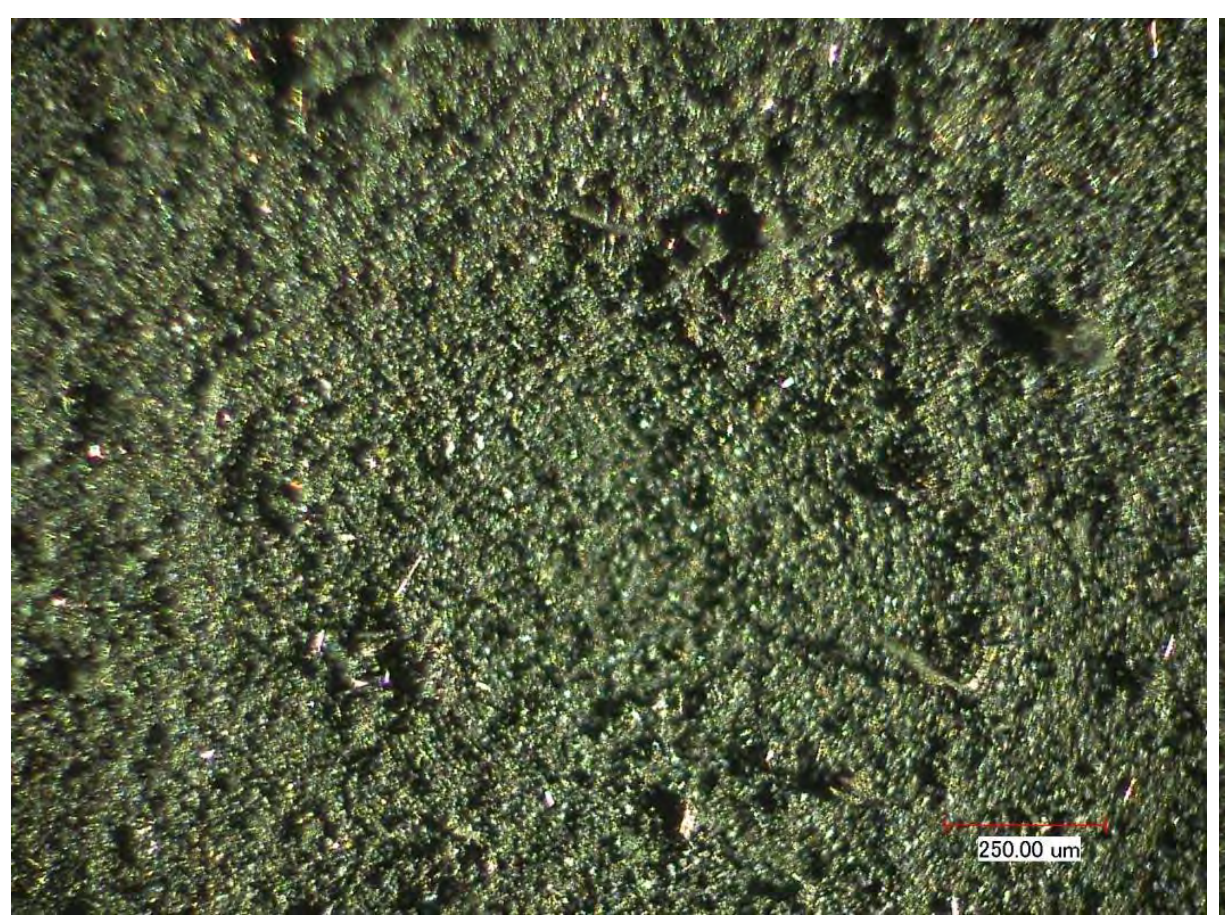

Exposed (B2)

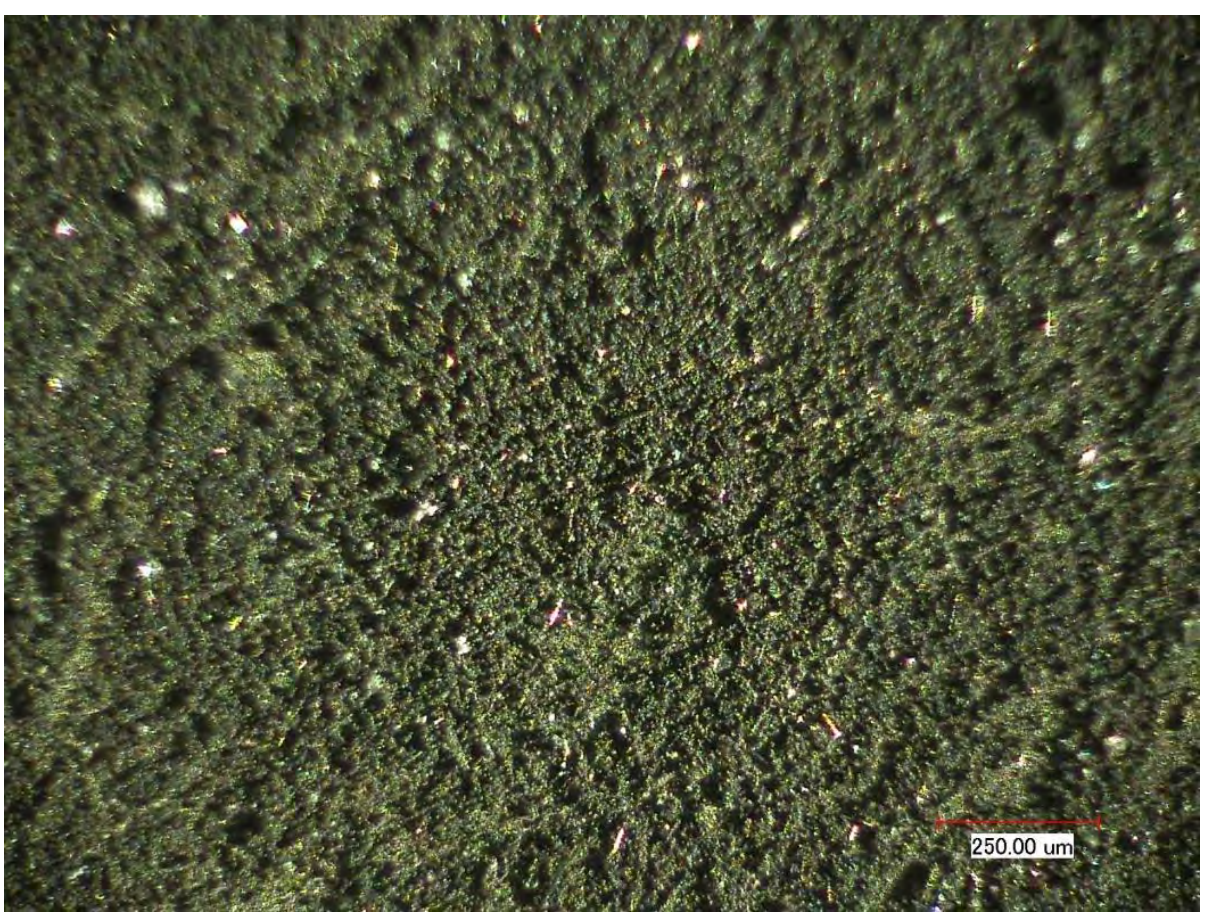

Protected (D2) 


\section{Witness Plate Post Test : Aluminum Disk B2 (exposed) SEM EDS Average Composition (10KV)}

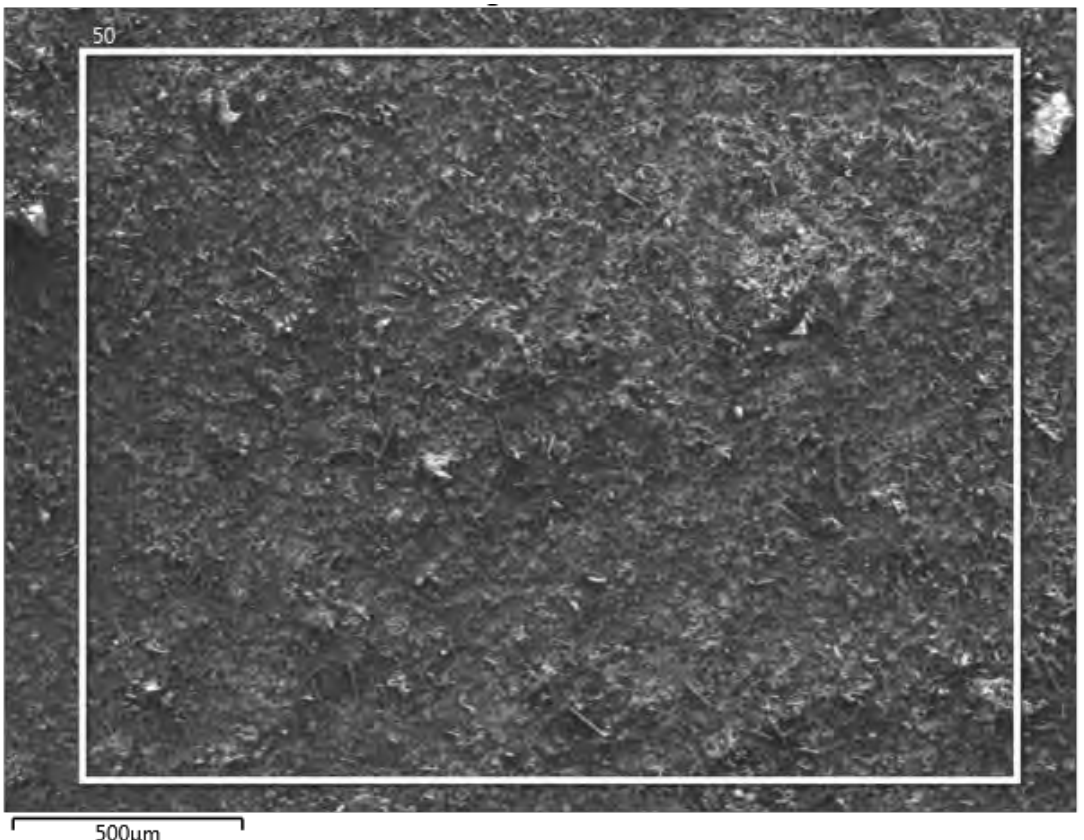

Elemental abundances are similar to SEM stub witness plates on soft catch panels.

\begin{tabular}{|l|r|r|}
\hline & Atomic \% & \multicolumn{1}{|c|}{ Atomic \% } \\
\hline $\mathrm{C}$ & 63.67 & 64.82 \\
\hline $\mathrm{O}$ & 15.89 & 15.58 \\
\hline $\mathrm{F}$ & 1.22 & 1.61 \\
\hline $\mathrm{Na}$ & 0.00 & 0.00 \\
\hline $\mathrm{Mg}$ & 0.22 & 0.27 \\
\hline $\mathrm{Al}$ & 13.74 & 12.72 \\
\hline $\mathrm{Si}$ & 0.46 & 0.43 \\
\hline $\mathrm{P}$ & 0.34 & 0.41 \\
\hline $\mathrm{S}$ & 0.07 & 0.06 \\
\hline $\mathrm{Ca}$ & 0.00 & 0.00 \\
\hline $\mathrm{Cr}$ & 0.34 & 0.35 \\
\hline $\mathrm{Fe}$ & 1.51 & 1.29 \\
\hline $\mathrm{Cu}$ & 2.11 & 1.83 \\
\hline $\mathrm{Zn}$ & 0.00 & 0.00 \\
\hline $\mathrm{Ge}$ & 0.37 & 0.47 \\
\hline $\mathrm{Ag}$ & 0.08 & 0.11 \\
\hline $\mathrm{Sn}$ & 0.00 & 0.07 \\
\hline $\mathrm{Total}$ & 100.00 & 100.00 \\
\hline
\end{tabular}


Witness Plate Post Test : Aluminum Disk B2 (exposed) SEM Images of particles suspended on lacey carbon films on Cu TEM grid
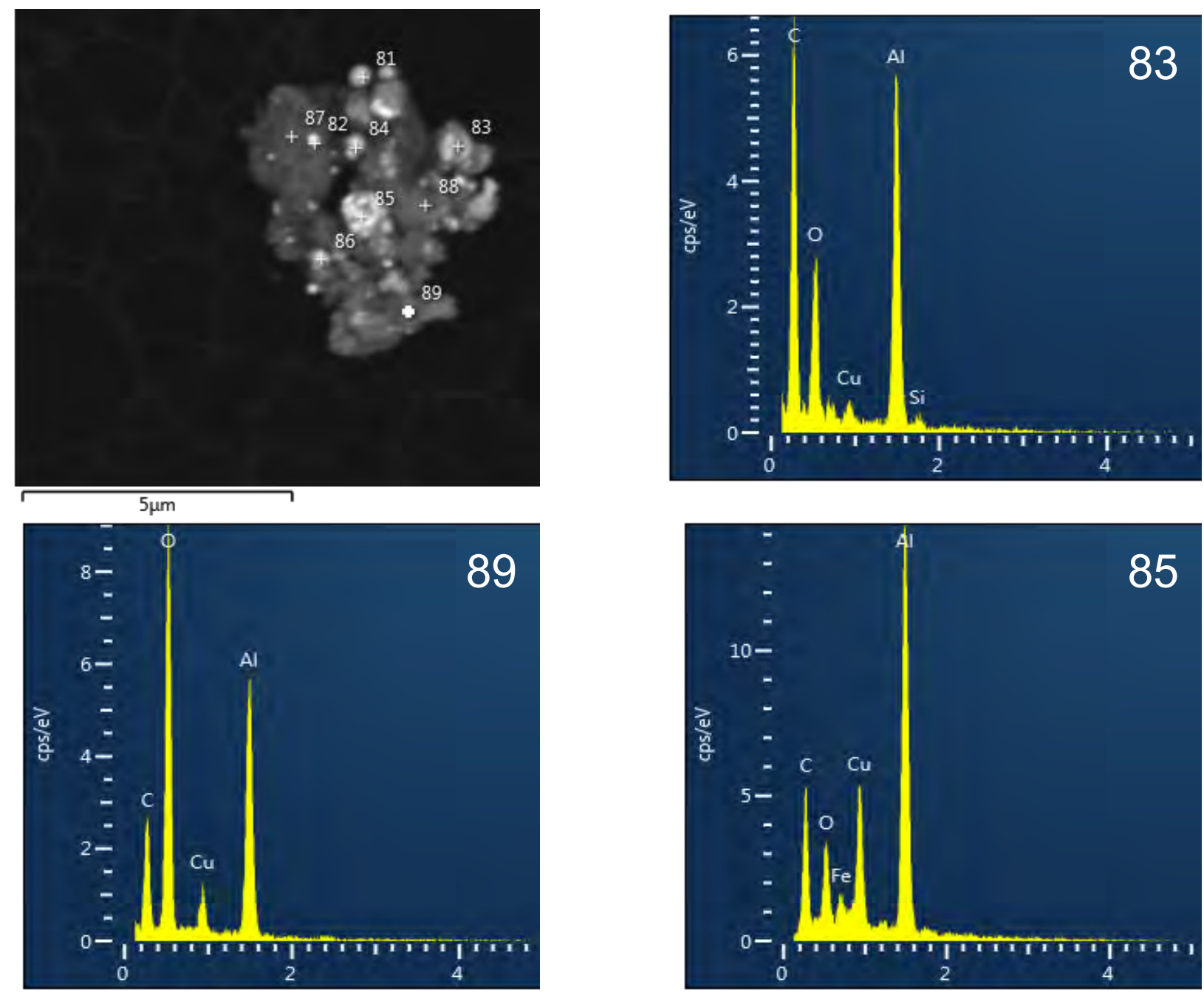

$\mathrm{Al}, \mathrm{C}$ and $\mathrm{O}$ the are most common constituents, also minor $\mathrm{Cu}$. 


\section{Witness Plate Post Test: Z93 Painted Aluminum Disks}

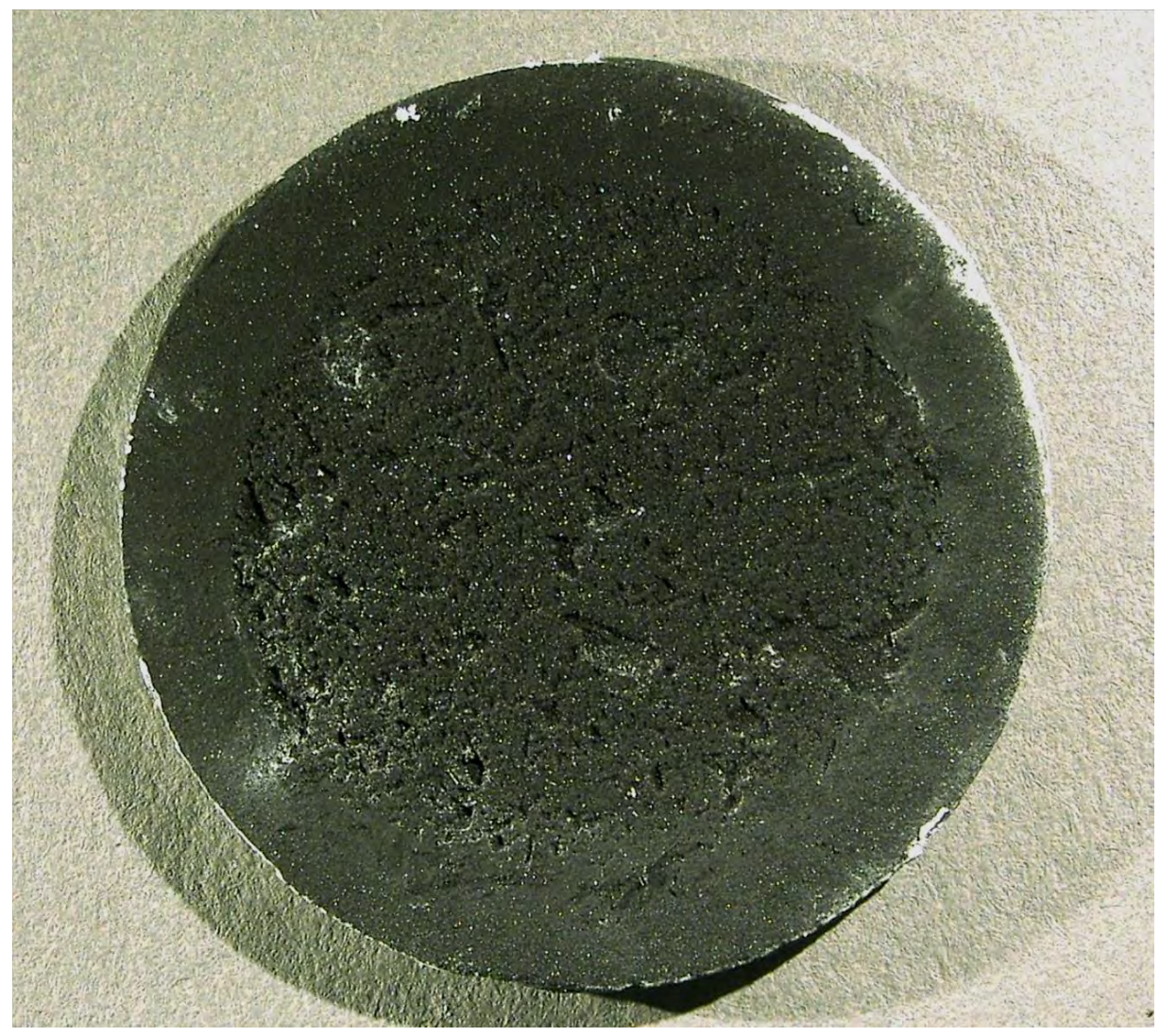

Exposed

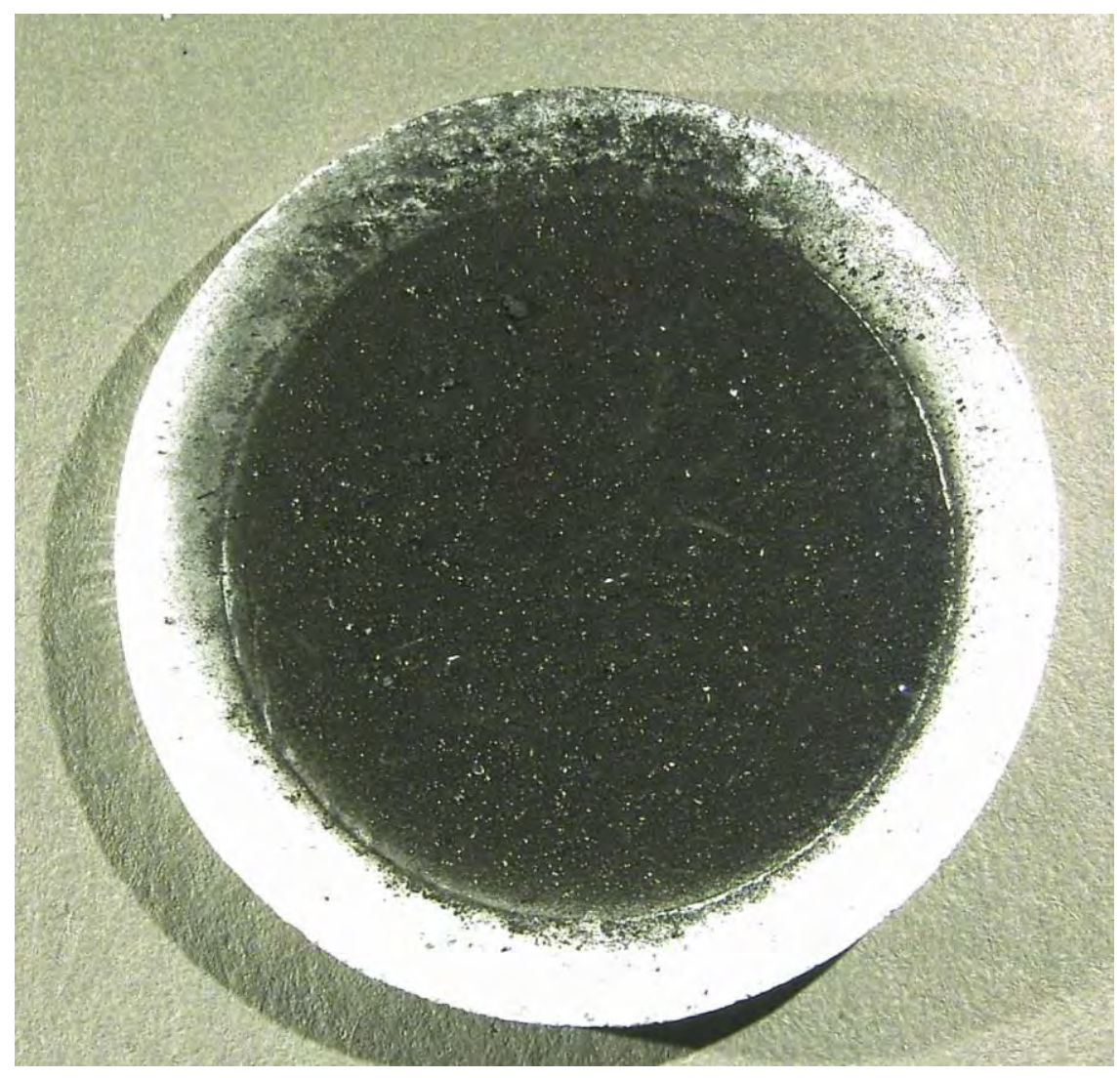

Protected

Z-93 paint consists of $\mathrm{ZnO}$ in a potassium silicate binder 


\section{Witness Plate Post Test : Fused Silica Disks}

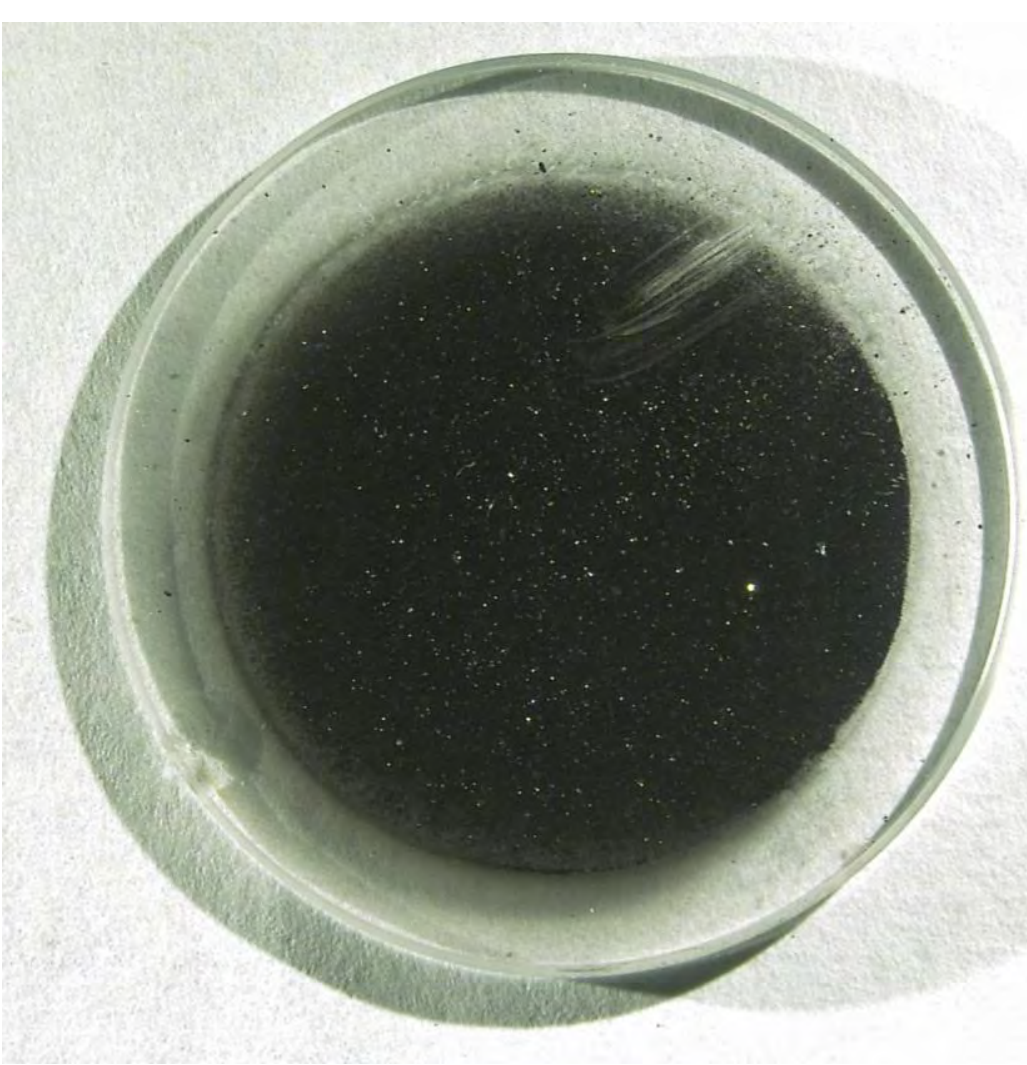

Protected (C1)

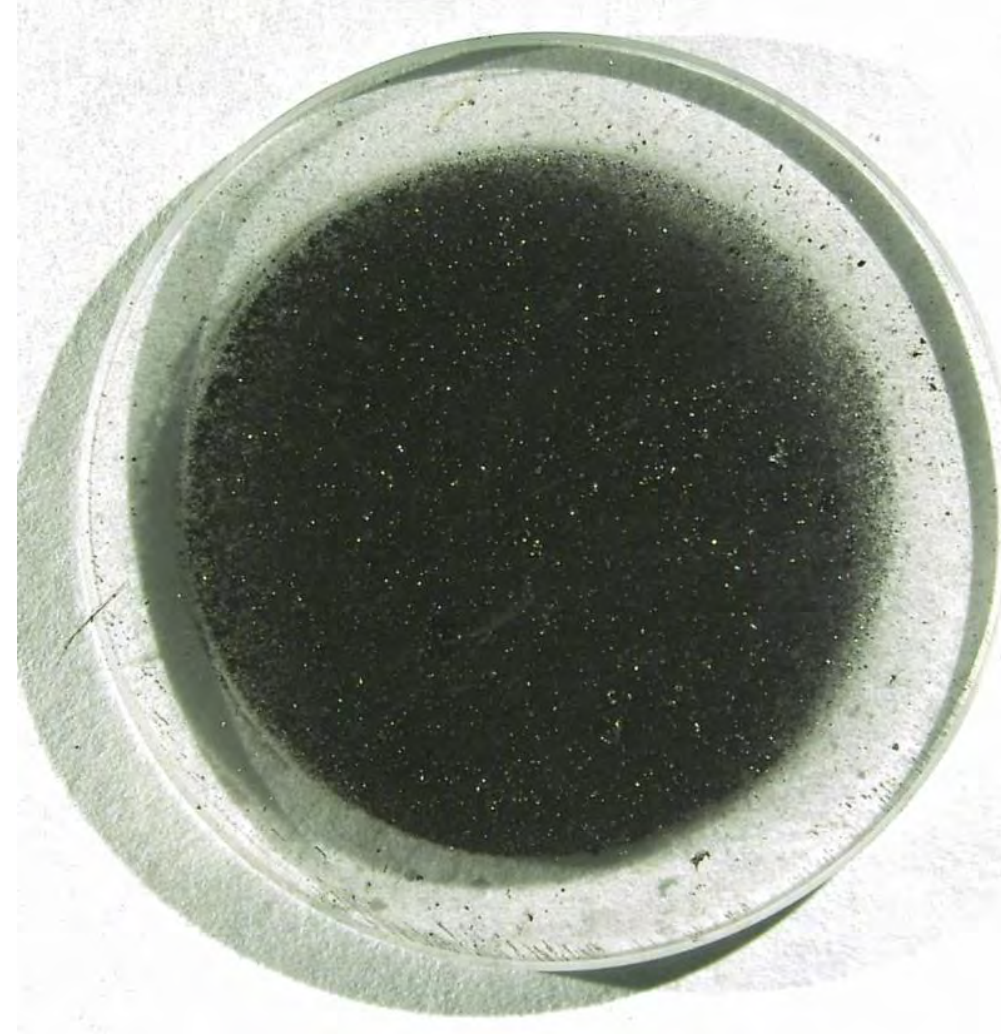

Protected (D1)

The directly exposed disks were destroyed 


\section{Witness Plate Post Test : Fused Silica Disks - Optical Images (150X)}

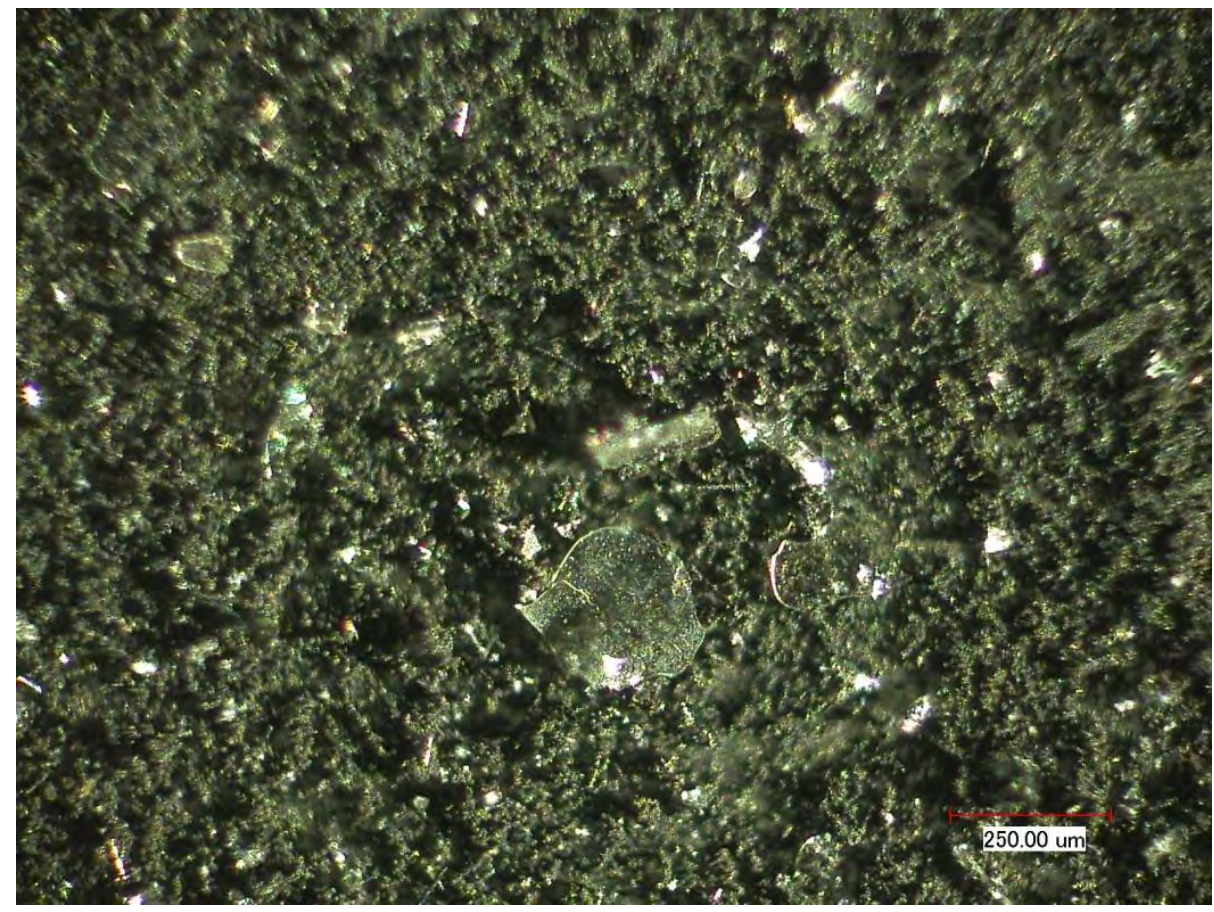

Protected (C1)

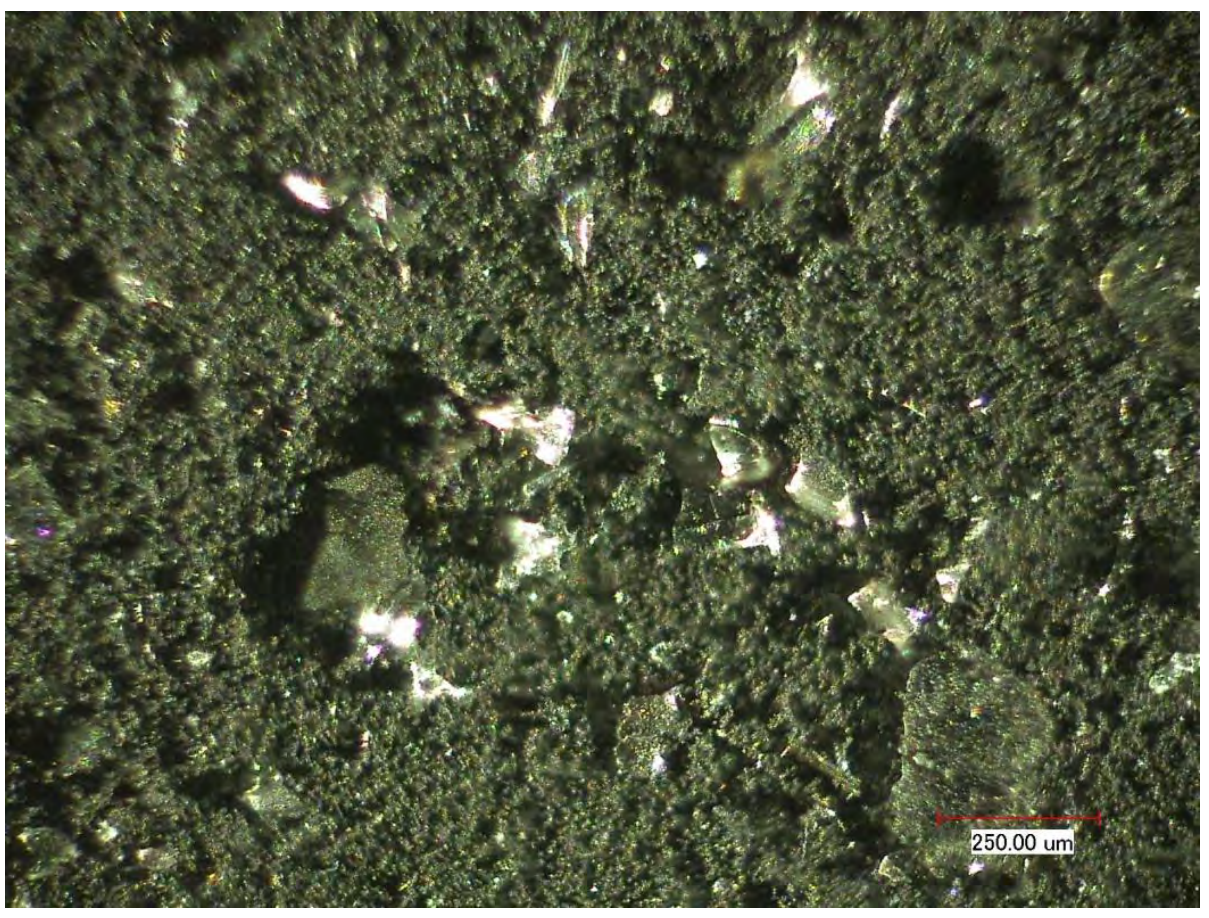

Protected (D1)

Clear angular fragments are soft catch foam debris. 


\section{Witness Plate Fused Silica Disks UV-VIS-NIR Transmission}

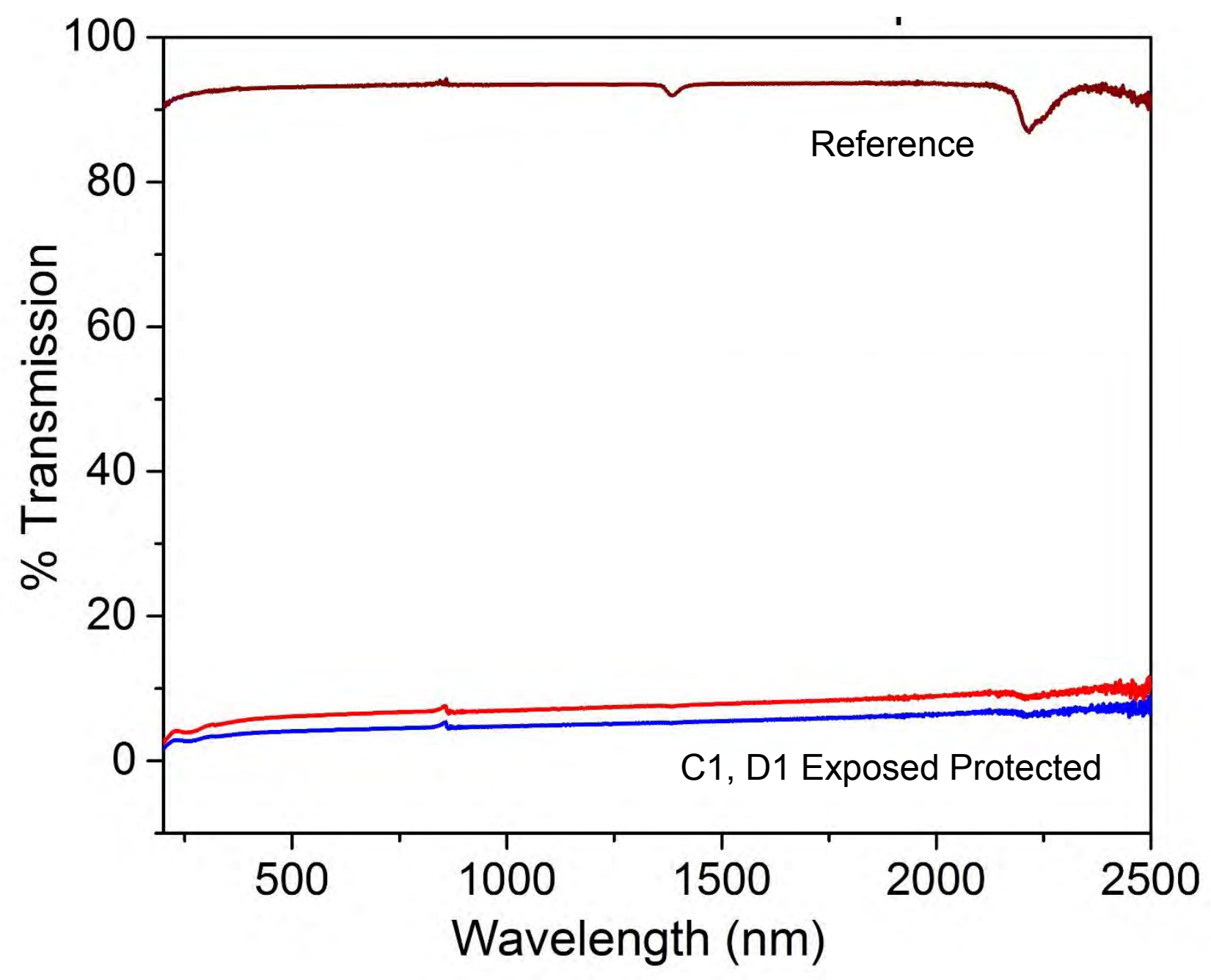

Significant decrease in transmission from $94 \%$ to $8 \%$. 


\section{Witness Plate $\mathrm{NaCl}$ Disk}

\section{UV-VIS-NIR Transmission}

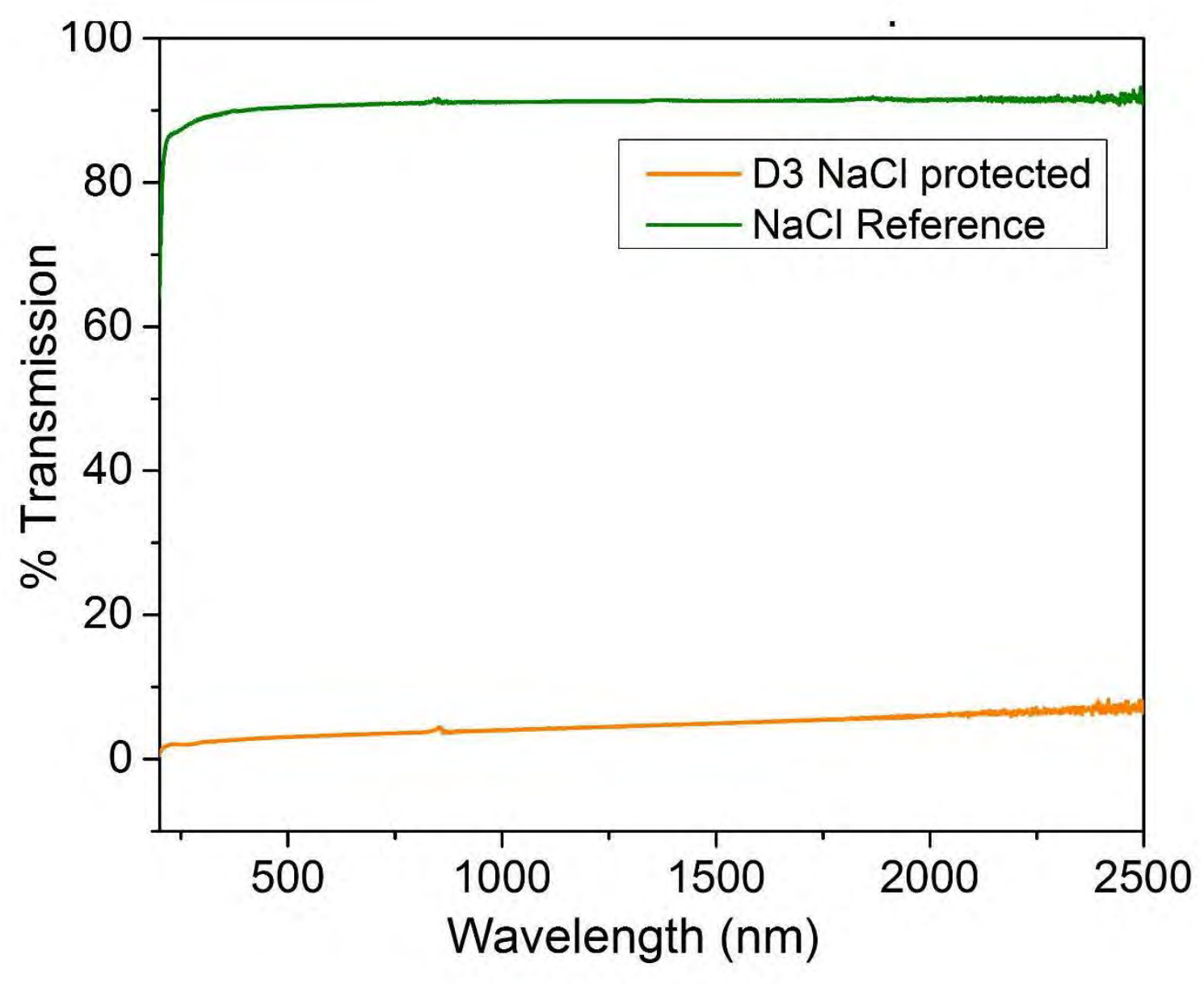

Significant decrease in transmission from $90 \%$ to $12 \%$. 
Appendix 2 


\section{Technical Reports Addendum Asset Summary A AROSPACE}

TRAAS ID \#: 2015011406454314820

Report Name: DebriSat Laboratory Analyses

Aerospace Report Number: TOR-2014-00876
Start Date of Test: 2014-05-01
Created By: 14820
Adams, Paul M
JO: 850672
End Date of Test: 2014-12-31
First Aerospace Author/ PI: 14820 Adams, Paul M

Program: DebriSat

Description:

Keywords:

\begin{tabular}{|c|c|c|c|c|c|c|c|c|c|c|}
\hline Asset: AAA123 & Manufacturer: & $\begin{array}{l}\text { PER } \\
\text { COR }\end{array}$ & $\begin{array}{l}\text { INELMER } \\
\text { ORATION }\end{array}$ & Model: & LAMBDA 900 & Usage Start Date: & 2014-05-01 & Usage End Date: & $2014-12-31$ & Asset Comment: \\
\hline Date: & Calibration Due D & Date: & Comment: & & Certificate Num & ber: & & & & \\
\hline $2013 \cdot 04-17$ & $2014-08-17$ & & TMT-NORMAL & & fa6f32fleed $80 \mathrm{~b} 4$ & 58d87b46e4dfeclaa & & & & \\
\hline $2014-08-18$ & $2016-03-13$ & & TMT-NORMAL & & $777773 \mathrm{c} 04920 \mathrm{e} 6$ & $4 b 8$ f1 $07 f 76514 d 6 a 40$ & & & & \\
\hline Asset: AAA126 & Manufacturer: & $\begin{array}{l}\text { PER } \\
\text { COR }\end{array}$ & $\begin{array}{l}\text { INELMER } \\
\text { ORATION }\end{array}$ & Model: & PELA-1000 & Usage Start Date: & 2014-05-01 & Usage End Date: & $2014-12-31$ & Asset Comment: \\
\hline Date: & Calibration Due D & Date: & Comment & & Certuficate Num & ber: & & & & \\
\hline $2013.04-17$ & $2016-04-17$ & & TMT-NORMAL & & ed846df747a191. & $19 b b 42006784$ ea95a7 & & & & \\
\hline Asset: ABH857 & Manufacturer: & REN & SHAW & Model: & INVIA & Usage Start Date: & 2014-05-01 & Usage End Date: & 2014-12-31 & Asset Comment: \\
\hline Date: & Calibration Due D & Date: & Comment: & & Certificate Num & & & & & \\
\hline $\begin{array}{l}2013-07-18 \\
2014-07.16\end{array}$ & $2014-07-13$ & & $\begin{array}{l}\text { TMT-NORMAL } \\
\text { SAE }\end{array}$ & & fd9ec878f3a7f24 & 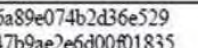 & & & & \\
\hline $2014-07-16$ & $2015-12-13$ & & TMT-NORMAL & & af $200 \mathrm{cfb} 9 \mathrm{e} 350 \mathrm{~s}$ & $2 \mathrm{a} 2 \mathrm{2} 667015 \mathrm{~d} 97550$ & & & & \\
\hline
\end{tabular}




\section{SBU Marking}

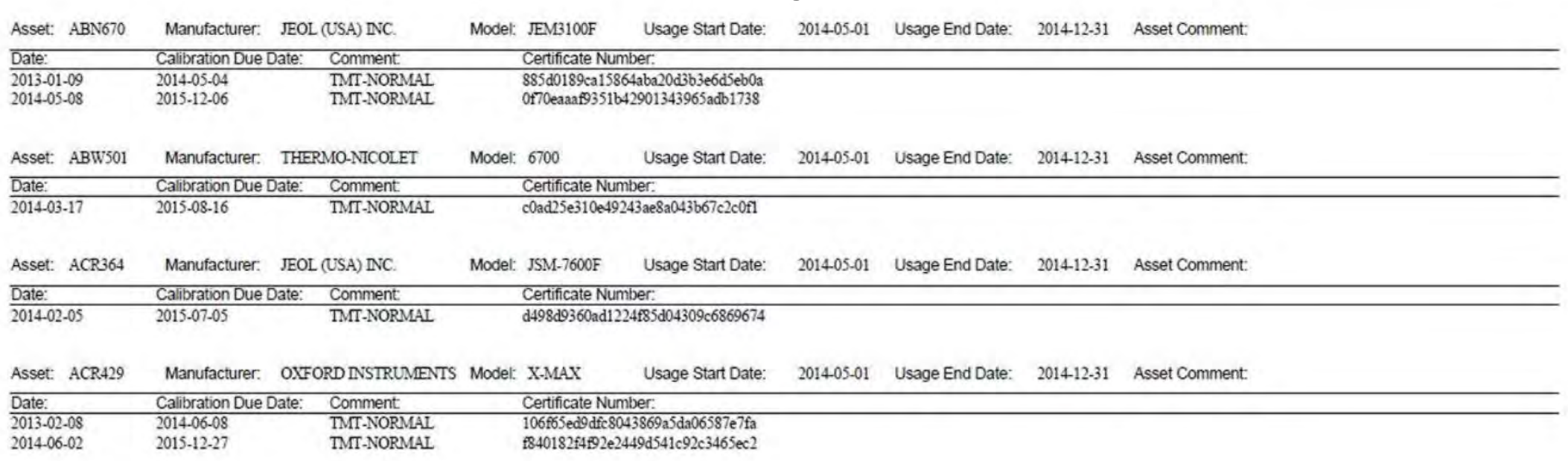

"Support and Auxiliary Equipment are not calibrated.

Wed Jan 14 09:29:24 PST 2015 


\section{DebriSat Laboratory Analyses}

Approved Electronically by:

Frank L. Knight, SYSTEMS DIRECTOR ENGINEERING ENGINEERING DIRECTORATE OFFICE OF EVPISSG

David J. Gorney, EXECUTIVE VP OFFICE OF EVP/SSG

Technical Peer Review Performed by:

Shant Kenderian, DIRECTOR DEPT MATERIALS PROCESSING DEPT SPACE MATERIALS LABORATORY ENGINEERING \& TECHNOLOGY GROUP

\author{
Steven C. Moss, DIRECTOR DEPT \\ MICROELECTRONICS TECHNOLOGY \\ DEPT \\ ELECTRONICS \& PHOTONICS \\ LABORATORY \\ ENGINEERING \& TECHNOLOGY GROUP
}

(C) The Aerospace Corporation, 2015.

All trademarks, service marks, and trade names are the property of their respective owners. 


\section{External Distribution}

REPORT TITLE

DebriSat Laboratory Analyses

\begin{tabular}{c|c|c}
\hline $\begin{array}{c}\text { REPORT NO. } \\
\text { TOR-2015-00876 }\end{array}$ & $\begin{array}{r}\text { PUBLICATION DATE } \\
\text { May 4, 2015 }\end{array}$ \\
\hline
\end{tabular}

Thomas Huynh

SMC/ENC

thomas.huynh@us.af.mil

Jesse Edwards

SMC/ENC

jesse.edwards.4@us.af.mil

J.-C. Liou

NASA-JSC

jer-chyi.liou-1@nasa.gov

John Opiela

NASA-JSC

john.n.opiela@nasa.gov

Heather Cowardin

NASA-JSC

heather.cowardin@nasa.gov
Mitch Nolen

AEDC

mitchell.nolen.ctr@us.af.mil

Brian Roebuck

AEDC

brian.roebuck.ctr@us.af.mil

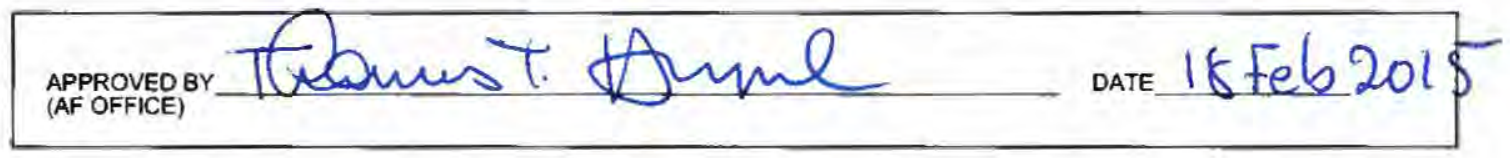

